HONG KONG

INTERNATIONAL VIOLENCE

AGAINST WOMEN SURVEY

Between 2003 and 2009, the International Violence Against Women Survey (IVAWS) has been conducted in 12 developed and developing countries. The IVAWS is a comprehensive instrument that measures women's experiences of physical and sexual violence by men, including intimate partners, victims' help-seeking behaviour and the response of the criminal justice system. This report presents the findings of the 2006 Hong Kong IVAWS. This was the first time such a specialised survey was conducted in Hong Kong and, for this reason, no trends in violence over time are available; however, because the IVAWS uses standardised questions and data collection methods, results can be compared with those of the other countries that participated in the survey.

The report shows rates of victimisation for seven types of physical violence and five types of sexual violence over the adult lifetime, the previous five years and the previous 12 months. Further questions probe who the perpetrator was, particularly whether it was an intimate partner, a relative, a friend or acquaintance, or a stranger. Women who had experienced violence since the age of 16 were asked details about the most recent incident, such as whether they had reported the assault to the police or victim support services.

Drawing on socio-demographic and behavioual information on both respondents and their partners, the report examines the predictors of violent victimisation by partners and non-partners.

Roderic Broadhurst Brigitte Bouhours John Bacon-Shone January 2012 


\section{HONG KONG}

\section{THE INTERNATIONAL VIOLENCE AGAINST WOMEN SURVEY}

Final Report of the 2006 Hong Kong IVAWS 



\section{HONG KONG}

\section{THE INTERNATIONAL VIOLENCE AGAINST WOMEN SURVEY}

Final Report of the 2006 Hong Kong IVAWS

Roderic Broadhurst

The Australian National University

Brigitte Bouhours

The Australian National University

John Bacon-Shone

The University of Hong Kong 
(C) 2012 The University of Hong Kong, Social Sciences Research Centre and Authors

Published by:

The University of Hong Kong, Social Sciences Research Centre

The Australian National University, Centre of Excellence in Policing and Security

The opinions expressed in this publication are those of the authors and do not necessarily reflect the views of the University of Hong Kong, Social Sciences Research Centre or the University of Hong Kong, Centre for Criminology, or the Australian National University node of the Australian Research Council, Centre of Excellence in Policing and Security.

This report should be cited as follows:

Broadhurst, R., B. Bouhours and J. Bacon-Shone, 2012, Hong Kong, the International Violence Against Women Survey: Final Report of the 2006 Hong Kong IV AWS. Hong Kong SAR and Canberra: The University of Hong Kong and The Australian National University.

Contact:

Professor Roderic Broadhurst

ARC Centre of Excellence in Policing and Security

Regulatory Institutions Network

School of Regulation, Justice and Diplomacy

Australian National University

Acton, ACT, 0200

Roderic.Broadhurst@anu.edu.au 


\section{FOREWORD}

Violence against women has not for too long been recognised as a real-world phenomenon and a policy issue at all. The International Violence Against Women Survey (IVAWS) has proven to be an important instrument of awareness-raising regarding this issue, and of specifying the nature of the problem and many of the special needs of women victims of violence. Such considerations were behind the development of the IVAWS, which representatives of Statistics Canada, HEUNI and UNICRI started to promote in the 1990s, inspired by the success of the ICVS, as well as its critics who maintained that this 'general' victimisation instrument was not sufficiently sensitive to capture the reality of female victimisation.

Considerably earlier, 'general' victimisation surveys did the same for perceptions of overall victimisation matters. The IVAWS, then, represents a first attempt at making VAW not only visible but also comparable - indeed many IVAW surveys have often served both functions as they have in many cases also been the first survey of this kind in their respective countries. So it is with great interest that I introduce the first such study of a Chinese population using the IVAWS protocol.

The IVAWS is also experiencing a renaissance in many developing countries. Its advantages may be most obvious in that environment: they may often be the first victimisation surveys overall and thus introduce the survey approach to crime victimisation into their respective countries. The introduction of victimisation surveys as instruments for assessing some previously unknown aspects of crime was, in its time, revolutionary, not just for the seemingly sensational findings showing that there was so much more 'crime' than we had known, but also because this approach demonstrates that the victim perspective must be taken into account in crime policy related decision-making and debate.

If a VAW survey is done, it is a major advantage if a standardised approach like the IVAWS is applied, since comparability is the next question: if there is so much of this, how do we compare? Is this more or less - better or worse - than elsewhere, in relevant reference countries? This feature gives an extra justification to the standardised approach. A disadvantage of the standardised approach may be that local particularities are not readily captured. In effect, the value of a general standardised assessment would be much enhanced, if also a more detailed in-depth study could be carried out for additional local detail.

That the comparative interest of knowledge has not dwindled is illustrated by the recent decision by the European Union Agency for Fundamental Rights (FRA) to prepare a 'new European VAWS'. This endeavour promotes the IVAWS approach, but introduces some improvements and cuts to the original model.

The authors are to be congratulated for their current achievement. It is especially valuable to have available a detailed description of the survey for Hong Kong. I am looking forward to the report on the IVAWS Singapore 2009, in which the same authors are involved.

Kauko Aromaa

Director

European Institute for Crime Prevention and Control (HEUNI)

Helsinki, Finland

December 2011 



\title{
PREFACE
}

This final report of the International Violence Against Women Survey (IVAWS) in the Hong Kong Special Administrative Region of the People's Republic of China ${ }^{1}$ contributes to research about violent victimisation of women in Chinese communities. Relatively few studies are available on the prevalence of violence against women in Asian societies in general and it would be very valuable if further studies, particularly in developing countries in Asia were undertaken. We hope that the publication of these survey findings and a further report on the same survey in Singapore due in the coming year will stimulate further practical and theoretical interest about the experience of women with violence in diverse cultures and settings.

The Hong Kong IVAWS was conducted in 2006 by telephone and a face to face survey under the guidance of Chan Wing Chong (National University of Singapore) and colleagues was undertaken in Singapore in 2009. The IVAWS was conceived in 2003 under the auspices of the United Nations Office of Drugs and Crime and the findings of the first sweep involving several countries, including Hong Kong was published in 2008: see Holly Johnson, Natalia Ollus and Sami Nevali, 2008, Violence Against Women: an International Perspective, Springer, New York. This report fully describes the Hong Kong survey and adds further detail to the comparative findings presented by Johnson and colleagues.

The Hong Kong IVAWS research team was also occupied with two other surveys that are now finalised and in publication. The findings of the fifth sweep of the United Nations International Crime Victim Survey in Hong Kong was extensively reported in Broadhurst, Roderic, John Bacon-Shone, Brigitte Bouhours, King Wa Lee, and Lena Y. Zhong, 2010, Hong Kong, The United Nations International Crime Victim Survey: Final Report of the 2006 Hong Kong UNICVS, Hong Kong and Canberra, The University of Hong Kong and The Australian National University (a PDF version may be downloaded from: $<$ www.aic.gov.au/crime_community/victims.aspx >). Another survey was the United Nations Crime Against Business Survey completed in May 2007 and conducted in Hong Kong, Shanghai, Shenzhen, and Xi'an that contacted over 5,000 businesses (see Broadhurst, Roderic, John Bacon-Shone, Brigitte Bouhours and Thierry Bouhours, 2011, Business and the Risk of Crime in China: the 2005-2006 International Crimes Against Business Survey 2005-2006, ANU E-Press, Canberra).

As with all large-scale surveys of crime victimisation a great deal of careful effort is necessary and the role of financial supporters was significant in helping to fund data collection. We thank the corporate sponsors, the Faculty of Social Sciences and the Centre for Criminology at the University of Hong Kong, and the Australian Research Council who made this report possible.

\author{
Roderic Broadhurst \\ Canberra \\ December 2011
}

\footnotetext{
1 Throughout this report and for brevity, Hong Kong will be used when referring to Hong Kong Special Administrative Region (SAR), People's Republic of China.
} 



\section{ACKNOWLEDGEMENT}

The authors are extremely grateful for the assistance provided by John van Kesteren, the SSRC interviewers and the many respondents who gave their valuable time to answer the survey. We are also grateful to Lena Zhong Yueyin and Lee Kingwa who helped with the translation of survey questions and the training of interviewers; Loretta Tang Sofong, whose thesis provided a rich context for the study; Lennon Chang Yaochung, for finding and translating from Cantonese some literature; and Irene Yeung Oi Yan, for her feedback on an early draft.

We also record our appreciation of the corporate sponsors (Microsoft, Mastercard, eBay, MPA, IFPI and ICG) of the $2^{\text {nd }}$ Asia Cybercrime Summit Hong Kong 2003, especially Mr Jeffrey Bullwinkel, chair of the organising committee, who granted a surplus from that event to be used to support this study. In addition the support of the Australian Research Council Centre of Excellence in Policing and Security was essential in bringing the report to fruition.

\section{The Research Team}

Professor Roderic Broadhurst

Ms Brigitte Bouhours

Professor John Bacon-Shone
The Australian National University ARC Centre of Excellence in Policing and Security

The Australian National University ARC Centre of Excellence in Policing and Security

The University of Hong Kong Social Sciences Research Centre 

Map of the Hong Kong Special Administrative Region, People's Republic of China (Source: http://www.reliefweb.int)

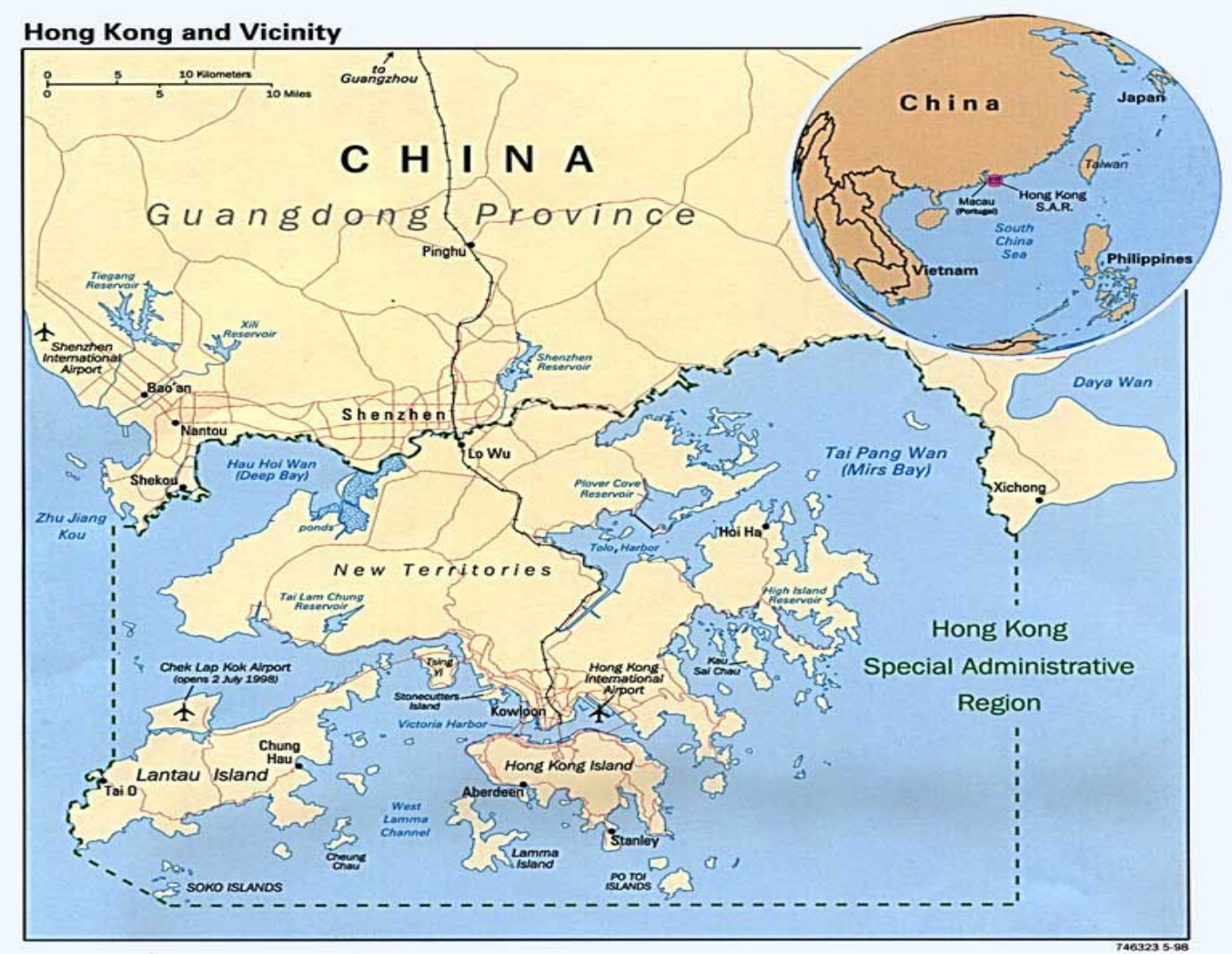





\section{ACRONYMS}

CEDAW Convention on the Elimination of All Forms of Discrimination against Women

DVO Domestic Violence Ordinance

FDH Foreign Domestic Helper

FPAHK Family Planning Association of Hong Kong

GDP Gross Domestic Product

HEUNI European Institute for Crime Prevention

HKCSS Hong Kong Council of Social Services

HKCVS Hong Kong Crime Victimisation Survey

HKSAR Hong Kong Special Administrative Region

SWD Social Welfare Department

IVAWS International Violence Against Women Survey

UNICRI United Nations Interregional Crime and Justice Research Institute

UNICVS United Nations International Crime Victims Survey

VAW Violence Against Women 



\section{CONTENTS}

EXECUTIVE SUMMARY

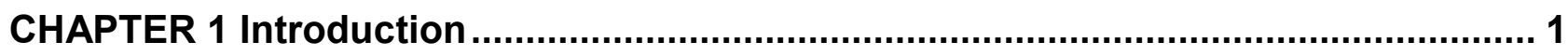

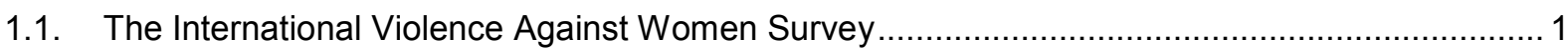

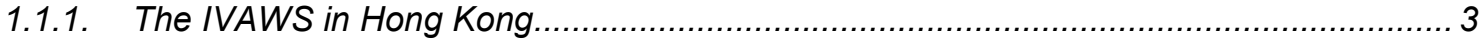

1.2. Hong Kong's Economic, Social and Cultural Characteristics.............................................. 4

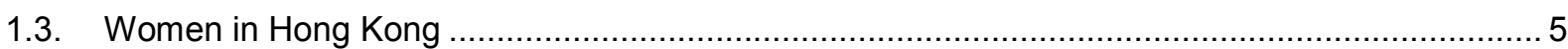

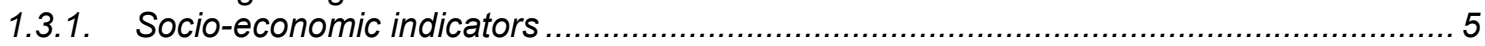

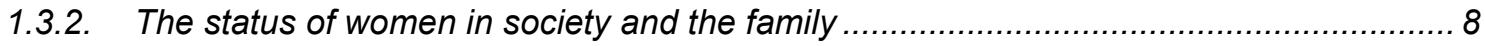

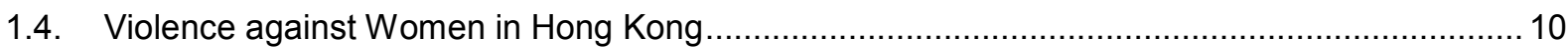

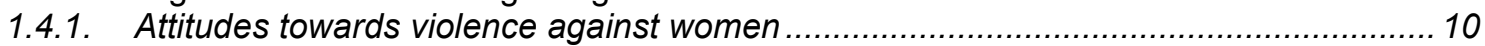

1.4.2. Legislation on and responses to violence against women........................................ 11

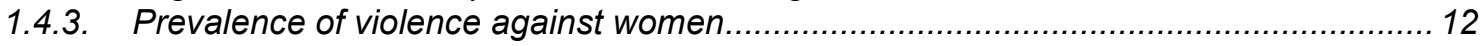

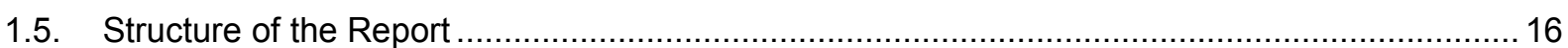

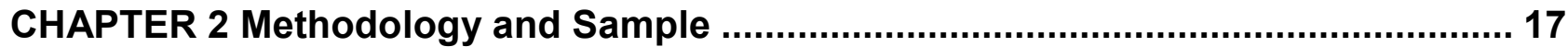

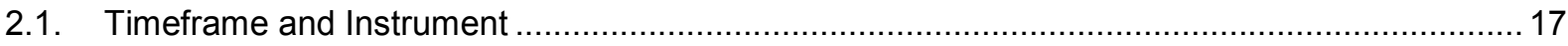

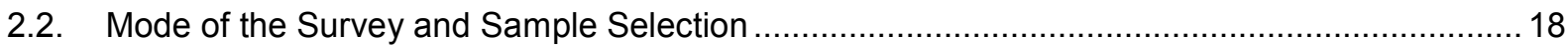

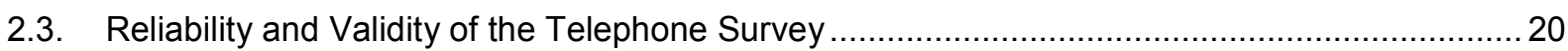

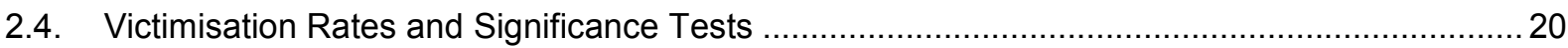

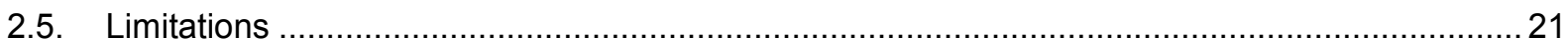

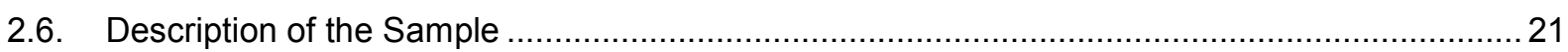

CHAPTER 3 Prevalence and Severity of Violence.................................................. 23

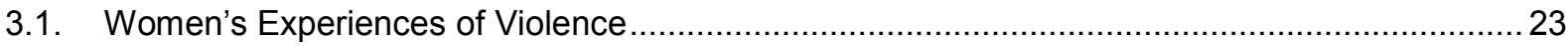

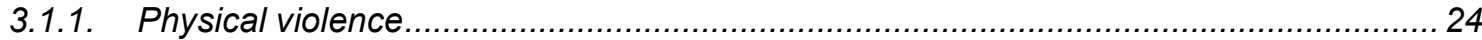

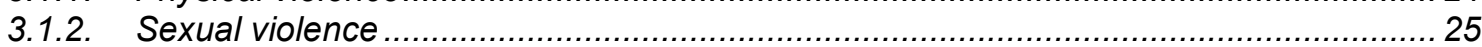

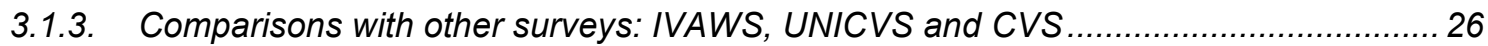

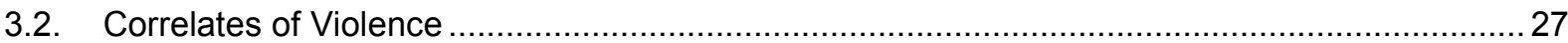

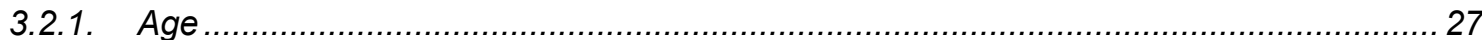

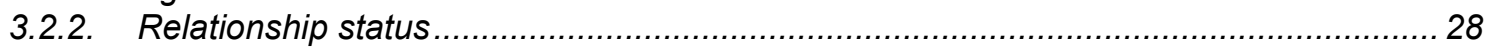

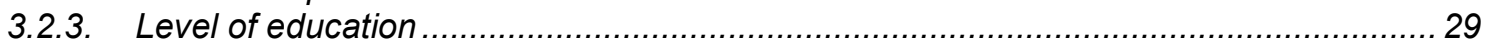

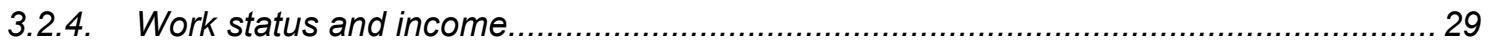

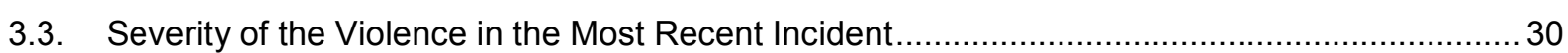

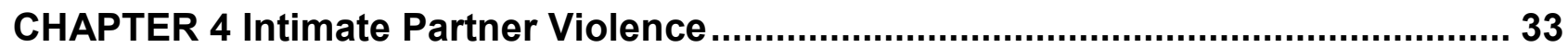

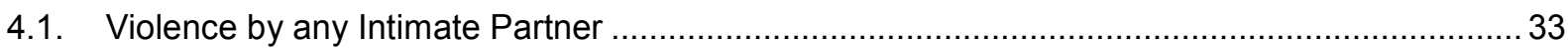

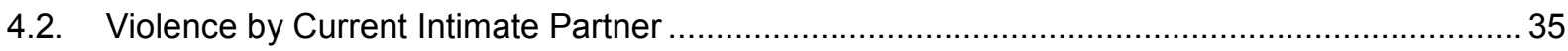

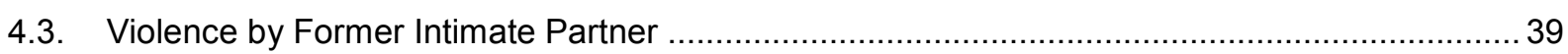

4.4. Correlates of Violence by Current Intimate Partners.............................................................. 41

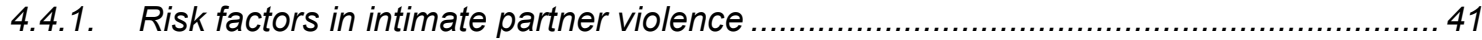

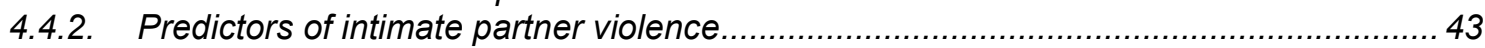

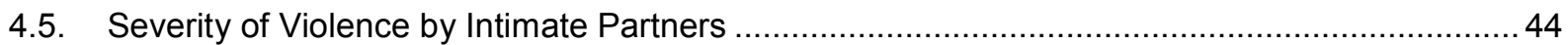




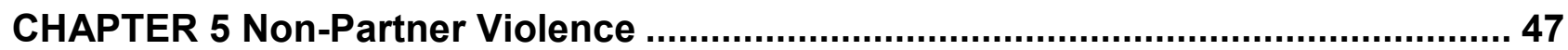

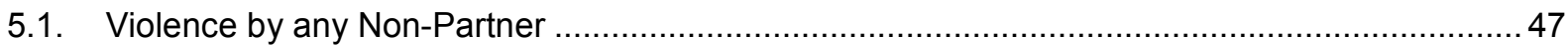

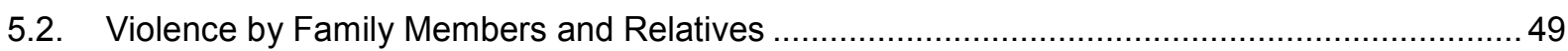

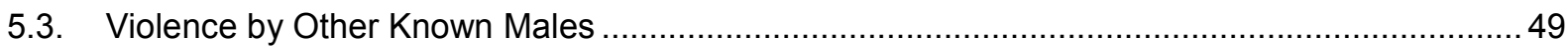

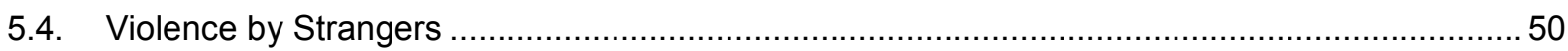

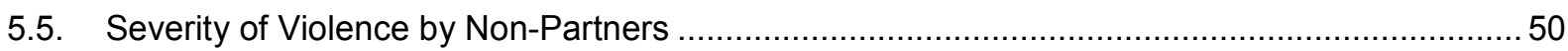

5.6. Correlates of Violence by Non-Partners .......................................................................... 51

5.6.1. Characteristics of the most recent incident by a non-partner .................................. 51

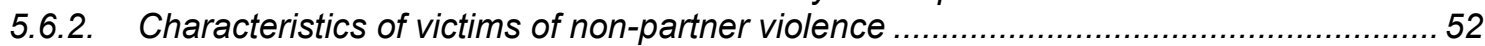

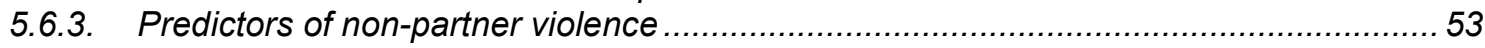

CHAPTER 6 Women's Perceptions \& Responses..................................................... 55

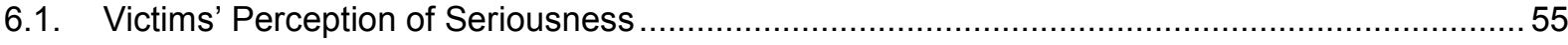

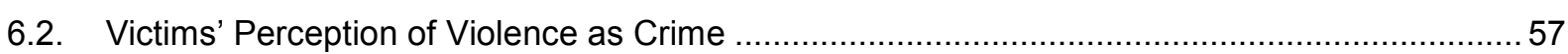

6.3. Reporting to Police and Satisfaction with Police Response .................................................59

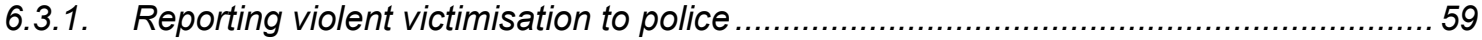

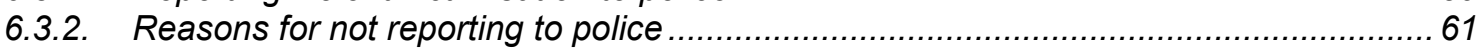

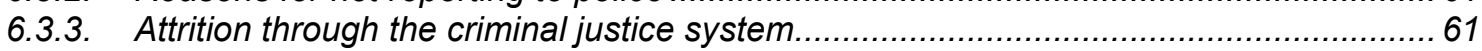

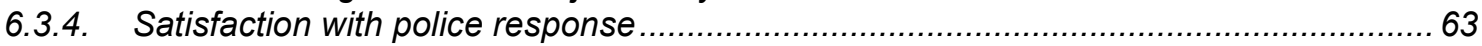

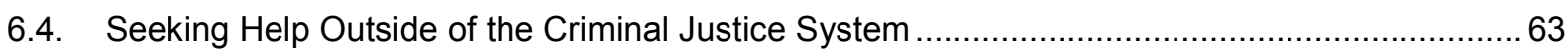

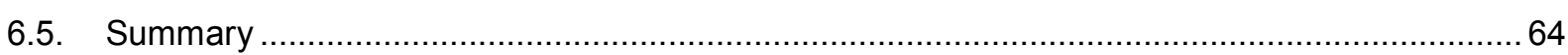

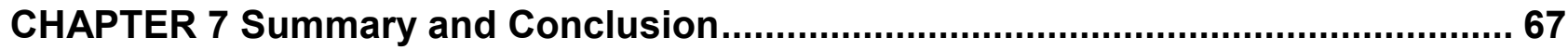

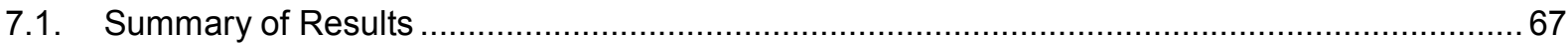

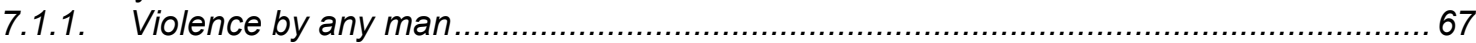

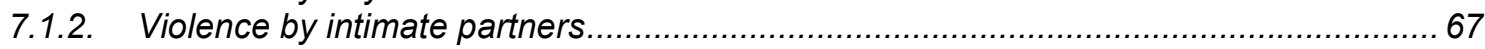

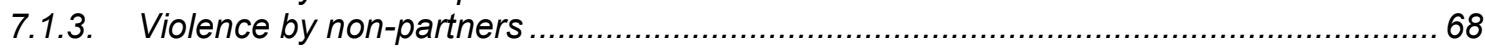

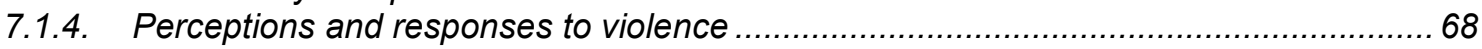

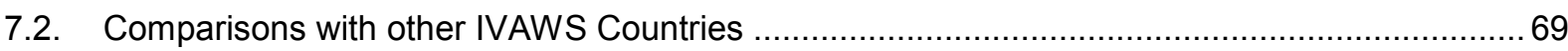

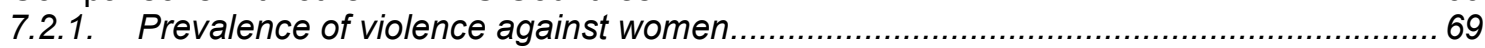

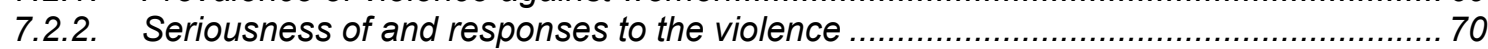

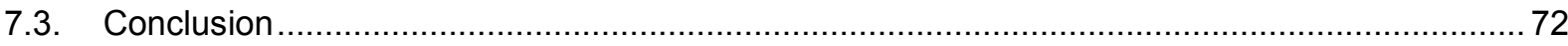

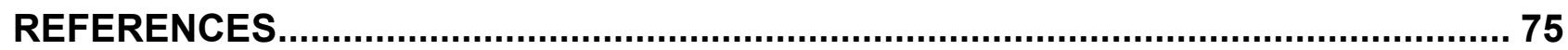

Appendix A Schematic Overview of the IVAWS Hong Kong Questionnaire, 2006... 83

Appendix B Weighting of the IVAWS Data .............................................................. 87 


\section{LIST OF TABLES}

Table 1.1. Socio-economic indicators related to the status of women, Hong Kong .................................... 7

Table 1.2. Rates of intimate partner violence in Hong Kong from three data sources, 1981-2010 ........... 13

Table 1.3. Sexual violence against women in Hong Kong, rate per 1,000 females of the relevant age,

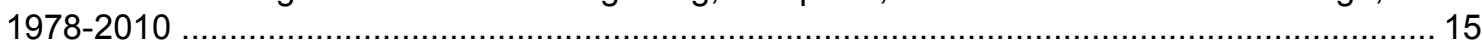

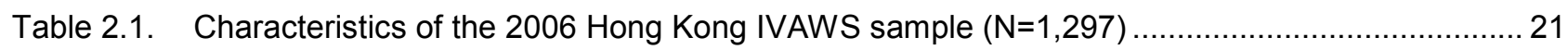

Table 3.1. Forms of physical violence in adult lifetime, past five years and one year (\%) ........................ 25

Table 3.2. Forms of sexual violence in adult lifetime, past five years and one year (\%) .......................... 26

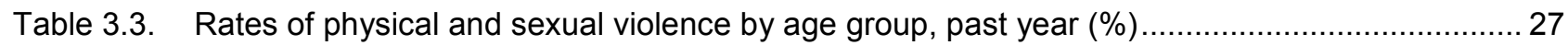

Table 3.4. Physical and sexual violence by type of intimate relationship, past year (\%) .......................... 29

Table 3.5. Physical and sexual violence by level of education, past year (\%) .......................................... 29

Table 3.6. Physical and sexual violence by work and income status, past year (\%) ............................... 30

Table 3.7. Severity of the most recent incident by type of violence and perpetrator (\%) .......................... 31

Table 4.1. Forms of physical and sexual violence by any intimate partner: adult lifetime, past five

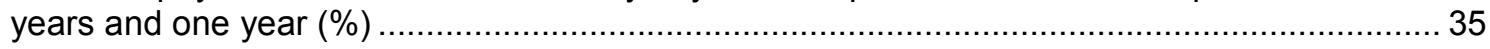

Table 4.2. Forms of physical and sexual violence by current intimate partner: adult lifetime, past five

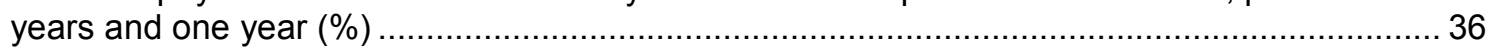

Table 4.3. Forms of physical and sexual violence by former intimate partner: adult lifetime, past five

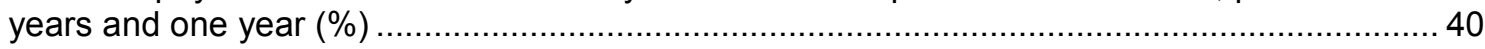

Table 4.4. Violence by current partner by age of female and male partner, past year $(\%)$...................... 42

Table 4.5. Violence by current partner by behaviour of the male partner, past year (\%)......................... 43

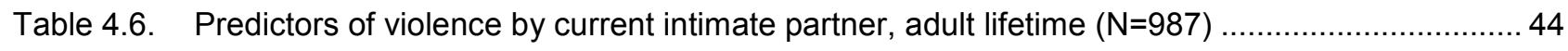

Table 4.7. Severity of violence in the most recent partner incident (\%) .................................................. 45

Table 5.1. Forms of physical and sexual violence by non-partners: adult lifetime, past five years and

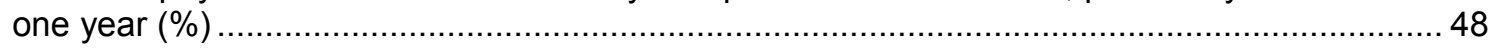

Table 5.2. Forms of physical and sexual violence by type of non-partner in adult lifetime (\%) ..................50

Table 5.3. Severity of the most recent incident of violence by non-partners (\%) ..................................... 51

Table 5.4. Violence by non-partner by age of female respondent, past year (\%) .................................. 52

Table 5.5. Violence by non-partner by relationship status of female respondent, past year (\%)............... 53

Table 5.6. Violence by non-partner violence by work and income status of female respondents, past

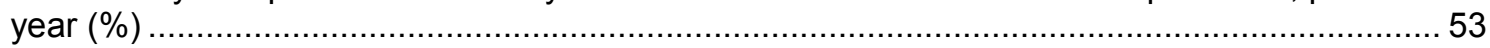

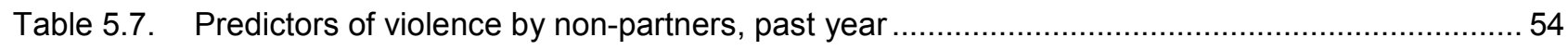

Table 6.1. Most recent incident reported to police by perpetrator and type of violence (\%) ...................... 60

Table 6.2. Most recent incident reported to police by perpetrator and severity of violence (\%) ................. 60

Table 6.3. Reasons for not reporting the most recent incident to the police by perpetrator (\%)................. 61

Table 6.4. Victims of partner and non-partner violence who talked to someone about the incident (\%) ..... 63

Table 6.5. Victims of partner and non-partner violence who talked to someone and severity of the

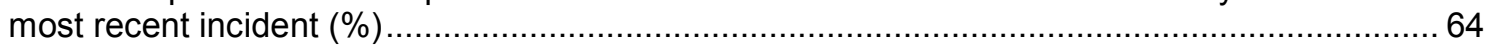

Table 7.1. Rates of violence in Hong Kong and IVAWS countries, adult lifetime .................................... 70

Table 7.2. Injuries and perception of seriousness, Hong Kong and IVAWS countries ............................. 71

Table 7.3. Reporting to police, Hong Kong and IVAWS countries .......................................................... 72 


\section{LIST OF FIGURES}

Figure 3.1. Women's experiences of violence in their adult lifetime, past five years and one year ............. 24

Figure 3.2. Forms of violence experienced by women in their adult lifetime ............................................... 25

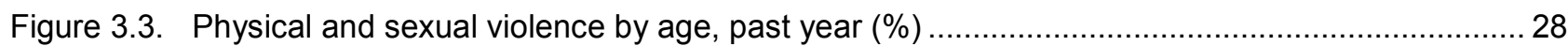

Figure 4.1. Types of intimate partner violence: adult lifetime, past five years and one year....................... 34

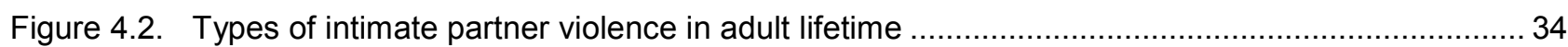

Figure 4.3. Types of violence by current intimate partner: adult lifetime, past five years and one year........ 36

Figure 4.4. Emotionally abusive and controlling behaviours by current intimate partner ............................ 37

Figure 4.5. Controlling and emotionally abusive behaviours by violent former partner and violent and non-violent current partner

Figure 4.6. Violence by current intimate partner by controlling and emotionally abusive behaviours, past five years

Figure 4.7. Types of violence by former intimate partner: adult lifetime, past five years and one year ........ 39

Figure 4.8. Emotionally abusive and controlling behaviours by violent former intimate partner .................. 41

Figure 5.1. Types of non-partner violence: adult lifetime, past five years and one year ............................. 47

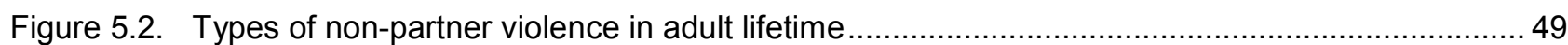

Figure 5.3. Location of the most recent incident of violence by non-partner .......................................... 52

Figure 6.1. Victims' perception of the seriousness of the most recent incident by perpetrator ....................55

Figure 6.2. Victims' perception of the seriousness of the most recent incident by type of violence............. 56

Figure 6.3. Victims' perception of the most recent incident as a crime by perpetrator ...............................57

Figure 6.4. Victims' perception of the most recent incident as a crime by type of violent act ..................... 58

Figure 6.5 The journey of the most recent cases through the criminal justice system............................... 62 


\section{EXECUTIVE SUMMARY}

From 2003 to 2009, the International Violence Against Women Survey (IVAWS) has been conducted in 12 developed and developing countries. The IVAWS is a comprehensive instrument that measures women's experiences of physical and sexual violence by men, including intimate partners, victims' helpseeking behaviour and the response of the criminal justice system. The instrument contains behaviourspecific questions and interviews are conducted solely by female callers, who have been trained in understanding the ways in which violence affects women and how they may react to the survey questions. The IVAWS uses standardised questionnaires and data collection methods, which makes it possible to reliably compare data across time, countries and cultures.

\section{The IVAWS in Hong Kong}

Between December 2005 and March 2006, a random sample of 1,297 Hong Kong women was interviewed by telephone about their experiences of violence using the IVAWS instrument. Demographic and socio-economic data were collected as well as details of their current and former intimate relationships. Women were asked whether since the age of 16 years, in the previous five years and in the past year they had been the victims of physical (including threats of violence) or sexual (including unwanted touching) violence by men. Further questions probed who the perpetrator was, particularly whether it was an intimate partner, a relative, a friend or acquaintance, or a stranger. From their responses, adult lifetime, five-year and one-year prevalence estimates are computed.

Women who had experienced violence since the age of 16 were asked a series of questions about the most recent incident either by an intimate partner or a non-partner, including whether they had reported their victimisation to the police and/or victim support services. Respondents involved in an intimate relationship were also asked about the socio-demographics and behavioural characteristics of their partner. Using information on the women and their partner, we examine the predictors of violent victimisation.

\section{Findings of the Hong Kong IVAWS}

\section{Prevalence of violence}

Overall 19.9 per cent of women had experienced at least one incident of physical or sexual violence by a man in their adult lifetime (i.e. since age 16). They were more likely to report sexual violence $(13.4 \%)$ than physical violence $(11.7 \%)$. In the past 12 months, 3.7 per cent of women had experienced violence: 1.9 per cent reported at least one instance of physical violence and 2.4 per cent reported at least one incident of sexual victimisation. Compared to the other countries that participated in the IVAWS, Hong Kong recorded the lowest rate of physical violence and the second lowest rate of sexual violence after the Philippines $(6 \%)$.

The more frequent forms of physical violence over the lifetime involved actual violence (e.g. pushing, grabbing, slapping, kicking, hitting with something) rather than threats, which often accompanied the violence. The most common form of sexual violence over the lifetime and the past year was unwanted sexual touching $(11.8 \%$ and $2.2 \%$ respectively).

The following factors were associated with higher risks of experiencing violence:

1. The likelihood of victimisation decreased with age. Women under 35 years were significantly more likely to have experienced violence in the past year than women aged 35 years and over. 
2. Women who were dating reported a higher level of victimisation than married/cohabiting women or single women.

3. Women who worked were significantly more likely to experience both physical and sexual violence than those who did not work.

4. Women who did not have a say in how their income was used were more at risk of experiencing violence than those who had control over their income.

\section{Intimate partner violence}

Overall under ten per cent $(9.4 \%)$ of women with a current or former intimate partner reported experiencing at least one form of violence by a partner in their adult lifetime. Physical violence (6.2\%) was more frequent than sexual violence $(4.8 \%)$ over the lifetime but levels were similar in the previous year (around 1\%). Hong Kong recorded the lowest rate of intimate partner violence among the IVAWS countries.

Women reported a higher level of violence by former partners $(9.4 \%)$ than by current partners $(5.3 \%)$. Intimate partner violence tended to involve actual violence (e.g. pushing, grabbing, slapping, kicking, hitting with something) rather than threats. The most common form of intimate sexual violence over the lifetime and the past year was unwanted sexual touching.

Women whose current partner used controlling or emotionally abusive behaviours were at significantly higher risks of experiencing violence than women whose partner did not use such behaviours. The four main risk factors for violence by current partners were:

1. Emotionally abusive behaviour by male partner;

2. Generally aggressive behaviour of male partner (violence outside of the family);

3. Male partner getting drunk at least twice a month; and

4. Controlling behaviour by male partner.

\section{Non-partner violence}

Fourteen per cent of respondents had experienced violence by a man other than an intimate partner since the age of 16 , with rates reducing to 2.6 per cent in the past year. Perpetrators of non-partner violence were most likely to be strangers: 8 per cent of women experienced violence by strangers over their adult lifetime; 4.9 per cent, by friends and acquaintances; and 2.5 per cent, by family members and relatives. Sexual violence was the most common form of violence by strangers and friends and acquaintances, but family members and relatives tended to inflict physical violence, and sexual violence by a family member or relative was relatively rare.

Three factors were significant predictors of violence by a non-partner:

1. Women in a dating relationship were more likely to experience violence (by men other than their boyfriends) than married/cohabiting women or single women.

2. Women who worked were significantly more likely to experience both physical and sexual violence than those who did not work.

3. Women who did not have a say in how their income was used were more at risk of experiencing violence than those who did.

\section{Perceptions of and responses to violence}

Victims of violence were asked to rate the seriousness of the most recent violent incident by a partner and a non-partner, and whether they considered it was a crime. Just under half the victims of nonpartner violence (47\%) perceived the assault was serious with little difference by type of non-partners. For intimate partner violence, however, women who had been abused by their current partner were less 
likely to say that the violence was serious (38\%) compared to women who had been abused by a former partner (62\% said it was serious). Physical violence by an intimate partner was considered more serious than sexual violence, but there was no difference in the perceived seriousness of the event for nonpartner violence.

Victims of violence were much more likely to regard violence inflicted by non-partners as a crime than violence by intimate partners ( $45 \%$ and $14 \%$ respectively). As the relational proximity decreased, women were increasingly likely to consider the violence as a crime and the highest proportion of victims who considered the violent incident was a crime were those attacked by strangers $(60 \%)$.

Few victims reported the most recent incident to the police with a similar proportion doing so for partner and non-partner violence (12\%). Only 3 per cent of incidents of sexual violence were reported to the police compared to 23 per cent of physical violence. Women were more likely to report to the police if they had been injured, if they perceived the incident was serious, or if they regarded it as a crime. The main reasons for not contacting the police were that the incident was too minor and that the victim or/and her family dealt with it.

Of the cases of intimate partner violence that were reported to the police, 8 per cent were charged and convicted, and these all involved former partners. Of cases of non-partner violence reported to the police, 14 per cent were charged and convicted, and all involved strangers. No cases of sexual violence ended up in conviction.

Victims were unlikely to contact victim support agencies: 6 per cent of victims of partner violence and 2 per cent of victims of non-partner violence did. By contrast, the majority talked to and sought help and support from others, particularly their family and friends.

\section{Conclusion}

Nearly 1,300 women participated in the survey and reported varying levels of violent victimisation. One in five women said that they had experienced violence by a man since they were 16 years of age and an intimate partner assaulted nearly one in ten. Of the countries surveyed by the IVAWS, Hong Kong, along with the Philippines, recorded the lowest levels of VAW. Preliminary results of the Singapore IVAWS also show a low rate of VAW in Singapore $(9.2 \%$ for all violence across the lifetime, see SAFV-NUS [2010]), and from the UNICVS, we know that rates of violence are also low in Japan (van Dijk et al. 2007). The low rate of VAW in Hong Kong is consistent with low prevalence rates across all types of crime, and suggests that cultural influences that maintain criminality at low levels in East Asia are at play. To explore these influences further, it would be important to extend the IVAWS to other Asian countries, such as Japan, Thailand and Cambodia; and of course in a number of cities in Mainland China, such as Beijing and Shanghai, and inland cities such as Xi'an or Chongqing. 



\section{CHAPTER 1}

\section{Introduction}

\subsection{The International Violence Against Women Survey}

The concept of violence against women as a specific category is relatively recent and has been defined in the 1993 United Nations Declaration on the Elimination of Violence Against Women as:

... any act of gender-based violence that results in, or is likely to result in, physical, sexual, or psychological harm or suffering to women, including threats of such acts, coercion or arbitrary deprivation of liberty, whether occurring in public or private life.

This definition emphasises that such violence is gender-based in nature, that is, it is intentionally targeted at women because of their sex or social role, and is overwhelmingly committed by men against women. The 1993 World Conference on Human Rights in Vienna for the first time recognised women's rights as human rights, and violence against women as a human rights issue. This perspective broadens the scope of the concept of violence against women from 'private' violence committed within the home or by a stranger to include sexual violations and rape during armed conflicts and by members of state organisations such as police and the military. It also highlights institutionalised harmful practices against women such as genital mutilation, forced marriages and honour killings, which have been tolerated by some states. Finally, it places the issue of violence against women in the context of societal discrimination and inequalities that perpetrate women's vulnerability to violence.

It is difficult to know the extent of violence against women and any comparative differences across the world, for a variety of reasons including:

- Legislation, definition and cultural interpretation of what constitutes violence differ between countries;

- Violence often occurs behind closed doors and many victims do not report to police or seek support from social services or victims' organisations;

- Record keeping and data collection are absent, incomplete or inconsistent in many countries;

- In most countries that do collect data, the sex of victims is rarely recorded and there is usually no separate section in police statistics for domestic violence, which is often recorded under the broader category of assault.

In the absence of official statistics, proxy measures such as the number of calls to help lines or crisis centres or hospital admissions for injuries can be used to estimate the prevalence of violence. Another approach is to conduct victimisation surveys, which ask a large random sample of the population about their experiences of victimisation during a specific timeframe, usually one year preceding the survey. Victimisation surveys have been conducted since the late 1970s in many countries, but mostly in industrialised western countries. Internationally, five sweeps of the United Nations International Crime 
Victims Survey (UNICVS) have measured crime victimisation in 78 countries from the developed and developing world and/or their main cities (van Dijk et al. 2007).

An advantage of victimisation surveys over official crime statistics is that they are able to uncover the 'dark figure' of crime, that is, the amount of crime that is not known to the police and therefore not recorded in official statistics. The 'dark figure' varies from country to country and partly reflects confidence in the police and differences in the severity and frequency of some offences. Victimisation surveys are one way to estimate this 'dark figure' and obtain a more accurate, although not perfect, representation of actual crime rates. But while surveys of the general population, whether national or international, are able to provide estimates of the prevalence of victimisation, reporting behaviour and responses to victimisation, they do not adequately address the question of violence against women, particularly violence by men known to the victims such as partners and family members. Some of their general limitations include:

- The broad scope of such surveys does not allow enough time to address sensitively and in depth the complex issues related to violence;

- Problems occur with how violence is defined and the specific wording of the questions, especially in translation;

- Lack of gender selection and specific training of interviewers;

- Lack of detailed follow-up questions about personal crime, e.g. domestic violence.

To attempt to address this lack of sensitivity a specialised survey focusing on women's experiences of violence was first developed by Statistics Canada in 1993 (Johnson 2001; Statistics Canada 1994). ${ }^{2}$ Since then, other countries have conducted such specialised surveys -- e.g. the Women Safety Survey in Australia (Australian Bureau of Statistics 1996), the National Violence Against Women Survey in the United States (Tjaden and Thoennes 2000) -- and a similar methodology was used in the World Health Organisation's international survey of women's health and domestic violence conducted in ten countries (Garcia-Moreno et al. 2005). These specialised surveys differ from general population surveys in a number of ways:

- They focus only on violence against women by men;

- They are conducted exclusively by female interviewers who have received specific training about the ways in which women are affected by violence and how they may react to some of the survey questions, and who try to ensure that the interview is as private as possible;

- Questions are worded in terms of behaviours and acts of violence rather than offences. For example, instead of asking, have you been raped, surveys ask, has a man forced you into sexual intercourse by threatening you, hurting you, or holding you down?

- Surveys contain detailed questions on perpetrators to make sure all violence by unknown and known men including intimate partners is reported.

The development of the IVAWS by the European Institute for Crime Prevention (HEUNI), which is affiliated with the United Nations, the United Nations Interregional Crime and Justice Research Institute (UNICRI) and Statistics Canada, began in 1997. The aim was to design a standardised instrument and methodology that could be implemented in developed and developing countries, and that would estimate the prevalence of violence against women, the level of reporting and help-seeking behaviour and the response of the criminal justice system. The IVAWS was piloted in 13 countries in 2001 and 2002, and full implementation started in 2003. A manual detailing the steps to follow for

\footnotetext{
${ }^{2}$ For an overview of the difficulties in measuring violence against women, see e.g. Schwartz (2000) and Tjaden (2005).
} 
carrying out the IVAWS was produced and so far, the IVAWS has been conducted in 12 countries, by telephone or face-to-face: ${ }^{3}$

- 2003: Australia, Costa Rica*, the Czech Republic*, Denmark, Switzerland

- 2004: Mozambique*, Poland*

- 2005: the Philippines*

- 2006: Greece*, Hong Kong, Italy

- 2009: Singapore*

A European Union-wide survey on violence against women using a similar protocol to the IVAWS is currently being implemented by the European Union Agency for Fundamental Rights (AFR). The survey will be conducted in the 27 member countries in 2011-2012 and results presented in 2013 (see $<$ fra.europa.eu/fraWebsite/research/projects/proj_eu_survey_vaw_en.htm> for details).

\subsubsection{The IVAWS in Hong Kong}

The Hong Kong sweep of the IVAWS was conducted by the University of Hong Kong Centre for Criminology and Social Sciences Research Centre with funding from the Faculty of Social Sciences and sponsors. The IVAWS was conducted during the same period as two other victimisation surveys:

- UN International Crime Victims Survey (ICVS), a survey of the general population of Hong Kong (2006) (Broadhurst et al. 2010)

- UN International Crime against Business Survey (ICBS), a survey of businesses in Hong Kong (2005) and Mainland China, in Shanghai, Shenzhen, and Xi'an (2006) (Broadhurst et al. 2011)

Although the Hong Kong government had been conducting a Crime Victimisation Survey (HKCVS) at regular intervals since 1978, it was the first time that international surveys were conducted in Hong Kong. These surveys are important because crime victim surveys conducted among Chinese population are rare $e^{4}$ and the standardised methodology provides the opportunity to compare crime rates between countries and examine potential cultural influences on crime and responses to crime. In addition, the CVS was not particularly sensitive to violence against women. There was no gender matching of interviewers and interviewees; the question on physical violence was limited to assault causing injuries; the question on sexual victimisation did not include rape but only indecent assault and indecent exposure. The UNICVS was a better instrument than the CVS for measuring violence against women because the questions were more precise and women respondents were interviewed by a female survey member (for a comparison of the HKCVS and UNICVS, see Broadhurst et al. 2010). However, it was still of limited value for exploring women's experiences of violence particularly intimate partner violence and over longer periods than the usual one and five-year frames used by the UNICVS.

The rest of this chapter presents a brief overview of Hong Kong's economic, social and cultural characteristics with a focus on the condition of women in Hong Kong. The final section outlines the structure of this report.

\footnotetext{
${ }^{3}$ Results for nine countries, excluding Greece, Italy and Singapore, have been published in Johnson et al. (2008). Other publications in English are: country reports for Australia (Mouzos and Makkai 2004) and Switzerland (Killias et al. 2005); and preliminary results for Singapore (SAFV-NUS 2010).

${ }^{4}$ The UNICVS was conducted face-to-face in Beijing in 1992 (see Zhu et al. 1995) and again in 1996; however, data for the second survey in 1996 (participating in the third sweep of the UNICVS) was never published. In 2004, a multi-stage cluster sample of 2,474 Tianjin residents completed a self-administered questionnaire (over 95\% response rate) that covered the following crimes: robbery, assault, personal theft, bicycle theft, swindling and burglary (for example, see Zhuo et al. [2008] from among several publications from this survey). Also in 2005 the Taiwan National Police Agency undertook the Taiwan Areas Criminal Victimization survey (see Sheu et al. 2005; and see also Kuo, Cuvelier and Chang 2009). An earlier study of a smaller sample of Taiwanese respondents is reported by Mon (2003).
} 


\subsection{Hong Kong's Economic, Social and Cultural Characteristics}

The Hong Kong Special Administrative Region (HK SAR) of the People's Republic of China (PRC) is located in the South China Sea at the mouth of the Pearl River delta and consists of a peninsula and over 200 islands (see Map after Acknowledgements section). ${ }^{5}$ Hong Kong's three main regions_-Hong Kong Island, Kowloon Peninsula and the New Territories - cover an area of 1,104 square kilometres, of which only five per cent is arable land. From 1842 to 1997 Hong Kong was a British colony. It was handed back to the PRC on 1 July 1997, but under the 'one country two systems' solution it was agreed that Hong Kong would maintain its autonomy in all domains except foreign affairs and defence, for at least 50 years following the transfer. Hong Kong has a two-tier system of government, headed by the Chief Executive: the central Legislative Council comprises 60 members elected every four years, and 18 District Councils manage the local affairs. The two official languages of Hong Kong under the Basic Law are English and Chinese, although the language policy is 'biliterate and trilingual' meaning that Cantonese is acknowledged as the de facto official spoken variety of Chinese, but the use of Mandarin is also accepted.

The 2006 census counted 6,864,300 residents in Hong Kong, including 3.3 per cent non-permanent residents. A slight gender imbalance in the population (52\% females compared to $48 \%$ males) is attributed to the presence of a large number of female foreign domestic helpers, and to an influx of Mainland wives who took up residence in Hong Kong. Following the trend in most industrialised countries, the rate of population growth has been declining $(0.4 \%$ for $2001-06$ compared to $0.9 \%$ for 1995-2000). The population is aging with the median age rising from 34 years in 1996 to 36 years in 2001 and 39 years in 2006.

Hong Kong continues to promote a capitalist economy based on free trade, low taxation and minimum government intervention. It is one of the world's leading financial centres. Four key industries contribute to its economic success and employ nearly half the workforce: trading (wholesale, retail and import/export) is the largest (29\% of Gross Domestic Product [GDP]), followed by financial services $(13 \%$ of GDP), various professional services (11\% of GDP) and finally tourism (3\% of GDP). In 2005 , Hong Kong GDP at purchasing power parity per capita was one of the highest among both Asian and western countries, surpassed only by the United States and Singapore (International Monetary Fund 2009). Overall, 61 per cent of the population was in the labour force. At 5.6 per cent, the rate of unemployment was slightly higher than in neighbouring countries (Singapore, 3.1\%; Taiwan, 4.1\%; Japan, 4.4\%), and closer to rates in the United States and Australia (5.1\%). Although its GDP has more than doubled since 1988, Hong Kong has a high level of income inequality, as measured by the Gini coefficient (for 2007). ${ }^{6}$ Hong Kong's Gini coefficient (53.3) is relatively close to Singapore's (48.1), but much higher than Korea (31.3), Taiwan (33.6) and Japan (38.1) (Central Intelligence Agency 2009).

Hong Kong's population is highly homogeneous. People of Chinese descent constitute 95 per cent of the population, while Filipinos $(1.6 \%)$ and Indonesians $(1.3 \%)$ form the largest ethnic groups in Hong Kong, largely because they comprise the bulk of foreign domestic helpers. Traditional Chinese values, which favour extended kinship structures and a communitarian rather than individualistic ethos, are still important but they are evolving and combining with western influences. Chan and Lee describe Hong Kong as 'a society caught in the throes of change. ... Chinese heritage sets the elementary behavioural code and moral fabric of everyday interaction, while the imperatives of modernity stretch, break, or add on to the plasticity of this original scaffolding. The result is a novel and idiosyncratic reconfiguration of traditional and modernistic values' (1995, pp. 83-84). Confucianism can no longer be seen as the

\footnotetext{
${ }^{5}$ This section draws mainly from the findings and figures of the Census and Statistics Department (2007a \& b). Unless otherwise indicated, figures are for 2006.

${ }^{6}$ The Gini coefficient is a measure of equality that varies from 0 to 100 . Zero represents perfect equality (everyone has the same income), and 100 represents perfect inequality (one person has all the income). Numbers closest to zero indicate countries with smaller income disparities.
} 
dominant ideological orientation, although its ethical norms infuse Hong Kong's culture. On the one hand, like other modern and wealthy industrial societies, pragmatism and individualism often take primacy over the common good. On the other hand, unlike most industrial societies, Chan and Lee (1995) argue that Confucianism's ethical norms provide 'both a framework of differentiation and of harmony in the structuring of social life' (p. 86), and therefore place limits on excessive individualism. For example, Chang (2006) found that young Chinese people who grew up in Shanghai, Hong Kong or Tapei engaged in non-traditional behaviours, such as having pre-marital sexual relations, but also retained and lived through traditional values, particularly familism and filial piety. Filial piety emphasises respect for parents, elders and ancestors, and, by extension, for authority more generally, which in turn often leads to social stability.

Hong Kong is one of the safest cities in the world, and it is perceived as one of the least corrupt countries in Asia. In 2000, Hong Kong overall recorded crime rate was 1,185.7 per 100,000 population, which was lower than Singapore $(1,202.6)$, Japan $(1,924.0)$, South Korea $(3,262.6)$ and England and Wales (9,766.7), but higher than the Philippines (106.0), China (288.7), Malaysia (717.5) and Thailand (931.0) (Broadhurst et al. 2008). The UNICVS, an international crime victims survey, which was conducted in HK at about the same time as the IVAWS, found that for all common crimes, victimisation rates were lower in Hong Kong than in Western nations, but close to that of other Asian countries such as Japan (Broadhurst et al. 2010). Low crime rates are also evident in the regular crime victimisation surveys conducted by the Hong Kong Government (for the latest sweep, see Census and Statistics Department 2006a). After a rise and fall in recorded crime during the 1970s, and a new rise in the late 1980s, crime rates for both violent and property crime declined throughout the 1990s. This drop matched a decline in the population group with the highest risk of offending-those aged 15-29 years. Broadhurst et al. (2008) discussed the reasons for the low crime rate in Hong Kong and suggested that, among other factors, it may be the result of family-oriented cultural traditions, proactive crime prevention, an increasingly professionalised police service, an ageing population, strict firearms law, ethnic homogeneity, high levels of formal and informal surveillance, and effective control of crossborder crime.

This snapshot describes Hong Kong as a wealthy, urbanised and highly developed mega-city, that combines traditional Chinese and modern western characteristics. Next, we examine the status of women in Hong Kong and the ways in which rapid industrialisation and modernisation have influenced their role in the family and in society.

\subsection{Women in Hong Kong}

Since the 1970s, strong economic growth and the emergence of a feminist movement have helped improve the economic, social, political and legal status of women. Women's participation in the labour force has become essential to Hong Kong's economic expansion. This trend has been accompanied by higher educational achievement and falling fertility rates. Table 1.1 summarises a variety of social indicators with a focus on women.

\subsubsection{Socio-economic indicators}

The proportion of women in the labour force has increased from 42.8 per cent in 1971 to 52.6 per cent in 2006. These figures are misleading, however, because they include all women aged 15 and over; that is, they include a proportion of women still in fulltime education as well as those who are past the retiring age. The 2006 census indicated that among women aged 25 to 44 years around 90 per cent of unmarried women and 68 per cent of married women were in the labour force. They were employed predominantly in the community, social and personal services sector, the wholesale and retail trades, the restaurant and hotel sector, and the finance, insurance and business services sector. The professions were still mostly dominated by males, but female representation was increasing. For example, 46 per cent of certified public accountants were female in 2006, up from 32 per cent in 1996; 42 per cent of solicitors were female, up from 33 per cent in 1996; and 29 per cent of managers and 
administrators were female, up from 20 per cent in 1996 (Women's Commission 2006). As Table 1.1 shows, in 2006 over one-quarter of senior government officials were female, up from just under 5 per cent in 1981.

Related to participation in the workforce are the level of education and patterns of marriage and fertility among Hong Kong women. Starting in the 1970s, women's educational achievements have improved continuously. Hong Kong parents value their daughter's education as much as their son's and women need to be educated to join the workforce. In 2006, 93 per cent of the female population aged 15 to 44 years had attended secondary education, up from 84 per cent in 1996 (Census and Statistics Department 2007a). From just 33 per cent in 1986, women now form the majority of students in higher education $(54.6 \%$ in 2006). Female students continue to choose traditionally feminine fields of study and are over represented in the arts and humanities $(73 \%)$, education $(71 \%)$, the social sciences $(66 \%)$, health ${ }^{7}(63 \%)$, and business and management $(60 \%)$; but under represented in the sciences $(36 \%)$ and engineering (31\%) (Women's Commission 2006). From about half the proportion of males with a postgraduate degree in 1986, women have nearly achieved parity in 2006, with the proportion of female postgraduates reaching 96 per cent that of males (Table 1.1).

In a parallel process, the fertility rate has fallen rapidly from 3.40 births per woman in 1971 to less than one birth per woman (0.97) in 2005 (Table 1.1). ${ }^{8}$ Yip et al. (2006) suggest this dramatic drop is due partly to delayed marriage and partly to married women having fewer children. In 2006, the median age of marriage for Hong Kong women was 28.2 years, which was the highest in the East Asia/Pacific region, up from 23.9 years in 1981 and 26.9 years in 1996 . Women's median age at first childbirth has also risen from 25.1 years in 1981 to 28.8 years in 1996 and 29.2 years in 2006 (Census and Statistics Department 2007c). Marriage and fertility patterns have followed a similar path to that of other developed countries, but the shift seems to have occurred over a shorter period of time and with a greater scope. In 2005, Hong Kong's fertility rate was one of the lowest in the world and lower than Japan (1.32), Singapore (1.37), the UK (1.64), Australia (1.75) and the US (2.01) (Yip et al. 2006).

The indicators presented above point toward an improvement in the economic and social status of women. Yet, like most other countries, women's average wage is lower than that of men. For example, in 2006, the median monthly wage of all women (i.e. including foreign domestic workers) was $\mathrm{HK} \$ 8,000$, rising to $\mathrm{HK} \$ 9,000$ if we exclude foreign domestic workers, compared to $\mathrm{HK} \$ 11,500$ for men. Women's lower wages are linked to the types of occupation they perform. The 2006 census showed that one-quarter of working women in Hong Kong were employed as clerks compared to eight per cent of men. Women were also more likely than men to perform low skilled occupations $26 \%$ and $13 \%$ respectively). By contrast, 13 per cent of working men were managers or administrators compared to six per cent of women (Census and Statistics Department 2007c). Data from the Hong Kong Council of Social Services suggest that the income gap started to close toward the end of the 1990 s (the median female wage was $80 \%$ of the male wage in 1997), but increased again in the 2000s (Table 1.1). In 2006, the median monthly female wage represented 70 per cent of the male wage, hardly more than in $1986(67 \%)$.

\footnotetext{
${ }^{7}$ The overrepresentation of female students in health studies does not mean that there are more female than male doctors. In 2006, just over one-quarter of all doctors were female (27\%). Women tend to enter the field of nursing rather than medicine.

${ }^{8}$ Note that the 'one child policy' in place in the Mainland does not apply in Hong Kong.

${ }^{9}$ Other data from the International Labour Organization (ILO, <laborsta.org.au>) indicate that in 2006 wages for full-time employed women represented 73\% of men's wages in Hong Kong, 73\% in Singapore, 80\% in the UK, and 86\% in Australia. For the US, the National Committee on Pay Equity reported a figure of $77 \%$ (<www.pay-equity.org/info-time.html>).
} 
1
5
0
0
5
0
0
$\vdots$
5

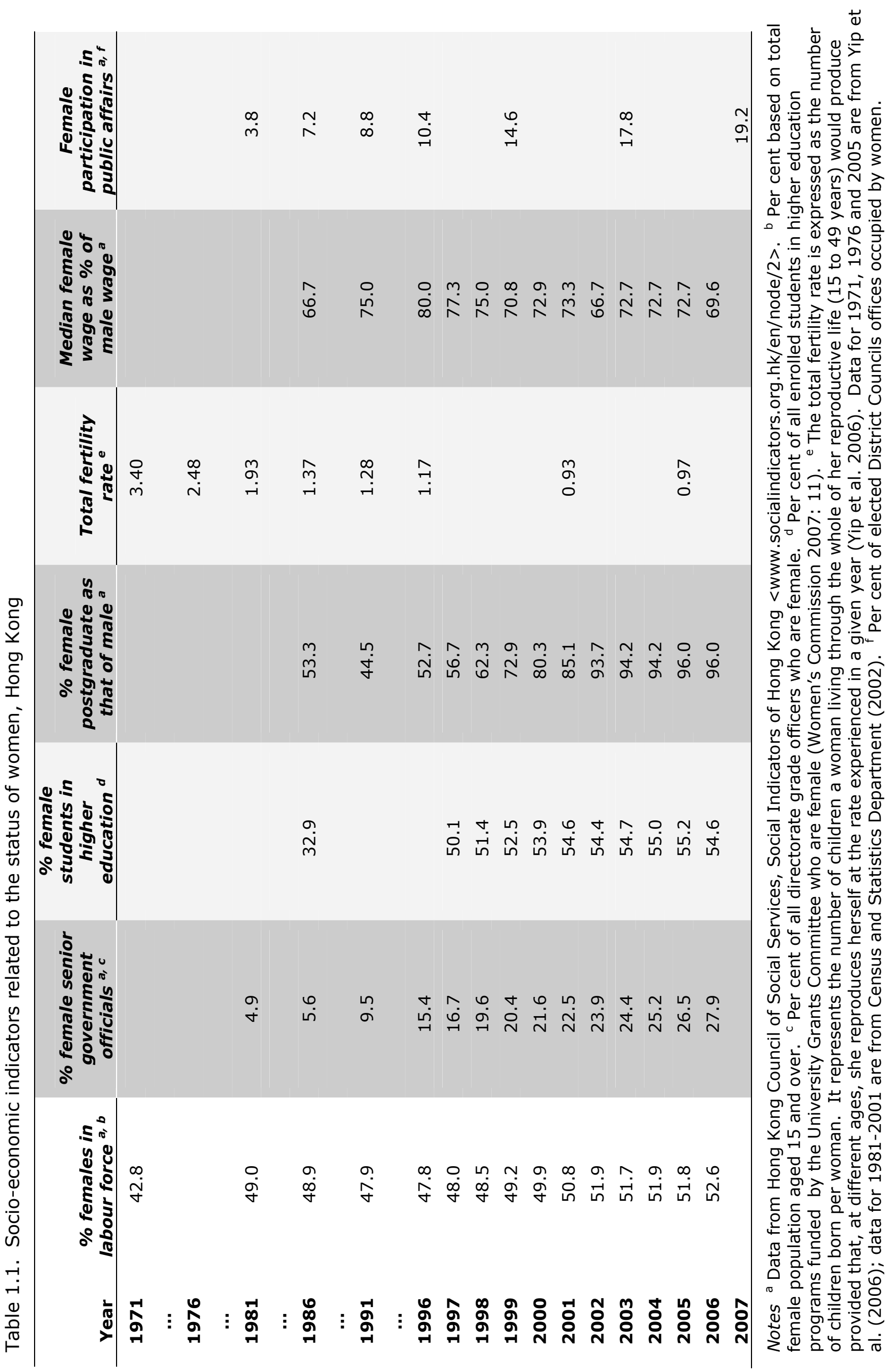


In the political arena women still represent a minority (less than one-quarter) of public representatives. The number of women in the Executive Council ${ }^{10}$ has remained the same since 1998 (3 or 4); but since the total number of Council members has increased from 14 to 29, there has in fact been a reduction in the proportion of female membership from 40 per cent in 1998 to just 12 per cent in 2006 . Of the 60 elected members of the Legislative Council, 12 per cent (N=7) were female in 1995 up to 18 per cent $(\mathrm{N}=11)$ in 2004. At the community level, just under 20 per cent of elected members of the District Councils were female, up from four per cent in 1981. Tang et al. (2000) suggest several reasons for women's low level of political participation: negative public attitudes towards women's role in politics, women's limited preparation for political life, family demands, the structure of the political system and women's perceived inexperience in political matters.

The 'objective' socio-economic indicators that we have reviewed so far present a picture similar to that of other industrialised countries: in the last half century women have generally gained in terms of educational achievements, workforce participation and entry into professional fields; however, on aggregate, the wages of female workers remain lower than those of male workers. Almost 80 per cent of female workers in Hong Kong believe that they are discriminated against because they receive lower salaries than men and have fewer promotion opportunities (SIGI 2010). The next section adopts a more qualitative approach and examines the cultural and historical influences, including that of the women's movement, which have shaped the condition of women in Hong Kong.

\subsubsection{The status of women in society and the family}

As Pearson and Leung (1995: 5) have remarked, 'it is tempting to see the prejudice and discrimination against women in modern Hong Kong as remnants of traditional patriarchal Chinese culture'. Yet, a variety of cultural, social and economic factors have influenced Hong Kong women's current position: for one and a half century Hong Kong was a British colony, it has developed a successful industrial capitalist economy, and in recent decades, a women's movement has emerged, which helped bring about significant law reform. ${ }^{11}$ In the Chinese tradition women were expected to be submissive to their fathers when young, to their husbands when married and to their sons after the death of the husband, and were mostly relegated to the domestic sphere. The selective intervention and non-intervention of the British colonial state and the co-option of Chinese elites by the colonial administration helped sustain patriarchal social institutions. For example, polygamy through concubinage was tolerated until the reform of the marriage law established monogamous marriages as the legal norm in the early 1970s. Equal rights to inheritance were obtained only as late as 1994 in the New Territories. Ultimately, laws that discriminated against women could no longer be accepted and justified on the grounds of culture (Samuels 1999).

The Hong Kong women's movement emerged after the second World War and followed a comparable path to that in western countries, with broadly similar concerns and achievements, but on a more recent timeline (Tsang 1995a and b). Prior to the 1980s, it mostly involved the wives of Chinese elites and expatriate women or services-oriented groups. From the 1980s the creation of over 200 grassroots groups, such as the Association for the Advancement of Feminism, have made women's issues more prominent. Their discourse shifted from a language of familial and maternal welfare to a language of women's rights, gender equality and a critique of patriarchy (Fishler 2004; Lee 2000; Tsang 1995b). Women's concerns became recognised and supported by major political groups and members of the Legislative Council. In 1995 the Sex Discrimination Ordinance, which prohibits discrimination based on sex, pregnancy and marital status in the workplace, education and social life was enacted. A year later, the Equal Opportunity Commission was established to facilitate the implementation of the

\footnotetext{
10 The Executive Council is a policy-making organ in the executive branch of the HK government, equivalent to the Prime Ministerial Cabinet. The Legislative Council is the legislature.

${ }^{11}$ See Ngo (1999) for a history of the colonial state; Cheung (1997), Cheung and Holroyd (2009), Edwards and Roces (2000), Lee (2004), and Pearson and Leung (1995) for discussions of the position of women in Hong Kong; and Yates (2009) for an extensive bibliography of works in western languages about women in China including Hong Kong.
} 
Ordinance. The same year Hong Kong finally ratified the Convention on the Elimination of All Forms of Discrimination against Women (CEDAW), although Britain had been a signatory since 1981. In 2001 the Women's Commission was established, as an advisory body, to promote the well-being and interests of women in Hong Kong (Wu 2008).

Advances in the legal framework do not automatically translate into complete gender equity: ‘... [T] he international literature attests that even in countries that have been trying to combat gender inequality for decades, women continue to be disadvantaged - in pay, in political participation and representation, and in job segregation - and that they carry in addition the double burden of work and housework. It is hardly surprising that Hong Kong women share these experiences' (Pearson and Leung 1995, p. 2). For example, it was estimated that in 2006 women spent an average of 3.1 hours a day on household and caring duties compared to just one hour for men (Census and Statistics Department 2006b). A survey carried out by the Women's Commission in 2010 revealed that over 80 per cent of a sample of 3,000 Hong Kong men and women agreed that both sexes should contribute to the family income; however, less than half (48.4\%) thought that men should take on a greater share of household and childcare duties -- not surprisingly, women were more likely to agree than men $(52.3 \%$ and $43.9 \%$ respectively) (Women's Commission 2010). This survey echoes the recent literature in this area, which has suggested that while the concept of 'males as family breadwinners' may no longer be prevalent in Hong Kong, that of 'women as homemakers' remains so (Chan and Lee 1995; Lo 2003; Thein et al. 2010).

Women's entry into the workforce has been greatly aided by the introduction in Hong Kong of female foreign domestic helpers (FDH) initially from the Philippines and increasingly from Indonesia. FDHs usually live with the family who employs them; they are entitled to a low minimum wage set by the government and are protected under the Employment Ordinance. ${ }^{12}$ They perform most household duties, e.g. cleaning, ironing, shopping, and often care for children or elderly members of the household. In 2006 there were around 232,800 FDHs in Hong Kong, representing 6.5 per cent of the total female population. Just over half $(52 \%)$ were Filipinas, 45 per cent Indonesians and the rest from various Asian countries (Census and Statistics Department 2007a). FDHs are typically employed by small nuclear families with an above average income. Chan (2006) estimated that in 2000, 32 per cent of all households with a monthly income over $\mathrm{HK} \$ 50,000$ (around US $\$ 6,410$ ) employed at least one foreign domestic helper. With limited child-care facilities in Hong Kong, FDHs have become indispensible to women who wish to re-enter the workforce after the birth of their children but cannot rely on close relatives to care for them. The rights and interests of foreign domestic workers, however, may clash with those of the women employing them. For example, women employers have lobbied against paid maternity leave for domestic workers, arguing that if their helper became pregnant they would have to give up their own jobs (Samuels 1999). Despite legal protection, up to one-quarter of FDHs reported breaches of their employment contract (e.g. being underpaid or not having statutory days off), 26 per cent said they had been verbally or physically abused and 4.5 per cent that they had been sexually abused (Asian Migrant Centre 2001). ${ }^{13}$

Women joining the workforce en masse has led to a redefinition of their role within the family through a merging of traditional Chinese and modern western influences (Chan and Lee 1995; Salaff 1981). The nuclear family has become the dominant form but traditional and ethical norms reflecting the Confucian tenet of filial piety remain prevalent. Patriarchal authority has declined and the monetary contribution wives and daughters make to the family has earned them a greater say in decision-making. All family members, whether male or female, are expected to contribute to the well being of the greater familial group, particularly parents and seniors, and assist other members in time of difficulties (Chan

\footnotetext{
12 In 2006, a FDH's monthly minimum wage was set at HK\$3,270 (plus board), that is about one-third of the median monthly income of HK\$10,000 (Census and Statistics Department 2007a).

${ }^{13}$ FDHs were included in the Hong Kong IVAWS sample; however, because no question about ethnicity was asked and the question about occupation has broad categories we were not able to distinguish them from other low-paid workers.
} 


\section{Hong Kong IVAWS}

and Lee 1995). Lo (2003) described how the demands of work and family led to an exhausting lifestyle for married professional women, who wished for more flexible working hours. Yet, focus groups with women from Singapore and Hong Kong revealed different perceptions and experiences of work/family conflicts than those of western women. In contrast to western women, Hong Kong women considered their engagement in paid work as a family responsibility, which did not detract from but was a way of caring for family members (emphasis added). Most of the participants employed a domestic helper and in return for the working women's contribution to serving the collective financial needs, mothers, mothers in law and other (mostly female) members of the extended family assisted with childcare and home maintenance (Thein et al. 2010)..$^{14}$

The picture that emerges from this brief review is that Hong Kong women are active in the workforce and in society, but continue to carry out most of the duties related to family and household. The traditionally patriarchal structure of Chinese societies suggests a potential tolerance for and acceptance of violence against women (VAW). We turn now to an examination of the attitudes to, the legislative framework, and the prevalence, from official statistics of VAW in Hong Kong.

\subsection{Violence against Women in Hong Kong}

\subsubsection{Attitudes towards violence against women}

Until the 1980s, there was little discussion, government action or academic interest in violence against women in Hong Kong. Historically, violence by husbands was seen as a domestic matter and it was rarely mentioned in public or in private (Chow 2009). Women's growing participation in the social and economic life as well as the emerging women's movement has, however, raised awareness of the problem (Tang, Chung and Ngo 2000). Following the establishment of the first women's shelter, Harmony House, in 1985 and the enactment of the Domestic Violence Ordinance in 1986, victim advocates called for the development of services and policies for the protection of women and children. Through the 1990s, the Hong Kong government strengthened its position on family violence. In 2000, the Child Protective Services Unit was renamed the Family and Child Protective Services Unit and was charged with handling all cases of family violence. The aim was to enhance the protection of vulnerable family members and put in place preventive mechanisms. The Association Concerning Sexual Assault Against Women was formed in 1997 and soon after it created the first rape crisis intervention service (Tsun and Lui Tsang 2005).

Relatively little research on VAW has been conducted in Hong Kong. One difficulty is the lack of definition of what constitutes VAW, particularly in the domestic context, which makes it difficult to measure (Tang et al. 2000). Chow (2009) argues that the culture of 'face saving', which encourages people to maintain a good image in front of others, is still prevalent in Chinese societies and encourages victims to remain silent for the sake of family harmony. Cheung et al. (1997) reviewed some of the literature on gender stereotypes and attitudes in Hong Kong. They found that most of the studies dated from the 1980s and were descriptive in nature and concluded, 'these studies by and large confirm similar findings on traditional gender roles and stereotypes in western countries' (p. 229). For example, studies on attitude to rape revealed a relatively widespread adherence to traditional rape myths, particularly by men.

A recent study by Tam and Tang (2005) examined perceptions of wife abuse in a sample of Hong Kong social workers and police officers. They found a strong effect of profession on gender role attitudes and perceptions of wife abuse. Social workers were significantly more egalitarian in their overall gender attitudes than police officers. Police officers were more likely to endorse wife abuse myths, such as 'some wives ask to be beaten', and had a narrower definition of what constitutes wife

\footnotetext{
14 The focus groups were conducted in two rounds in 2005 and 2006, and involved around 80 women. The majority of participants were employed full-time, in a range of industries and over $50 \%$ had tertiary qualifications. Thirty per cent of participants had children and $43 \%$ were married.
} 
abuse than social workers. Respondents' gender only had a small effect: male police officers held more conservative attitudes than their female counterparts, but male social workers had the most egalitarian gender attitudes. The study did not consider how these beliefs and attitudes translated in the respondents' professional activities.

\subsubsection{Legislation on and responses to violence against women}

As a signatory to the CEDAW the Hong Kong government is required to take appropriate measures to eliminate gender-based violence and ensure that laws give adequate protection from all types of physical and sexual violence, including violence by partners and family members, to all women. Any kind of violence against women is illegal under Hong Kong's general law and three main bodies of law deal with it:

1. the Offences Against the Persons Ordinance (Cap. 212);

2. the Crime Ordinance (Cap. 200); and

3. the Domestic Violence Ordinance (Cap. 189).

The Offences Against the Person Ordinance covers many acts of violence against men and women, but not sexual violence. Among other offences it deals with murders and homicides, wounding and bodily harm, serious and common assaults, child abuse, and kidnapping and detention of persons. Sexual offences ranging from indecency to indecent assault to rape are sanctioned under the Crime Ordinance. In 2002 the Crime Ordinance was amended to make it clear that marital rape was to be considered a criminal offence. ${ }^{15}$ Other changes were introduced to ensure that the victim's sexual history could no longer be included as evidence in rape trial as well as measures aiming at reducing women's revictimisation in court such as the possibility of giving evidence via video.

Various pieces of legislation cover domestic violence. While the Crime Ordinance and the Offences Against the Persons Ordinance provide criminal sanctions for acts of violence irrespective of the relationship between perpetrators and victims or where the violence takes place, the Domestic Violence Ordinance (DVO) offers additional civil protection to victims of domestic violence taking into accounts their special circumstances and needs. The DVO came into force on 19 December 1986 and mirrored the English legislation. It aimed at providing speedy protection to victims of domestic violence by creating a system of injunctions and restraining orders against an abusive partner. The inadequacies and limitations of the original DVO were highlighted in 2004 with the tragedy in Tin Shui Wai when a man murdered his wife and daughters shortly after the woman had sought protection from the police (Chow 2009). A lengthy review process started and in August 2008, the 'new' DVO was enacted. The amended legislation greatly enhanced the Court's power to protect victims by expanding the definition of the violence to physical, sexual and psychological abuse as well as threats and harassment; extending the protection to any person in a current or former domestic relationship (for example, ex-spouses, parents and relatives); strengthening enforcement with powers to arrest; and extending the length of injunctions to 24 months. Chow (2009) argues that the 2008 DVO represents a conscious effort by the Hong Kong government to improve its ability to tackle domestic violence.

The Hong Kong government has recently placed more emphasis on reducing domestic violence and adopted a 'zero tolerance' policy. In a policy address in 2006, the Chief Executive of Hong Kong stated, 'the government does not tolerate domestic violence. We provide protection to victims of domestic violence ... we will also pursue the perpetrators of violence and bring them to justice' (cited in Chow 2009). There have been criticisms, however, that the government has not really acted on the problem (SIGI 2010). For example, the US Department of State (2007) noted that while laws against domestic violence were enforced, perpetrators were generally sanctioned through injunctions rather than criminal penalties. Yet, in 2006 the Hong Kong Women's Commission released a report to raise

\footnotetext{
${ }^{15}$ Like other reforms related to the status of women, the criminalisation of marital rape came relatively late to Hong Kong; for example, spousal rape was criminalised in 1983 in Canada, 1990 in France, between 1974 and 1993 across the US, and in 1994 in the UK.
} 


\section{Hong Kong IVAWS}

awareness of the domestic violence and put forward strategies to reduce violence against women and assist victims. The report contained 21 recommendations on law reform and law enforcement, health and other services for victims, gender mainstreaming and early intervention. Three years later the Commission reported that many of these recommendations had been fully or partially implemented by the government and various stakeholders (Women's Commission 2009). For example, social services and government departments, including the police, have set up guidelines on how to work with victims of rape and violence. Police now receive training in how to respond to emergencies relating to domestic violence and they increasingly work in tandem and exchange information with social services (Hong Kong Police Force 2007).

In 2004, the Social Welfare Department (SWD) established guidelines for intervention, which included a multi-disciplinary approach to dealing with cases of intimate partner violence, child abuse and adult sexual violence involving various parties such as the police, the Department of Justice, the Department of Housing and non-governmental organisations (see e.g. SWD Working Group on Combating Violence 2011). The SWD also established a range of services that provide early intervention, investigation, referrals and counselling services for victims, abusers and other family members. Nongovernment organisations expanded their counselling services to include intervention programmes for abusers, such as the Third Path Man Service operated by Harmony House (Harmony House 2006). Shelters for victims of domestic violence, rape crisis centres and hotlines have been set up although it appears that they are routinely underfunded and suffer from a lack of qualified staff (Chan 2003; Tang, Chung and Ngo 2000).

\subsubsection{Prevalence of violence against women}

The Hong Kong government keeps easily accessible and relatively complete statistical records on victimisation through both recorded crime and social services data. In this section we draw on Hong Kong Police recorded crime figures and data from the Social Welfare Department (SWD), the Hong Kong Council of Social Services (HKCSS) and the Family Planning Association of Hong Kong (FPAHK), which provides counselling to victims of sexual assault. We also use victimisation data from Hong Kong Crime Victimisation Surveys and the 2006 UNICVS. These data give us an overview of the prevalence of VAW in Hong Kong and changes over time (Tables 1.2 and 1.3).

We have compiled the rates presented in Tables 1.2 and 1.3 drawing from the data recorded by various organisations and, as is usual when doing such work, comparisons are not straightforward. First, the recorded data vary by organisations: police only count offences that were officially reported; social services count clients to whom they provided support but who did not necessarily report the case to the police; victim surveys count all instances of victimisation mentioned to interviewers, which may include incidents that were reported to neither the police nor social services. Therefore, we expect police rates to be the lowest and rates from victim surveys to be the highest. Second, figures are provided in various forms: total number of cases and/or victims or per capita rates, and this changes over time. To deal with this problem, we have standardised the data by calculating rates per 1,000 females of the relevant age. Victims' age varies because police data typically include victims of all ages ${ }^{16}$ while social services often deal with specific categories of victims, for example, children (under 18 years) or adult women (aged 15 or 16 and over). We calculated rates by using United Nations population data, which go back to the mid-1940s and disaggregate the population count by sex and by age.

\section{Violence by intimate partners (domestic violence)}

This category includes crime cases related to domestic violence: homicide, wounding, serious assault, criminal damage and criminal intimidation, as well as sexual violence (rape and indecent assault),

\footnotetext{
${ }^{16}$ However, we calculated rates of domestic violence cases reported to police per 1,000 females aged 16 and over because the legal age of consent to sexual activity in Hong Kong is 16 years.
} 
committed in the context of an intimate relationship between current or former partners. ${ }^{17}$ All three measures show a rise in the prevalence of intimate partner violence over the last 25 years: for police recorded cases from 0.15 per 1,000 female aged 16+ in 1986 to 0.65 in 2010; for SWD data, from 0.56 in 2000 to 0.73 in 2010; and for HKCSS data, from 0.21 in 1981 to 2.29 in 2008 (Table 1.2).

Table 1.2. Intimate partner violence in Hong Kong from three data sources, 1981-2010, rates per 1,000 females aged 16 years and over

\begin{tabular}{cccc}
\hline Data source $^{\mathbf{a}}$ & Police $^{\mathbf{b}}$ & SWD $^{\mathbf{c}}$ & HKCSS \\
\cline { 1 - 2 } $\mathbf{1 9 8 1}$ & & & 0.21 \\
$\ldots$ & & & \\
$\mathbf{1 9 8 6}$ & 0.15 & & 0.39 \\
$\ldots$ & & & \\
$\mathbf{1 9 9 6}$ & & & 0.49 \\
$\mathbf{1 9 9 7}$ & & & 0.40 \\
$\mathbf{1 9 9 8}$ & & & 0.42 \\
$\mathbf{1 9 9 9}$ & & 0.56 & 0.39 \\
$\mathbf{2 0 0 0}$ & & 0.60 & 0.38 \\
$\mathbf{2 0 0 1}$ & & 0.74 & 0.42 \\
$\mathbf{2 0 0 2}$ & & 0.80 & 0.57 \\
$\mathbf{2 0 0 3}$ & & 0.90 & 0.81 \\
$\mathbf{2 0 0 4}$ & & 0.94 & 0.76 \\
$\mathbf{2 0 0 5}$ & & 1.05 & 0.86 \\
$\mathbf{2 0 0 6}$ & 0.59 & 1.20 & 1.51 \\
$\mathbf{2 0 0 7}$ & 0.79 & 1.10 & 2.39 \\
$\mathbf{2 0 0 8}$ & 0.73 & 1.07 & 2.29 \\
$\mathbf{2 0 0 9}$ & 0.73 & 0.73 & \\
$\mathbf{2 0 1 0}$ & 0.65 & & \\
\hline
\end{tabular}

Notes \& Sources a SWD and police data include homicide, wounding, serious assault, criminal damage and criminal intimidation, rape and indecent assault committed in the context of an intimate relationship between current or former partners; HKCSS data include these acts as well as psychological abuse.

Rates computed using United Nations population data <data.un.org/Data.aspx?d=POP\&f=tableCode:22>. ${ }^{b}$ Cases reported to police. Rate for 1986 estimated from Tang (1994); other years are from Hong Kong Police, Crime statistics comparison <www.police.gov.hk/ppp_en/09_statistics/csc.html>. ' Social Welfare Department; data for 2004-07 compiled from the Central Information System on Battered Spouse Cases and Sexual Violence Cases (CISBSSV) <www.swd.gov.hk/vs/english/stat.html>; data for 2000-03 from Hong Kong Council of Social Service, Social Indicators of Hong Kong, Number of reported battered spouse cases <www.socialindicators.org.hk/en/indicators/family_solidarity/27.8.1>. ${ }^{\mathrm{d}}$ HKCSS: Hong Kong Council of Social Service, Social Indicators of Hong Kong, Reported domestic violence cases per 100,000 households <www.socialindicators.org.hk/en/indicators/family_solidarity/27.5>. Rates per 1,000 females estimated based on a ration of females 16 and over to domestic households of 1.4.

Figures from HKCSS are higher than both police and SWD rates because they include psychological abuse in addition to physical and sexual abuse. All three measures show a peak in the incidence of domestic violence in 2007 followed by a decreasing trend in 2008-2010. It is likely that rates from social services are closer to actual experience than police rates because women who are reluctant to report to police for a variety of reasons may still contact social services if they need support for

\footnotetext{
${ }^{17}$ Hong Kong Police defines domestic violence as 'any incident involving an assault or breach of peace between parties who could generally be described as married or having a family relationship'. This definition covers married couples living together as well as co-habitants, lovers and spouses/partners who are divorced or separated. The police keep specific statistics on domestic violence cases since 2006.
} 


\section{Hong Kong IVAWS}

themselves or their children. These women may also have been contacted by social services because of reporting by third parties such as teachers.

While the media and others may interpret this trend as the sign of a growing social problem (e.g. Cheng 2007), it is difficult to say whether it reflects an increase in the prevalence of violence or changing attitudes and a greater willingness to report such cases, similar to what had occurred in western countries in the 1970s and 1980s. As the role, status and social involvement of women has improved, acceptance and tolerance of violence has decreased and women are more willing to report abuse. In addition, awareness campaigns, proactive government policies and increases in the range and number of services available to victims make it easier for women to report violence against them than before. For example, Cheng (2007) described how awareness building and support groups have been formed in Tin Shui Wai, a district of the New Territories considered to have a high level of domestic violence.

We found few independent studies on VAW that had been conducted in Hong Kong and all of them date from the 1990s. In 1996, the Hong Kong Social Welfare Department conducted the first community survey on family violence $(\mathrm{N}=3,008)$. Tang (1999) focused on a sub-sample of $\mathrm{N}=1,132$ female respondents aged 18 and over who were in a current or previous cohabiting relationship with a male partner in the past year. She found that ten per cent of male partners had physically abused their female partners in the last year. The most frequent behaviour was throwing, smashing or hitting something $(7.4 \%)$ followed by pushing, grabbing or shoving (4.1\%). Although this item was not counted as physical but as verbal abuse, five per cent of women said that their partners had threatened to hit them. ${ }^{18}$

Chan et al. $(2003,2010)$ have described patterns of extreme violence by examining homicides followed by suicide and homicides of intimate partners in Hong Kong. In the period between 1989-1998, 56 events of homicide-suicide (HS) involving 133 deaths took place. The majority of offenders were males $(75 \%)$ and the majority of victims, females $(64 \%)$. Nearly half the victims were spouses and lovers $(46 \%)$ and 36 per cent were children. Spouses and lovers were usually the victims of male offenders, while children were most often the victims of female offenders. In 39 per cent of cases, the catalyst for the HS involved separation, jealousy or the ending of a romantic involvement and in one in five case the HS followed a domestic dispute; however, unlike other such events in western jurisdictions, one-quarter of HS were due to economic difficulties (Chan et al. 2003). In a more recent study, Chan et al. (2010) examined 112 homicides involving intimate partners between 1989 and 2002. All but one event occurred between heterosexual couples and 68 per cent of them were cohabiting. Nearly 80 per cent of offenders were male. Seventy per cent of homicides were prompted by romantic reasons including jealousy.

\section{Sexual victimisation}

Violent sexual victimisation includes rape and indecent assault. ${ }^{19}$ We consider three sources of data: police recorded crime, SWD and the Family Planning Association (Table 1.3). All three indicators show similar rates for rape and a slightly declining trend from 0.06 per 1,000 females in 1981 down to 0.03 in 2010 for rape recorded by police, and from 0.05 in 1981 down to 0.01 per 1,000 in 2006 for FPAHK data. It is surprising that rates of recorded crime are the highest and this suggests that victims are more likely to report to the police than seek counselling. For indecent assault, police recorded rates are relatively stable and lower than in victim surveys, but about twice SWD rates. It is likely that women who were the victims of minor indecent assault may have reported the offence to the police, but did not require specialist support. At 8.18 per 1,000 females aged 16 and over the UNICVS

\footnotetext{
${ }^{18}$ Both physical and verbal abuse was measured using the Conflict Tactics Scale, which records the behaviour people might engage in when in conflict with their spouse/partners. Tang reported that 67.2 per cent of husbands had engaged in verbal abuse in the previous year; the measures used, however, included common behaviours such as sulking and not talking. While such behaviours are negative conflict resolution strategies, it is questionable whether they constitute abuse.

${ }^{19}$ For a short review of research on rape conducted in Hong Kong, see Beh (1998).
} 
indicates a rate nearly double that of the CVS (4.30). It is probable that the UNICVS data are more valid than the CVS data because the UNICVS is conducted by telephone rather than face-to-face with a strict gender matching of interviewees and interviewers; these methods enhance privacy and anonymity and reduce the psychological discomfort associated with disclosing sensitive personal information. Unlike rape, which has declined slightly since the 1980s, the CVS shows an increase in rates of indecent assault from 0.70 per 1,000 female of all ages in 1978 to 4.30 in 2005. A study by Chui and Ong (2008) confirmed an increase in the frequency of indecent assault in public transport in the mid-2000s.

Table 1.3. Sexual violence against women in Hong Kong, rate per 1,000 females of the relevant age, 1978-2010

\begin{tabular}{|c|c|c|c|c|c|c|c|}
\hline \multirow[b]{2}{*}{$\begin{array}{l}\text { Data source } \\
\text { Victim's age }\end{array}$} & \multicolumn{3}{|c|}{ Rape $^{\text {a }}$} & \multicolumn{4}{|c|}{ Indecent assault $^{a}$} \\
\hline & $\begin{array}{c}\boldsymbol{F P A H K}^{\boldsymbol{b}} \\
\text { all ages }\end{array}$ & $\begin{array}{l}\boldsymbol{S W D}^{c} \\
\text { all ages }\end{array}$ & $\begin{array}{l}\text { Police }^{d} \\
\text { all ages }\end{array}$ & $\begin{array}{l}\boldsymbol{S W D}^{\boldsymbol{C}} \\
\text { all ages }\end{array}$ & $\begin{array}{c}\text { HK CVS }^{\mathrm{e}} \\
12+\end{array}$ & $\begin{array}{c}\text { UNICVS }^{f} \\
16+\end{array}$ & $\begin{array}{l}\text { Police }^{d} \\
\text { all ages }\end{array}$ \\
\hline 1978 & & & & & 0.70 & & \\
\hline $\begin{array}{c}\ldots \\
1981\end{array}$ & 0.05 & & 0.06 & & 0.40 & & \\
\hline$\ldots$ & & & & & & & \\
\hline 1985 & 0.03 & & & & & & \\
\hline 1986 & & & 0.04 & & 1.60 & & \\
\hline$\ldots$ & & & & & & & \\
\hline 1989 & & & & & 1.60 & & \\
\hline 1990 & 0.03 & & & & & & \\
\hline 1991 & & & 0.05 & & & & \\
\hline$\ldots$ & & & & & & & \\
\hline 1994 & & & & & 2.00 & & \\
\hline 1995 & 0.03 & & & & & & \\
\hline 1996 & & & 0.03 & & & & \\
\hline 1997 & & & & & & & \\
\hline 1998 & & & 0.03 & & 4.30 & & \\
\hline 1999 & & & & & & & \\
\hline 2000 & 0.03 & & 0.04 & & & & 0.33 \\
\hline 2001 & 0.03 & & 0.03 & & & & 0.29 \\
\hline 2002 & 0.02 & & 0.03 & & & & 0.29 \\
\hline 2003 & 0.01 & & 0.02 & & & & 0.29 \\
\hline 2004 & 0.01 & 0.02 & 0.03 & 0.08 & & & 0.29 \\
\hline 2005 & 0.01 & 0.03 & 0.03 & 0.13 & 4.30 & 8.18 & 0.32 \\
\hline 2006 & 0.01 & 0.03 & 0.03 & 0.16 & & & 0.33 \\
\hline 2007 & & 0.03 & 0.03 & 0.19 & & & 0.38 \\
\hline 2008 & & 0.02 & 0.03 & 0.16 & & & 0.37 \\
\hline 2009 & & 0.03 & 0.04 & 0.08 & & & 0.35 \\
\hline 2010 & & 0.02 & 0.03 & 0.07 & & & 0.39 \\
\hline
\end{tabular}

Notes \& Sources ${ }^{\text {a }}$ Rates computed using United Nations population data

$<$ data.un.org/Data.aspx?d=POP\&f=tableCode:22>. ${ }^{b}$ Family Planning Association of Hong Kong. Data for 1981-98 from Hong Kong Human Rights Monitor, Submission on the HKSAR CEDAW Report (1999) <www.hkhrm.org.hk/english/reports/ cedaw.html>; data for 2000-06 from Statistics of help, sexually assaulted victims service <www.famplan.org.hk/fpahk/en-text/template1.asp?style=template1.asp \&content $=$ info/statistics. asp\&type $=5>$. ${ }^{~ C}$ Social Welfare Department, compiled from the Central Information System on Battered Spouse Cases and Sexual Violence Cases (CISBSSV)

<www.swd.gov.hk/vs/ english/stat.html>. ${ }^{d}$ Cases reported to police. Data for 1981-98 from Hong Kong Council of Social Service, Social Indicators of Hong Kong, Reported rape per 1,000 women $<w w w . s o c i a l i n d i c a t o r s . o r g . h k /$ en/indicators/personal_safety/25.5>; other years from Crime statistics

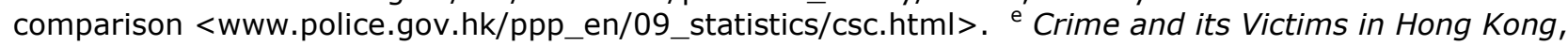
crime victimisation surveys conducted by the Census and Statistics Department in 1979, 1982, 1987, 1990, 1995, 1999, and 2006. ' United Nations International Crime Victim Survey, Broadhurst et al. (2010). 


\section{Hong Kong IVAWS}

Rates of police recorded sexual assault in Hong Kong are lower than in several western countries. In the United States, rates of rape stood at 0.36 per 1,000 female population in 1981 and 0.31 in 2006; that is, around ten times higher than in Hong Kong. In 2006, rates of rape and indecent assault combined were 0.88 per 1,000 population in Australia and the UK, and 0.68 per 1,000 population in Canada; that is between two and two and an half times larger than in Hong Kong (Daly and Bouhours 2010).

\subsection{Structure of the Report}

This report has seven chapters that focus on the Hong Kong component of the IVAWS. Chapter 2 outlines the methodology of the survey and describes the sample. Overall prevalence rates and severity of violent victimisation are presented in Chapter 3. Chapter 4 focuses on intimate partner violence and Chapter 5, on violence by non-partners; both chapters include an analysis of correlates of victimisation. In Chapter 6, we turn to women's perception of and responses to the violence, including reporting to police, satisfaction with police action and access to victim support services. Finally, in Chapter 7, we review the results of the Hong Kong IVAWS and compare those with the results of other countries surveyed. We conclude with a brief discussion of the survey's findings in the context of Hong Kong. 


\section{CHAPTER 2}

\section{Methodology and Sample}

\subsection{Timeframe and Instrument}

The Hong Kong IVAWS was conducted by telephone between December 2005 and March 2006 (including some delays and suspension periods) and refers to victimisation that occurred during the respondents' adult lifetime (i.e. since age 16), the five years period preceding the survey (i.e. 2001-2005) and the 12 months (one year) preceding the survey (i.e. 2005). First, screening questions asked respondents about experiences of violent victimisation by any man since age 16. Those who mentioned an incident were asked when it happened - in the past 12 months, one to five years, or earlier than that. If the respondent answered that it happened in the past 12 months, the interviewer then asked her how many times it occurred during 2005. These questions were designed to elicit information on the prevalence as well as volume and frequency (incidence) of VAW.

The instrument used in Hong Kong followed the standard IVAWS instrument excluding most of the optional items and some questions not relevant to the Hong Kong context. The survey included 143 pre-coded questions. ${ }^{20}$ The questionnaire was bilingual, with the Mandarin and Cantonese versions translated from the original English version. The questionnaire consisted of seven sections:

1. Respondent's demographics, and current and previous relationships;

2. Experiences of male violence for seven types of physical violence and five types of sexual violence and including frequency of the abuse and relationship to perpetrator;

3. Victimisation by non-partner records details of the most recent incident of victimisation by a man other than an intimate partner (e.g. friend, stranger) including type and severity of the abuse, injuries, reporting to police, and perceptions of the seriousness of the incident;

4. Victimisation by partner follows a similar format to (3) but focuses on abuse by an current or former intimate partner (e.g. husband, boyfriend);

5. Characteristics of violent former intimate partner was asked only of women who reported victimisation by a former partner; questions covered the ex-partner's demographics, income, use of alcohol, violent behaviour outside of the family, and use of emotionally abusive and controlling behaviours;

6. Characteristics of current partner was asked of all women who mentioned they were currently in a relationship and followed a format similar to (5); and

7. Housebold income and conclusion including a request for a follow up interview. ${ }^{21}$

\footnotetext{
${ }^{20}$ The total number of 143 questions includes all the questions on every type of victimisation. Respondents actually answered fewer questions, depending on whether they had been abused at all, and if they had, the types of behaviour they were the victims of.

${ }^{21}$ As part of her Master's thesis Loretta Tang conducted a series of follow-up interviews with 20 women who had experienced male violence that focused on victims' reporting behaviour and the reasons why they did or did not report the incident to the police. Results of this study are available in Tang (2006).
} 


\section{Hong Kong IVAWS}

Appendix A outlines the content of the survey instrument. The standard IVAWS questionnaire is presented in Johnson et al. (2008: Appendix IV). Rather than using broad terms such as 'violence', 'assault' or 'rape', the items measuring experiences of violence described specific acts of physical and sexual violence such as since you were 16 or older has any man threatened to burt you physically in a way that frightened you; slapped, kicked, bit or hit you with a fist? Forced you into sexual intercourse by threatening you, holding you down or hurting you in some way? The questions were worded in such specific terms because respondents have different views on what constitutes violence; for instance, some women may not perceive threats as violence. For similar reasons, a list of potential perpetrators or abusers was presented, because some respondents may be reluctant to talk about violence by husbands.

A small pilot study was conducted in June 2005 to test the length, likely response rate and Chinese translation of the IVAWS questionnaire. There were concerns that the response rate may be low because of Hong Kong hectic work schedule and 'time-poor' culture; therefore, the section on 'mother abuse and childhood victimisation' was not included in the Hong Kong questionnaire to reduce the length of the survey. Following the pilot some optional questions, which did not yield useful answers were removed:

- Dowry payments and arranged marriages because these are no longer common in Hong Kong;

- Respondent's and current/former partner's ethnic background and religion because respondents are usually Chinese;

- Respondent's drinking behaviour since the pilot survey yielded negligible positive responses from respondents; and

- Helpfulness of victim services in relation to the violence the respondent experienced because of the extremely low number of victims who contacted such services.

Data from the pilot survey were not included in the final survey, but were used to improve the Chinese translation.

\subsection{Mode of the Survey and Sample Selection}

Internationally two interview methods have been used in conducting the IVAWS: face-to-face interviewing and Computer Assisted Telephone Interviewing (CATI). CATI is routinely used in industrial countries with high telephone penetration (over $70 \%$ of the population) for a range of surveys. In Hong Kong, where fixed-line telephone line penetration of households was about $93 \%$ in 2005 (Bacon-Shone and Lau 2006), CATI using fixed-lines was an appropriate mode for conducting the IVAWS. When using CATI, interviewers read the instructions and the questions in the spoken language of the respondent (displayed in English and Chinese, together with any pre-coded answers) from a computer screen. Answers are directly entered into the computer system and used by the system to select the next question. This process effectively reduces the possibility of potential routing error by the interviewers.

All interviewers were female. In addition to technical guidance on how to run the survey through the CATI system, interviewers were trained according to the training module of the IVAWS, which gave them an understanding of how violence may affect women and how to respond to emotional trauma caused by responding to the survey (see Johnson et al. 2008). During the 2-day training period interviewers did several trial runs of the IVAWS with each other, role-playing the respondent and the interviewer in order to clarify and solve any potential problems prior to the implementation. Interviewers were also taught some ways in which to build rapport with the respondents, for example by not rushing through the survey and showing empathy to respondents. Interviewers were supported throughout the survey period with frequent debriefings and group and individual counselling. 
The survey was introduced as a study related to women's personal safety rather than to violence against women for several reasons. First, the use of the term 'violence' may deter women from participating; second, if a male answered the phone, the mention of violence may stop him from calling a female member of the household to the phone if he thought she may identify him as a perpetrator. It may also have placed the female household members at risk of potential violence. Because interviewers could not know if respondents lived in an abusive household, they were trained on how to deal with the possibility that the interview may be overheard by others and situations when an abuser would intrude in the interview. If respondents indicated that they would like to participate but lacked the privacy or time to do so at the time of the call, a more convenient time for the interview was arranged. The survey was administered during evening hours on weekdays and on Saturday mornings and early afternoons. Calls were not made during the Christmas and Chinese New Year holiday periods. For the majority of respondents, who had not experienced violence, the interview lasted around 15 minutes; however, some interviews lasted up to one hour when women reported multiple incidents of victimisation.

For sample selection, all fixed-line telephone numbers were generated from the Hong Kong 2005 English residential telephone directory ${ }^{22}$ by dropping the last digit, removing duplicates, adding all 10 possible final digits, randomising the order, and selecting numbers as needed. This method provided an equal probability sample that covered unlisted and new numbers, but excluded businesses large enough to use blocks of at least 10 numbers. Survey samples drawn from telephone directories, which only include landline telephone numbers, have resulted in an under-representation of young people in European countries because they are those most likely to be reached by mobile phones only (Gelb 2008). In Hong Kong fixed-line penetration for households is higher than in European countries and we expected that young women would be reachable via the household landline phone. The exception would be young women who had recently formed new households and who tend to dominate the households without fixed-lines in Hong Kong (Lau 2006). Younger women, particularly those under 25 , were underrepresented in our sample, but it is difficult to say whether this was due to the inability to reach them or because they were the busiest and most likely to refuse to answer the questionnaire.

The sample was drawn by the random dialling of telephone numbers generated by the procedure noted above. Non-relevant contacts such as businesses were ignored. Eligible female respondents were aged 18 and above ${ }^{23}$ and could be Cantonese, Mandarin or English speakers. Foreign domestic helpers who were eligible were included in the survey. In each household, a single respondent was selected using the 'next birthday' rule: the selected respondent was the female household member aged 18 and over, whose birthday came first after the survey date. This rule helped to reduce the over-representation of elderly women and homemakers in the sample. The selected respondent was not replaced if she refused to participate. This process continued until the desired number of completed interviews was reached. The aim was to reach a sample size of approximately 1,200 women.

Overall, 2,902 women were invited to participate: 1,378 women refused to participate, 42 withdrew during the interview and 185 questionnaires were only partially completed. The final sample included 1,297 completed questionnaires; the response rate was 45 per cent. This response rate was higher than that of Australia (39\%) but lower than other countries where telephone interviewing was used (Denmark, 52\%; Switzerland, 59\%; Italy, 72\%). Generally response rates are higher with face-to-face interviewing. This response rate was only slightly lower than the 49 per cent success achieved during the 2006 Hong Kong UNICVS.

\footnotetext{
${ }^{22}$ The Chinese residential telephone directory was not used because the total number of telephone contacts was less than the English version.

${ }^{23}$ Most IVAWS samples include women between the ages of 18 and 69; however, we decided to include all women aged 18 and over.
} 


\subsection{Reliability and Validity of the Telephone Survey}

Reliability consists of the degree to which the instrument used will produce consistent measures when repeated. Test-retest and alternate-form checks were not applicable to the IVAWS because respondents were contacted once by a single interviewer. Intra- and inter-observer reliability was ensured by standard interviewer training and careful monitoring of each interviewer's performance during the survey implementation. Validity relates to how well the instrument measures what it sets out to measure. The IVAWS instrument has been designed carefully and takes into account differences in culture and subjectivity. The content validity of the Chinese questionnaire was reviewed by local and overseas criminologists. Face validity was controlled by inviting the surveyors and their supervisors to assess how fluent the Chinese questionnaire was in practice.

Quality checks were carried out at each stage of the survey to ensure satisfactory standards of performance. A validation assessment was conducted on the day following the survey, through a telephone call-back to randomly selected respondents. The Social Sciences Research Centre supervisors or IVAWS project staff subsequently checked around 15 per cent of the questionnaires completed by each interviewer.

\subsection{Victimisation Rates and Significance Tests}

Statistical weighting was applied to compensate for the over- and under-sampling of particular groups and to make the results more representative of the Hong Kong female population aged 18 and above. Weights were calculated as the ratio of the population distribution by age group and sex compared to that of the sample (Appendix B).

In this study we express the prevalence rate as the percentage of respondents who were victimised one or more times in their adult lifetime, in the previous five years, or during the year preceding the survey. Prevalence rates do not reflect the volume of crime, but the proportion of the population who have been victimised at least once. The incidence rate measures the total number of incidents and represents the number of times that people are victimised during a year (usually expressed as $\mathrm{N}$ per 100,000 population). Except when specified, rates are computed including missing values, such as 'don't know' and refusals to answer in the denominator. The total Ns reported in the various sections will vary depending on the population of interest: overall rates of victimisation are calculated based on the entire sample; for intimate partner violence, rates are based on the number of women who had ever been in a dating, cohabiting or marital relationship with a man; for non-partner violence, rates are based on the whole sample. Descriptive statistics are presented for most of the results. The strength of differences is tested using the Chi-square procedure, and the associated $p$ (statistical significance) values and confidence intervals are reported as appropriate.

As in all surveys, the results of the Hong Kong IVAWS are estimates and their accuracy depends on the size of the sample and the observed percentages. Because results are based on a sample of the population rather than the whole population, it is probable that differences between sample and population results will occur (sampling error). However, if the sample is large enough and representative of the population, these differences are not expected to be substantial. For our sample, we calculated the maximum sampling error to be \pm 2.7 per cent at the 95 per cent level of confidence; that is, for each given survey question we can be 95 per cent confident that the difference between the proportion of the sample and that of the population answering positively will vary by no more than plus or minus 2.7 per cent. 


\subsection{Limitations}

Some population groups were not included in the sample selection. First, some people cannot be contacted by telephone, for example, those living in institutions such as prisons, hospitals, hostels or homes for the elderly. Past research has suggested that people in institutions may be at a higher risk of crime victimisation than those in the community. Second, households with no fixed telephone line, such as those using only mobile phones, and those living on boats, in temporary housing or in remote areas were also excluded. Finally, because the survey was usually carried out in the evening, women who worked regularly at night or did shift work were more likely to be excluded, although some were successfully contacted on Saturdays.

Crime surveys are prone to a number of response errors. First, participants may not recall minor incidents. For each type of victimisation, respondents were asked to recall details of the last incident. Respondents who have been victimised multiple times may recall the most serious incident rather than the most recent. Certain groups, such as the better educated and more affluent, are more likely than other groups to report incidents of minor violence (Lynch 1995). Some respondents may fail to realise that an incident is relevant or may be unwilling to report certain incidents-particularly those involving people they know; others may have been participating in unlawful activities during the course of their own victimisation. Therefore, the IVAWS measures only crimes that respondents were prepared to reveal to interviewers.

Despite the assistance of CATI, interviewers may commit errors during data collection, such as misinterpreting answers or mistakenly entering the wrong code. Together these factors may affect the reliability of the data obtained. However, every effort was made during the administration, data coding and analysis stages to minimise these problems. A small number of cases were excluded due to data inconsistencies or only partial completion of the questionnaire.

\subsection{Description of the Sample}

The sample consisted of 1,297 respondents. Table 2.1 describes selected characteristics of the 2006 IVAWS sample in Hong Kong. As mentioned above, the sample was not entirely representative of the Hong Kong female population; the far right column of Table 2.1 presents the weighted proportions. Women's age ranged from 18 to 78 years, with a weighted mean of 41.4 years. Two-thirds of respondents were married or lived with a male partner. About one-third of the women $(34.7 \%)$ did not have their own income, half worked for pay, and the rest had an income from sources other than work. The nett household monthly income of about 60 per cent of participants was equal or above the general population monthly median income for households (HK\$16,000), which suggests that higher income households may have been slightly overrepresented in this sample.

Table 2.1. Characteristics of the 2006 Hong Kong IVAWS sample

\begin{tabular}{|c|c|c|c|}
\hline$N=1,297$ & $\begin{array}{c}\% \% \\
\text { Unweighted }\end{array}$ & $\begin{array}{c}\% \\
\text { Weighted }\end{array}$ & Difference \\
\hline \multicolumn{4}{|l|}{ Age in years } \\
\hline $18-24$ & 12.0 & 13.4 & +1.4 \\
\hline $25-34$ & 17.2 & 20.9 & +3.7 \\
\hline $35-44$ & 29.7 & 24.8 & -4.9 \\
\hline $45-54$ & 27.9 & 21.3 & -6.6 \\
\hline $55+$ & 13.2 & 19.6 & +6.4 \\
\hline Mean age (years) & 41.0 & 41.4 & +0.4 \\
\hline
\end{tabular}


Table 2.1. cont'd

\begin{tabular}{|c|c|c|c|}
\hline Characteristic & $\begin{array}{c}\% \\
\text { Unweighted }\end{array}$ & $\begin{array}{c}\% \% \\
\text { Weighted }\end{array}$ & Difference \\
\hline \multicolumn{4}{|l|}{ Relationship status } \\
\hline Married & 67.8 & 64.0 & -3.8 \\
\hline De-facto living & 2.0 & 2.2 & +0.2 \\
\hline Dating & 9.1 & 10.0 & +0.9 \\
\hline Single/ separated/ not living with husband & 21.1 & 23.8 & +2.7 \\
\hline \multicolumn{4}{|l|}{ Respondent lives with } \\
\hline Male partner \& children of any age & 46.5 & 42.0 & -4.5 \\
\hline Male partner only & 14.0 & 14.8 & +0.8 \\
\hline Male partner, children $\&$ relatives & 8.0 & 8.2 & +0.2 \\
\hline Relatives \& with or without children & 20.6 & 23.2 & +2.6 \\
\hline Alone with children of any age & 6.0 & 5.8 & -0.2 \\
\hline Alone or with non-family members & 4.9 & 6.0 & +1.1 \\
\hline \multicolumn{4}{|l|}{ Highest level of education } \\
\hline Primary & 14.0 & 14.7 & +0.7 \\
\hline Junior secondary & 21.1 & 18.8 & -2.3 \\
\hline Senior secondary / Matriculation & 38.2 & 36.8 & -1.4 \\
\hline Tertiary & 26.7 & 29.7 & +3.0 \\
\hline \multicolumn{4}{|l|}{ Employment/income } \\
\hline Works for pay & 52.1 & 50.5 & -1.6 \\
\hline Has own income from other sources & 13.7 & 14.8 & +1.1 \\
\hline No personal income & 34.2 & 34.7 & +0.5 \\
\hline \multicolumn{4}{|l|}{ Occupation } \\
\hline Management \& professional & 14.5 & 14.2 & -0.3 \\
\hline Administration \& services & 23.6 & 22.8 & -0.8 \\
\hline Unskilled, self-employed \& other & 11.2 & 10.4 & -0.8 \\
\hline Student & 6.5 & 7.2 & +0.7 \\
\hline Home duties, retired, unemployed & 44.2 & 45.4 & +1.2 \\
\hline \multicolumn{4}{|l|}{ Nett household monthly income (HK\$) } \\
\hline Nil income & 2.4 & 3.9 & +1.5 \\
\hline $1-9,999$ & 14.3 & 15.3 & +1.0 \\
\hline $10,000-19,999$ & 23.1 & 21.7 & -1.4 \\
\hline $20,000-29,999$ & 15.7 & 14.8 & -0.9 \\
\hline $30,000+$ & 26.0 & 25.0 & -1.0 \\
\hline Refused/don't know & 18.5 & 19.3 & +0.8 \\
\hline
\end{tabular}




\section{CHAPTER 3}

\section{Prevalence and Severity of Violence}

This chapter presents rates of victimisation for physical and sexual violence by all perpetrators combined (i.e. intimate partners and non-partners) over the adult lifetime, the past five years and the past year. We also compare rates found in Hong Kong with those of other countries included in the IVAWS. Correlates of victimisation and the severity of the violence are discussed. All analyses are performed using weighted data.

\subsection{Women's Experiences of Violence}

Figure 3.1 presents a schematic picture of the number and proportion of Hong Kong women who had experienced physical or/and sexual violence in their adult lifetime (since age 16), in the five years and in the year preceding the survey. This is a simple measure of the percentage of women who reported having experienced violence by men during the survey periods. Overall, 19.9 per cent of the women surveyed reported having experienced at least one incident of violence by a man in their lifetime. The proportion of women who were victim of violence by men in the five years preceding the survey reduces to 8.3 per cent, and in the year preceding the survey, to 3.7 per cent.

Across the adult lifetime, we find that 80.1 per cent of women did not experience any violence, and:

- 8.3 per cent experienced sexual violence only;

- 6.5 per cent experienced physical violence only; and

- 5.2 per cent experienced both physical and sexual violence, in the same or separate incidents.

In the five years preceding the survey, 91.7 per cent of the women did not experience any violence, and:

- 3.9 per cent experienced sexual violence only;

- 2.9 per cent experienced physical violence only; and

- 1.5 per cent experienced both physical and sexual violence, in the same or separate incidents.

In the past year (2005), 96.3 per cent of respondents did not report any violence against them, and:

- 1.8 per cent experienced sexual violence only;

- 1.3 per cent experienced physical violence only; and

- 0.6 per cent experienced both physical and sexual violence, in the same or separate incidents.

Across all three time periods, higher proportions of women reported that they experienced sexual violence compared to physical violence. 
Figure 3.1. Women's experiences of violence in their adult lifetime, past five years and one year

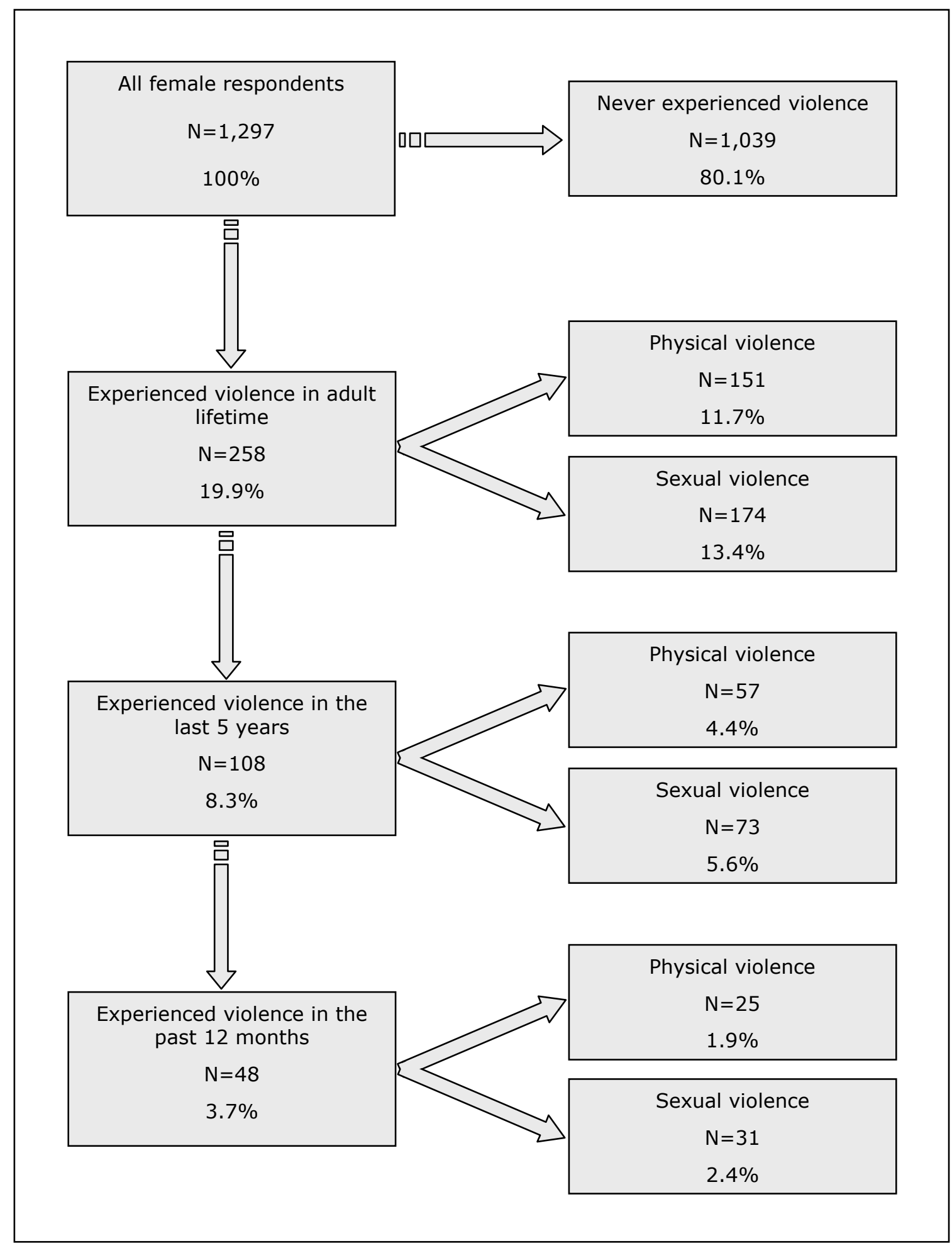

\subsubsection{Physical violence}

The IVAWS defines physical violence as a continuum ranging from threats of physical harm to actual harm, and including acts such as hitting, pushing, slapping, kicking, burning, attempting to strangle and using weapons (see Appendix A). Although it can be argued that threats of harm do not constitute physical violence, we found that in the majority of violent incidents $(93 \%)$ threats were associated with actual physical violence. Indeed, if we exclude threats of harm, the proportion of women who 
experienced at least one incident of violence since the age of 16 reduces only slightly from 11.7 per cent to 10.8 per cent.

The most frequent forms of physical violence reported by Hong Kong women were pushing, grabbing, twisting arm or pulling hair; slapping, kicking, or hitting; and throwing or hitting with something (4.94.8\%) (Table 3.1). These were followed by threats of physical harm (3.5\%). Other forms of violence were less frequent. While proportions differ depending on the time period considered, the relative frequency of each form of violence is similar.

Table 3.1. Forms of physical violence in adult lifetime, past five years and one year (\%)

\begin{tabular}{|c|c|c|c|}
\hline$N=1,297$ & Lifetime & Past 5 years ${ }^{b}$ & Past 1 year $^{\text {b }}$ \\
\hline At least one form of physical violence ${ }^{a}$ & 11.7 & 4.4 & 1.9 \\
\hline Pushing, grabbing, twisting arm, pulling hair & 4.9 & 2.0 & 0.8 \\
\hline Slapping, kicking, biting or hitting with a fist & 4.9 & 1.3 & 0.7 \\
\hline Throwing/hitting with something & 4.8 & 1.5 & 0.6 \\
\hline Threats to hurt physically & 3.5 & 1.4 & 0.9 \\
\hline Using/threatening to use a knife or other weapon & 1.6 & 0.2 & 0.0 \\
\hline Strangling, trying to suffocate, burning or scalding & 0.7 & 0.3 & 0.1 \\
\hline Other physical violence & 0.5 & 0.3 & 0.1 \\
\hline
\end{tabular}

Notes ${ }^{a}$ Totals may not add up to $100 \%$ because of multiple responses. ${ }^{b}$ Five-year and one-year rates may be underestimated because a few respondents said they had been physically abused, but did not specify when the incident occurred.

Just under half $(45.7 \%)$ of the 151 women who reported one or more incidents of physical violence in their adult lifetime experienced more than one form of violence (Figure 3.2). Several forms of physical violence may occur during the same violent incident but it can also indicate a pattern of victimisation over time. About one-third of victims experienced several forms of violence in the five years and one year preceding the survey $(35.1 \%$ and $36 \%$ respectively).

Figure 3.2. Forms of violence experienced by women in their adult lifetime

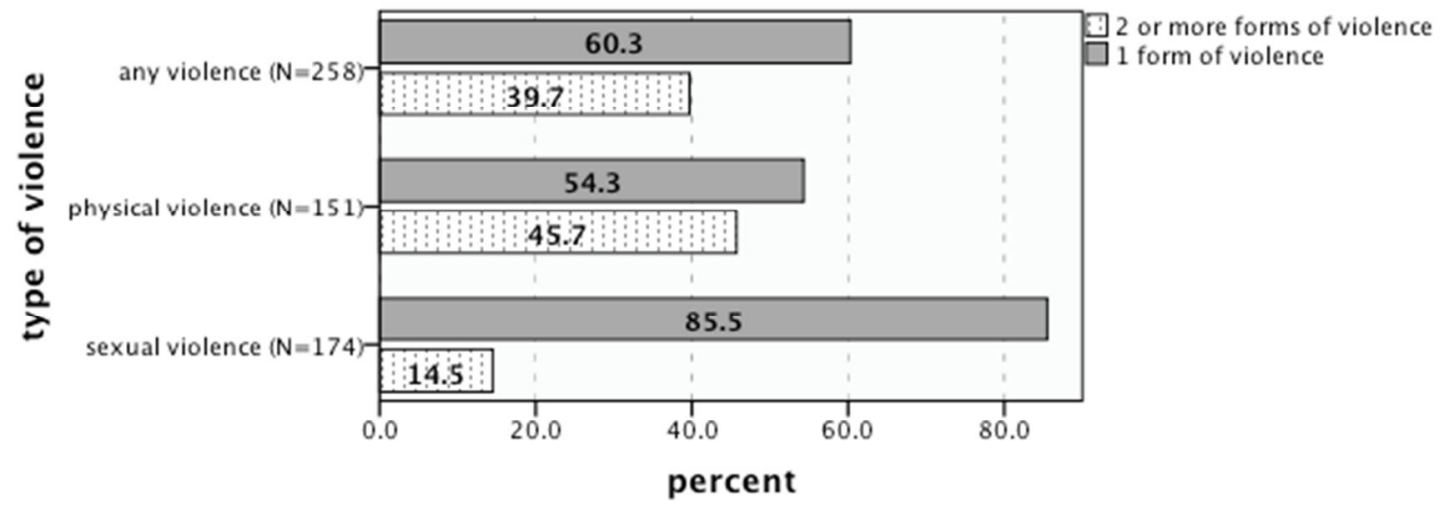

\subsubsection{Sexual violence}

Rates of sexual violence may differ depending on the breadth of the chosen definition; for example, rates will be higher if no-touch offences such as indecent exposure (exhibitionism or 'flashing') are counted. The IVAWS's definition of sexual violence includes forced intercourse and attempted forced intercourse (rape and attempted rape), unwanted sexual touching (indecent assault) and forced or attempted forced intercourse with another man for money or goods, i.e. forced prostitution, but excludes indecent exposure. 
Just over 13 per cent of the Hong Kong IVAWS sample reported one or more incidents of sexual violence in their adult lifetime, reducing to 5.6 per cent in the past five years and 2.4 per cent in the past year. The most frequent form of sexual violence was unwanted sexual touching, reported by 11.8 per cent of women over their lifetime $(4.7 \%$ and $2.2 \%$ in the previous five years and previous year respectively). Around 2 per cent of respondents indicated that since they turned 16 years, a man forced or attempted to force them into sexual intercourse. Less than one per cent of women said this occurred in the previous five years, and just 0.4 per cent, in the last year. No woman mentioned having been forced to have intercourse with a third party for money (forced prostitution).

Table 3.2. Forms of sexual violence in adult lifetime, past five years and one year (\%)

\begin{tabular}{|c|c|c|c|}
\hline$N=1,297$ & Lifetime & Past 5 years ${ }^{b}$ & Past 1 year $^{\text {b }}$ \\
\hline At least one form of sexual violence ${ }^{a}$ & 13.4 & 5.6 & 2.4 \\
\hline Unwanted sexual touching & 11.8 & 4.7 & 2.2 \\
\hline Forced sexual intercourse & 2.1 & 0.9 & 0.4 \\
\hline Attempted forced sexual intercourse & 1.8 & 0.8 & 0.4 \\
\hline Forced prostitution & 0.0 & 0.0 & 0.0 \\
\hline Other sexual violence & 0.1 & 0.0 & 0.0 \\
\hline
\end{tabular}

Notes a Total may not add up to $100 \%$ because of multiple responses. ${ }^{b}$ Five-year and one-year rates may be underestimated because a few respondents said they had been sexually abused, but did not specify when the incident occurred.

While nearly half the women who reported physical abuse had been victim of multiple forms of physical violence, a smaller proportion (14.5\%) of victims of sexual abuse reported multiple forms of abuse (Figure 3.2). Of the 153 women who had been victim of unwanted sexual touching in their lifetime, about nine per cent said they had also experienced actual or attempted forced sexual intercourse (9.1\% and $9.2 \%$ respectively), which could have occurred in the same incident or at different times.

\subsubsection{Comparisons with other surveys: IVAWS, UNICVS and CVS}

Compared to the other countries that participated in the IVAWS, Hong Kong's rates of both physical and sexual violence were low. The Philippines recorded the lowest rate $(17 \%)$ of any violence over the adult lifetime followed by Hong Kong (19.9\%). Costa Rica recorded the highest rate: 60 per cent of women said they had experienced violence in their lifetime (for detailed results for each country see Johnson et al. 2008).

Although Hong Kong recorded generally low rates of VAW, it differed from most of the other countries in that the rate of sexual violence was as high as the rate of physical violence. Apart from Switzerland, which had comparable rates of physical $(27 \%)$ and sexual $(25 \%)$ violence, the likelihood of physical violence was higher than that of sexual violence in all other countries. For example, while the rate of sexual violence in the Philippines (6\%) was over half that in Hong Kong (13.4\%), physical violence was more frequent in the Philippines (15\%) than in Hong Kong $(11.7 \%)$.

It is more difficult to compare the results of the IVAWS with those of previous surveys conducted in Hong Kong because definitions and counting rules differ. The UNICVS asked a general question about threats of and actual physical attacks by any male or female perpetrator in the previous year; and one question about sexual assault, including rape and indecent assault. Overall, 2.4 per cent of female respondents indicated that they had been victims of any kind of violence in the previous year: 1.5 per cent of physical violence and 0.9 per cent of sexual violence (Broadhurst et al. 2010). Although the UNICVS includes perpetrators of both sexes and the IVAWS includes only men, UNICVS rates are lower than those recorded by the IVAWS $(1.9 \%$ and $2.4 \%$ for physical and sexual violence respectively); 
this is not surprising because the UNICVS asked only one general question for each type of violence, while the IVAWS canvassed a range of specific acts, which is likely to elicit higher response rates.

The Hong Kong government's own crime victimisation survey (CVS) also measured victimisation that occurred in 2005 (Census and Statistics Department 2006a). Like the UNICVS, the CVS included both male and female perpetrators. For physical violence, the CVS focused only on the most serious assaults that caused injuries, however minor, to the victim. It did not explicitly mention, but did not exclude, domestic assaults. For sexual violence, the CVS was limited to assaults accompanied by circumstances of indecency; that is, excluding rape and non-contact offences. ${ }^{24}$ The CVS found that in 2005, 0.1 per cent of women had been seriously physically assaulted and 0.4 per cent had been the victim of indecent assault. Again these rates were lower than those of the IVAWS. Although the scope of the questions was more restricted, it is likely that the lack of gender matching of respondents and interviewers in the CVS and the face-to-face interview method did not encourage female respondents to reveal sexual victimisation.

\subsection{Correlates of Violence}

Previous research has found some risk factors associated with violent victimisation. Age is the strongest predictor for both physical and sexual violence, with younger women victimised more often than older women (Lauristen and White 2001; Mouzos and Makkai 2004; Tjaden and Thoennes 2000). Socio-economic factors such as marital status, level of education, income and participation in labour force have also been associated with risk of violent victimisation, but results are less consistent. In this section, we examine how four variables - age, relationship status, level of education, and work status and income - correlate with the likelihood of victimisation in the past year (2005).

\subsubsection{Age}

We found that age was strongly and negatively associated with the likelihood of experiencing both physical and sexual violence; that is, risks of victimisation in the past year decreased as age increased (Figure 3.3). The group of women most at risk for all types of violence were those aged 18 to 24 years; however, women 25 to 34 years also had a significantly higher risk of victimisation than older women (Table 3.3). Women who had been the victims of physical violence in the past year were on average 14 years younger than non-victims (27.7 years and 41.7 years respectively, $p<.001)$; victims of sexual violence were 7.5 years younger than non-victims (34.1 years and 41.6 years respectively, $p<.001$ ).

Table 3.3. Rates of physical and sexual violence by age group, past year (\%)

\begin{tabular}{llccc}
\hline \multirow{N}{*}{$\mathbf{N = 1 , 2 9 7}$} & $\begin{array}{l}\text { Physical } \\
\text { violence }\end{array}$ & Sexual violence & Any violence \\
\cline { 5 - 5 } $18-24$ years & $5.8^{* * *}$ & $4.6^{*}$ & $9.2^{* * *}$ \\
25-34 years & $4.1^{* * *}$ & $3.7^{*}$ & $6.3^{* * *}$ \\
$25-44$ years & 0.9 & 2.2 & 2.8 \\
$45-54$ years & 0.4 & 1.8 & 1.8 \\
$55+$ years & 0.0 & 0.4 & 0.4 \\
\hline
\end{tabular}

${ }^{*} p<.05 ;{ }^{* * *} p<.001$.

The Australian IVAWS found that younger age was a predictor of victimisation for the group aged 18 to 24 years, but rates dropped by more than half for the group aged 25-34 years. For example, looking at any type of violence, 28 per cent of women aged 18-24 years in Australia reported experiencing at least one incident in the past year, but only 11 per cent of women between 25 and 34 years (Mouzos

\footnotetext{
${ }^{24}$ Rape was included pre-1998, but the question is no longer asked due to low or non-existent responses.
} 


\section{Hong Kong IVAWS}

and Makkai 2004, p. 29). In Hong Kong, the comparable rate was 9.2 per cent for the age group 18-24 years, and it dropped by about one-third to 6.3 per cent for the age group 25-34 years.

Figure 3.3. Physical and sexual violence by age, past year (\%)

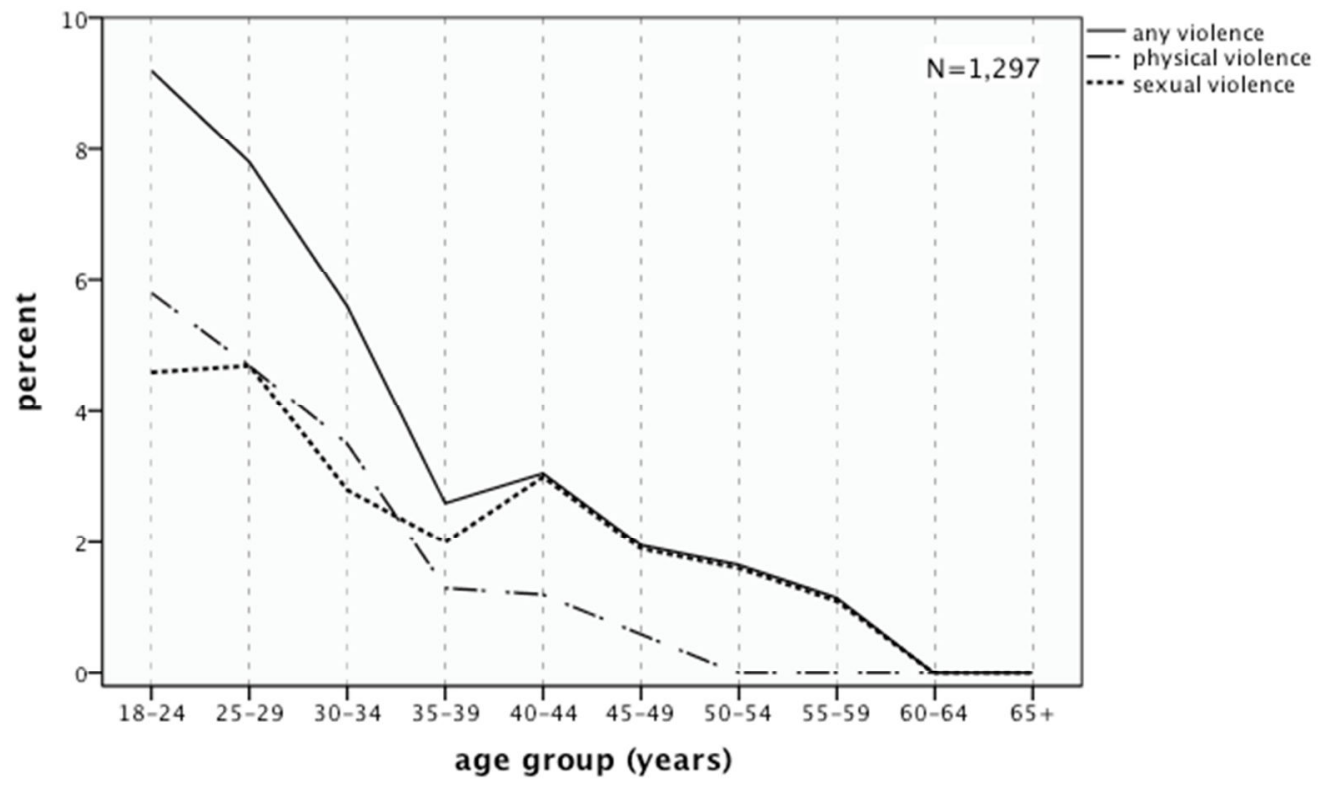

\subsubsection{Relationship status}

We did not find significant differences in the risk of victimisation between women who were in an intimate relationship ${ }^{25}$ and those who were not (3.2\% and 3.9\% respectively, for any violence). However, the types of relationship women were involved in were important. Women who were dating a boyfriend were four to six times more likely to report physical or sexual violence (by any man) in the past year than married or single women (Table 3.4). This contrasts with the Australian IVAWS (Mouzos and Makkai 2004, p. 33), which found that single women had significantly higher risks of experiencing any type of violence than those who were married, living with a partner or dating a boyfriend. We found an interaction between the age of the women and the type of relationships they were forming: women dating a boyfriend were on average 27.4 years, compared to 37.5 years for single women and 45.2 years for women who were married or living with a partner $(p<.001)$. However, further analyses controlling for the effect of age showed separate effects of younger age and dating on the risks of violent victimisation. We explore these effects further when we look next at different types of violence by intimate partners and non-partners.

Like previous victimisation surveys, we found that women who had been previously involved in an intimate relationship - i.e. separated or divorced - were more likely to report violence than those who did not $(5.1 \%$ and $2.3 \%$ respectively, $p<.01)$.

\footnotetext{
${ }^{25}$ Women in an 'intimate relationship' were those who were married, not married but living with a partner, and those who were dating a boyfriend at the time of the IVAW survey. Note that in this chapter we consider violent victimisation by any man, not just intimate partners. Violence by partners and non-partners will be examined in Chapters 4 and 5 respectively.
} 
Table 3.4. Physical and sexual violence by type of intimate relationship, past year (\%)

\begin{tabular}{llccc}
\hline N=1,297 & $\begin{array}{l}\text { Physical } \\
\text { violence }\end{array}$ & Sexual violence & Any violence \\
\cline { 1 - 1 } Relationship status & & & \\
Currently in an intimate relationship & 1.9 & 2.7 & 3.9 \\
Not in an intimate relationship & 2.3 & 1.3 & 3.2 \\
Type of intimate relationship & & & \\
Married/de facto & 1.3 & 1.6 & 2.3 \\
Dating & $6.2^{* *}$ & $10.1^{* * *}$ & $13.8^{* * *}$ \\
Single & 2.3 & 1.3 & 3.2 \\
Previous relationship(s) & & & \\
Yes & $2.8^{*}$ & $3.4^{*}$ & $5.1^{* *}$ \\
No & 1.1 & 1.5 & 2.3 \\
\hline
\end{tabular}

${ }^{*} p<.05 ;{ }^{* *} p<.01 ;{ }^{* * *} p<.001$.

\subsubsection{Level of education}

Educational attainment had little predicting power. Only one result was statistically significant: women who reached senior secondary or matriculation level, but did not continue to tertiary education had a significantly higher risk of physical victimisation than other women (with no difference for sexual violence or both physical and sexual violence combined, Table 3.5). On average women with secondary education only were nearly five years younger than others and although the age difference was not large it was statistically significant (38.4 years vs. 43.2 years, $p<.001$ ). Younger age was correlated with both physical and sexual victimisation, and we found previously that the women most at risk of violent victimisation were those in the age group 18-34 years, that is, those younger than 35 years. Therefore, although age may be a contributing factor, it does not explain in a satisfactory fashion the higher rate of victimisation of women with only secondary education. There were also no differences in the relationship status between women with various educational attainments.

Table 3.5. Physical and sexual violence by level of education, past year (\%)

\begin{tabular}{|c|c|c|c|}
\hline$N=1,297$ & $\begin{array}{l}\text { Physical } \\
\text { violence }\end{array}$ & Sexual violence & Any violence \\
\hline \multicolumn{4}{|l|}{ Highest level of education } \\
\hline Primary & 0.0 & 2.1 & 2.1 \\
\hline Junior secondary & 1.2 & 2.5 & 2.9 \\
\hline Senior secondary / matriculation & $3.1^{*}$ & 2.5 & 4.6 \\
\hline Tertiary & 1.8 & 2.6 & 3.9 \\
\hline
\end{tabular}

${ }^{*} p<.05$.

\subsubsection{Work status and income}

Consistent with the results of the Australian IVAWS, we found no statistically significant differences in the likelihood of violent victimisation based on household income in Hong Kong (not shown in table); however, in contrast to the Australian IVAWS, Hong Kong women who were working for pay and those who had their own income (from work or other sources) reported higher levels of both physical and sexual violence (Table 3.6). We investigated whether age was a mediating factor that could explain these finding since working women and women with their own income were, on average, significantly 


\section{Hong Kong IVAWS}

younger than non-working women and those with no income. ${ }^{26}$ We note, however, that the average age of working women (36.3 years) was higher than that of women who were most at risk of violent victimisation (27.7 years). After controlling for age, we found a unique effect of work on the risk of victimisation, which is consistent with a routine activity perspective: women who worked, and paid work was the most frequent source of income, were more likely to come in contact with potential perpetrators at work or in public places. For example, indecent assault has been noted as a problem on Hong Kong public transport, and working women were likely to use public transport more often than non-working women.

Table 3.6. Physical and sexual violence by work and income status, past year (\%)

\begin{tabular}{|c|c|c|c|}
\hline$N=1,297$ & $\begin{array}{l}\text { Physical } \\
\text { violence }\end{array}$ & Sexual violence & Any violence \\
\hline \multicolumn{4}{|l|}{ Labour force status } \\
\hline Work for pay & $3.2^{* *}$ & $3.7^{* *}$ & $5.7^{* * *}$ \\
\hline Does not work for pay & 0.6 & 1.1 & 1.7 \\
\hline \multicolumn{4}{|c|}{$\begin{array}{l}\text { Has own income from work or } \\
\text { other sources }\end{array}$} \\
\hline Yes & $2.5^{*}$ & $3.3^{* *}$ & $4.9^{* *}$ \\
\hline No & 0.9 & 0.9 & 1.6 \\
\hline \multicolumn{4}{|c|}{$\begin{array}{l}\text { Has a say in how her income is } \\
\text { used }^{\text {a }}\end{array}$} \\
\hline Yes & 2.3 & 2.9 & 4.3 \\
\hline No & 4.1 & 6.2 & $9.3^{*}$ \\
\hline
\end{tabular}

$* p<.05 ; * * p<.01 ; * * * p<.001$. Note ${ }^{a}$ Based on $\mathrm{N}=833$ women with an income.

As shown in Table 3.6, women who did not have a say in how their income was spent were more likely to be victim of any violence $(9.3 \%)$ than those who had a say in how their income was used $(4.3 \%)$. The lack of statistical significance for physical or sexual violence is associated with the small numbers of respondents who said they were not in control of their income $(\mathrm{N}=97,11.6 \%)$. It is likely that women who had no say over how their income is used were under the control of their partner and/or their family, and this may include the use of violence to achieve such control.

The higher level of violent victimisation of younger women is generally explained by lifestyle factors: young women tend to have increased contact with young males, i.e. those most likely to be violent; they are more likely to work, study and socialise outside of home; and are also more likely to engage in risky behaviours such as getting drunk.

\subsection{Severity of the Violence in the Most Recent Incident}

Respondents who had been the victims of physical or sexual violence were asked to describe the most recent incident perpetrated against them by a partner and non-partner. Overall, 11.5 per cent of respondents mentioned a violent incident by a partner, 5.9 per cent a violent incident by a non-partner, and 2.3 per cent mentioned a violent incident by a partner and a different incident by a non-partner. In this section we examine $\mathrm{N}=289$ incidents, that is, we consider all violent incidents, even if they involved the same victim. ${ }^{27}$ About one in five women $(21.1 \%)$ received some injuries in the most recent incident (Table 3.7). For about one-third of injured women, the injuries were serious enough to require medical

\footnotetext{
${ }^{26}$ Women working for pay were on average 36.3 years, and those not working for pay were 46.7 years $(t$-test $=14.4, d f=1201$, $p=.000)$. Women with their own income from work or other sources were on average 39.4 years, and those with no income were 45.2 years $(t$-test $=7.11, d f=872, p=.000)$.

${ }^{27}$ We examine the characteristics of violence by partners and non-partners in detail in Chapters 4 and 5.
} 
care. The types of injury sustained included bruises (73.7\%) and cuts, scratches, or burns (18\%); under ten per cent of incidents with injuries resulted in head injuries $(9.8 \%)$ or broken bones $(3.3 \%)$.

Table 3.7. Severity of the most recent incident by type of violence and perpetrator (\%)

\begin{tabular}{|c|c|c|c|c|c|}
\hline & \multicolumn{2}{|c|}{ Type of violence } & \multicolumn{2}{|c|}{ Perpetrator } & \multirow[b]{2}{*}{$\begin{array}{l}\text { All violence } \\
\qquad \mathbf{N}=\mathbf{2 8 9}\end{array}$} \\
\hline & $\begin{array}{l}\text { Physical } \\
N=135\end{array}$ & $\begin{array}{l}\text { Sexual } \\
\mathrm{N}=154\end{array}$ & $\begin{array}{l}\text { Partner } \\
N=108\end{array}$ & $\begin{array}{c}\text { Non-partner } \\
\mathbf{N}=\mathbf{1 8 1}\end{array}$ & \\
\hline $\begin{array}{l}\text { Received physical } \\
\text { injuries }\end{array}$ & $38.1^{* * *}$ & 5.8 & $33.0^{* * *}$ & 13.3 & 21.1 \\
\hline $\begin{array}{l}\% \text { of women with } \\
\text { injuries needing } \\
\text { medical care }\end{array}$ & 36.5 & 33.0 & 36.1 & 37.5 & 36.1 \\
\hline $\begin{array}{l}\text { Felt her life was in } \\
\text { danger }\end{array}$ & $38.5^{* * *}$ & 7.2 & 27.5 & 18.4 & 21.9 \\
\hline
\end{tabular}

${ }^{* * *} p<.001$. Note a Overall $\mathrm{N}=61$ women were injured: 52 through physical violence and 9 , through sexual violence; 36 , by current or former partners and 24 , by non-partners.

Of these 289 incidents, 46.7 per cent consisted of physical violence and 53.6 per cent consisted of sexual violence. The majority of physical violence involved actual violence $(87.4 \%)$ and the rest, threats of violence; most of the incidents of sexual violence were of unwanted sexual touching $(80.6 \%)$. Physical violence was more likely to result in injuries than sexual violence $(38.1 \%$ of incidents of physical violence resulted in injuries compared to only $5.8 \%$ of all incidents of sexual violence); however, 11.1 per cent of rapes and attempted rapes led to injuries, but only 4.7 per cent of incidents of unwanted sexual touching. That physical violence resulted in injuries more often than sexual violence is not surprising since most of the sexual violence involved unwanted sexual touching. A larger share of incidents were perpetrated by non-partner men (62.6\%) than by current or former partners (37.4\%). One-third of women were injured by their partner compared to 13.3 per cent by non-partners, although a similar proportion (just over one-third) required medical care for these injuries.

Another measure of seriousness was whether women felt their life was in danger when faced with physical or sexual violence. Overall, 21.9 per cent reported they did fear for their life during the most recent incident of violence. A higher proportion of women who experienced physical violence feared for their life than those who experienced sexual violence (38.5\% compared to $7.1 \%)$. The next chapter examines the prevalence, correlates and severity of violence by intimate partners. In Chapter 5 , we conduct similar analyses focusing on violence by non-partners. 



\section{CHAPTER 4}

\section{Intimate Partner Violence}

The definition of what constitutes 'intimate partner violence' varies depending on whether dating partners, former partners, and non-cohabiting partners are included. The IVAWS has adopted a broad definition, which includes violence perpetrated by:

- husbands, current and previous;

- de facto partners, current and previous; and

- boyfriends, current and previous.

This chapter examines the prevalence, correlates and severity of violence by male intimate partners, current and former. First, we report the prevalence of intimate partner violence across the respondents' lifetime, and in the past five years and one year. The severity of the violence is analysed using the women's description of the most recent incident of partner violence. Then, we focus on violence by the current intimate partner and explore which characteristics of victims and their partners were associated with increased risks of victimisation.

\subsection{Violence by any Intimate Partner}

Analyses in this section are based on $\mathrm{N}=1,153$ women, who indicated that at the time of the survey they had or used to have an intimate male partner; i.e. women who were and had always been single are excluded. Overall, 9.4 per cent of women who had a partner at some stage in their life reported that they had experienced physical or sexual violence by this partner. Rates reduce to 3.4 per cent in the past five years, and 1.5 per cent in the past year. Across their adult lifetime, women were more prone to physical violence $(6.2 \%)$ than sexual violence $(4.9 \%)$ by a partner (Figure 4.1$)$. As the time frame reduces, the gap disappears and one-year rates are similar for sexual or physical violence at about 1 per cent.

Actual physical violence occurred more often than threats of violence, but over 80 per cent of those who reported threats also reported actual violence. Slapping, kicking or hitting with a fist was the most frequently reported form of physical violence by partners (3.7\%), followed by pushing, grabbing, twisting an arm, or pulling hair $(2.7 \%)$; throwing or hitting with something $(2 \%)$; and threats of violence (1.7\%) (Table 4.1). Other forms of violence were reported by less than 1 per cent of respondents. ${ }^{28}$ Turning to the forms of sexual violence, we see a pattern similar to that reported in the previous chapter: the most frequent form of sexual violence by intimate partners was unwanted sexual touching $(3.8 \%)$ followed by forced intercourse $(1.8 \%)$ and attempted forced intercourse $(1.2 \%)$. This result is in contrast to the Australian sweep of the IVAWS, which found forced intercourse to be the most frequently reported type of sexual violence by partners (Mouzos and Makkai 2004, p. 45).

\footnotetext{
${ }^{28}$ Because the numbers (Ns) of victimised women in the previous five years and 12 months are very small, we focus on the types of violence that occurred in the respondents' adult lifetime.
} 


\section{Hong Kong IVAWS}

Figure 4.1. Types of intimate partner violence: adult lifetime, past five years and one year

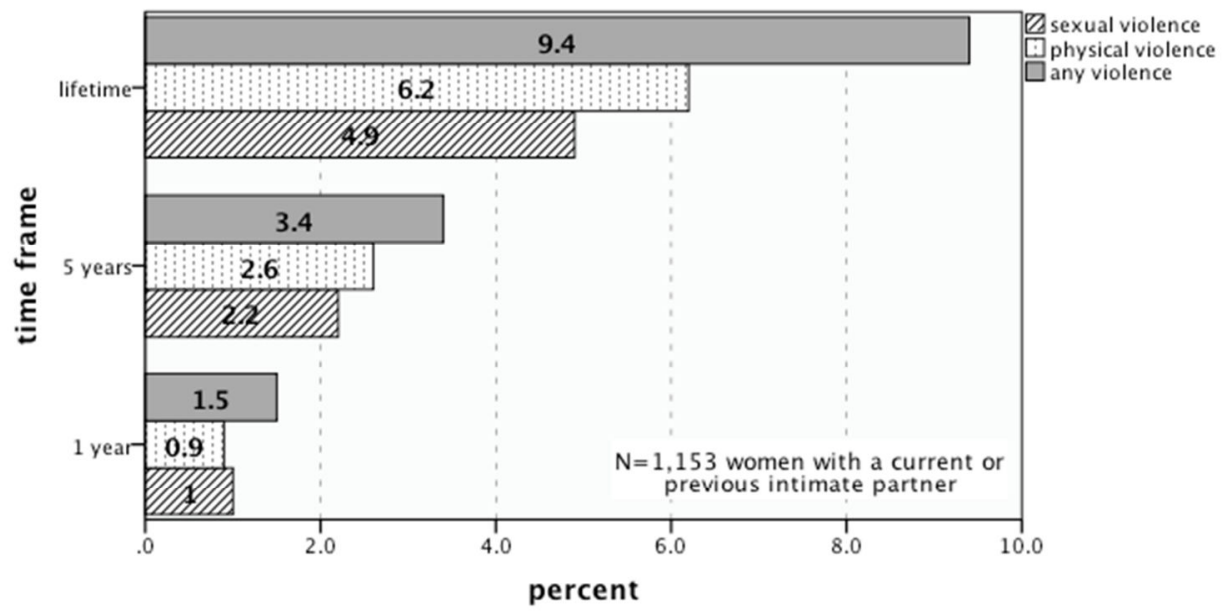

Figure 4.2 compares women's experience of violence in their current and former intimate relationships. Previous research shows that levels of violence by current partner are generally lower than those by previous partners. In our sample, 9.4 per cent of women said that they had experienced violence by their former partner, but only 5.3 per cent reported violence by their current partner. It is possible that respondents were reluctant to admit to a third party, or to themselves that their relationship is violent but it also likely that violent relationships end more rapidly than peaceful ones.

Figure 4.2. Types of intimate partner violence in adult lifetime

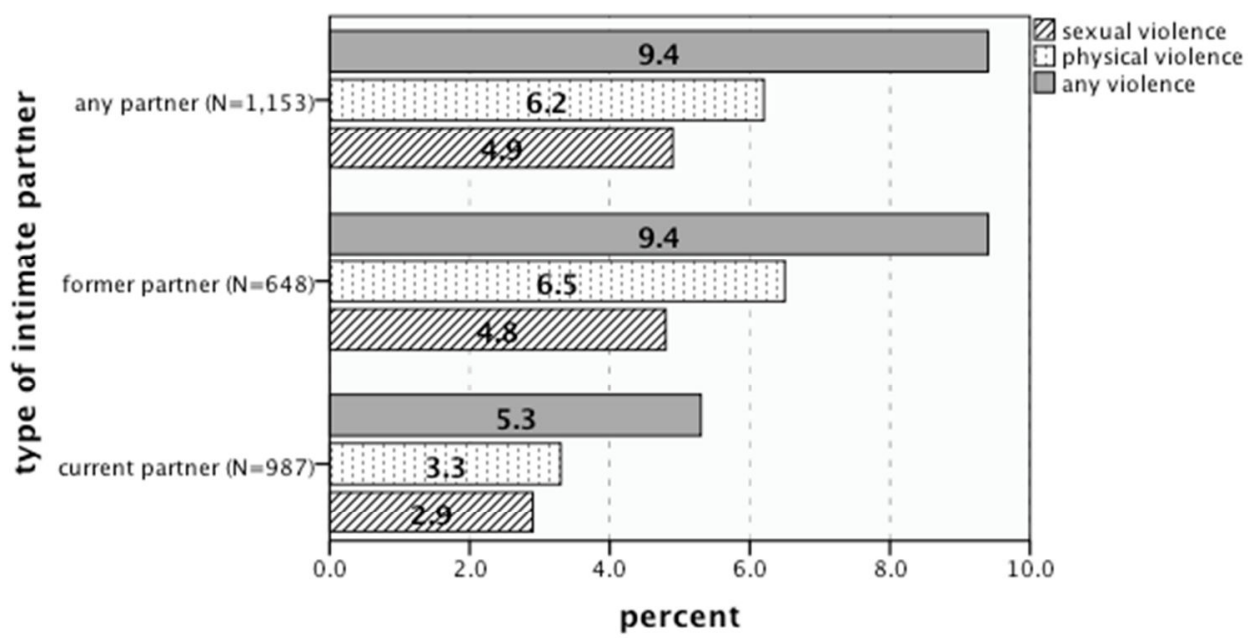

Comparisons with lifetime rates of violence by intimate partners in the other countries that participated in the IVAWS show that Hong Kong generally recorded amongst the lowest rates of violence. Three countries had particularly high rates of intimate partner violence: Mozambique (40\%), the Czech Republic (37\%) and Costa Rica (36\%). Australia and Denmark had comparable rates of 27 and 22 per cent respectively. With 8.3 per cent Hong Kong had the lowest rate of women who reported violent victimisation by intimate partners, close to that of the Philippines and Switzerland $(10 \%)$. Physical violence was also lowest in Hong Kong (6.2\%) followed by Switzerland (9\%) and the Philippines (10\%). Rates were highest in Costa Rica, the Czech Republic and Mozambique ranging between 33 and 36 per cent. Hong Kong's rate of sexual violence by non-partners (4.8\%) was similar to that of Poland (5\%), slightly higher than in the Philippines and Switzerland (3\%) but lower than in the other countries.

As in Hong Kong, violence by former intimate partners was generally more prevalent than violence by current partners. Along with Denmark and Switzerland, Hong Kong recorded the lowest rates of violence by current intimate partners. It also recorded the lowest rate of violence by former partners comparable to the rate in Switzerland (12\%) and the Philippines (13\%) (for details see Johnson et al. 
2008, pp. 38-44). The next two sections examine the characteristics of violence by current and former intimate partners.

Table 4.1. Forms of physical and sexual violence by any intimate partner: adult lifetime, past five years and one year (\%)

\begin{tabular}{|c|c|c|c|}
\hline$N=1,153$ & Lifetime & Past 5 years ${ }^{b}$ & Past 1 year $^{b}$ \\
\hline At least one form of physical violence ${ }^{a}$ & 6.2 & 2.6 & 0.9 \\
\hline Slapping, kicking, biting or hitting with a fist & 3.7 & 1.0 & 0.1 \\
\hline Pushing, grabbing, twisting arm, pulling hair & 2.7 & 1.0 & 0.1 \\
\hline Throwing/hitting with something & 2.0 & 0.7 & 0.1 \\
\hline Threats to hurt physically & 1.7 & 0.5 & 0.1 \\
\hline Using/threatening to use a knife or other weapon & 0.6 & 0.3 & 0.0 \\
\hline Strangling, trying to suffocate, burning or scalding & 0.5 & 0.3 & 0.0 \\
\hline Other physical violence & 0.2 & 0.1 & 0.0 \\
\hline At least one form of sexual violence ${ }^{a}$ & 4.9 & 2.2 & 1.0 \\
\hline Unwanted sexual touching & 3.8 & 1.3 & 0.8 \\
\hline Forced sexual intercourse & 1.8 & 0.5 & 0.1 \\
\hline Attempted forced sexual intercourse & 1.2 & 0.7 & 0.1 \\
\hline Forced sex with someone else & 0.0 & 0.0 & 0.0 \\
\hline Other sexual violence & 0.2 & 0.0 & 0.0 \\
\hline
\end{tabular}

Notes a Total may add up to more than $100 \%$ because of multiple responses. ${ }^{b}$ Five-year and one-year rates may be underestimated because a few respondents said they had been sexually abused, but did not specify when the incident occurred.

\subsection{Violence by Current Intimate Partner}

A total of $\mathrm{N}=987$ respondents indicated that they currently had an intimate male partner: 83.9 per cent were married, 2.9 per cent were living with a man but not married, and 13.1 per cent were dating. Just over 5 per cent of women currently in a relationship said that they had experienced violence from this partner in their adult lifetime, 3 per cent in the past five years, and 1.6 per cent in the past year (Figure 4.3). The levels of physical and sexual violence were comparable.

The most frequent forms of physical violence involved actual violence (e.g. slapping, hitting, pushing) (Table 4.2). Under one per cent of partnered women experienced threats of violence and these were often accompanied by actual violence. Unwanted sexual touching was the most frequently reported form of sexual violence $(2.2 \%)$, followed by forced intercourse $(1.1 \%)$. About one in five women who had been abused by their current partner experienced both physical and sexual violence, during the same or different incidents. 
Figure 4.3. Types of violence by current intimate partner: adult lifetime, past five years and one year

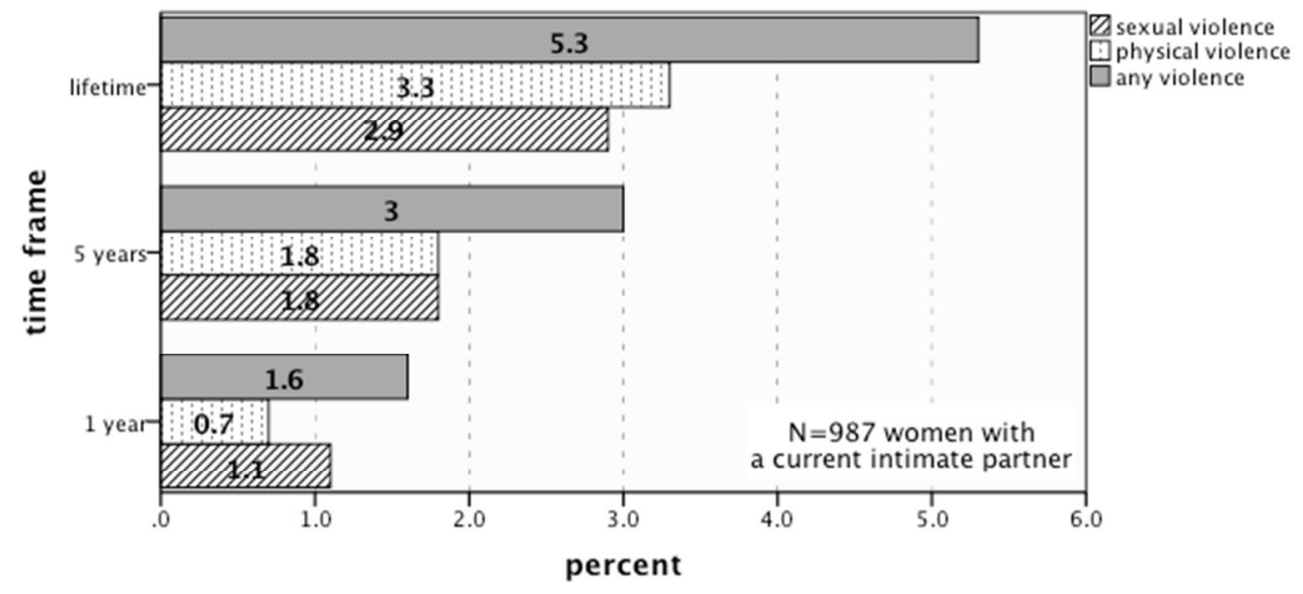

Table 4.2. Forms of physical and sexual violence by current intimate partner: adult lifetime, past five years and one year (\%)

\begin{tabular}{|c|c|c|c|}
\hline$N=987$ & Lifetime & Past 5 years $^{b}$ & Past 1 year $^{b}$ \\
\hline At least one form of physical violence ${ }^{a}$ & 3.3 & 1.8 & 0.7 \\
\hline Slapping, kicking, biting or hitting with a fist & 2.2 & 0.7 & 0.2 \\
\hline Pushing, grabbing, twisting arm, pulling hair & 1.1 & 0.7 & 0.3 \\
\hline Threats to hurt physically & 0.9 & 0.5 & 0.1 \\
\hline Throwing/hitting with something & 0.7 & 0.6 & 0.3 \\
\hline Strangling, trying to suffocate, burning or scalding & 0.4 & 0.3 & 0.0 \\
\hline Using/threatening to use a knife or other weapon & 0.3 & 0.2 & 0.0 \\
\hline Other physical violence & 0.1 & 0.1 & 0.0 \\
\hline At least one form of sexual violence ${ }^{a}$ & 2.9 & 1.8 & 1.1 \\
\hline Unwanted sexual touching & 2.2 & 1.1 & 0.9 \\
\hline Forced sexual intercourse & 1.1 & 0.5 & 0.3 \\
\hline Attempted forced sexual intercourse & 0.7 & 0.5 & 0.3 \\
\hline Forced sex with someone else & 0.0 & 0.0 & 0.0 \\
\hline Other sexual violence & 0.2 & 0.0 & 0.0 \\
\hline
\end{tabular}

Notes ${ }^{a}$ Total may add up to more than $100 \%$ because of multiple responses. ${ }^{\mathrm{b}}$ Five-year and one-year rates may be underestimated because a few respondents said they had been sexually abused, but did not specify when the incident occurred.

In addition to their experiences of violence, respondents were asked about their current partner's potential controlling and emotionally abusive behaviours. Controlling behaviours include insisting on knowing where and with whom she is, limiting contact with family and friends, and suspicion about fidelity. Emotionally abusive behaviours include name-calling and put downs, damaging or destroying property, threats of harm to themselves, their children or others and threats of suicide (Appendix A). Twelve questions are used in the IVAWS with answers ranging from 'never' to 'all the time'.

Three-quarters of respondents never experienced any of these behaviours (Figure 4.4). Apart from name-calling and put-downs, the prevalence of controlling behaviours was higher than that of emotionally abusive behaviours. Over one-quarter of women reported that at least sometimes their partner insisted on knowing their whereabouts (27.2\%), and he was angry if they spoke to other men (25.7\%). Nearly 10 per cent of male partners had tried to limit respondents' contact with their family 
and friends $(9.5 \%)$. One in five woman said that her partner insulted her or put her down at least sometimes $(19.4 \%)$. Less than 5 per cent of respondents had experienced other emotionally abusive behaviours at some time in their current relationship.

Figure 4.4. Emotionally abusive and controlling behaviours by current intimate partner

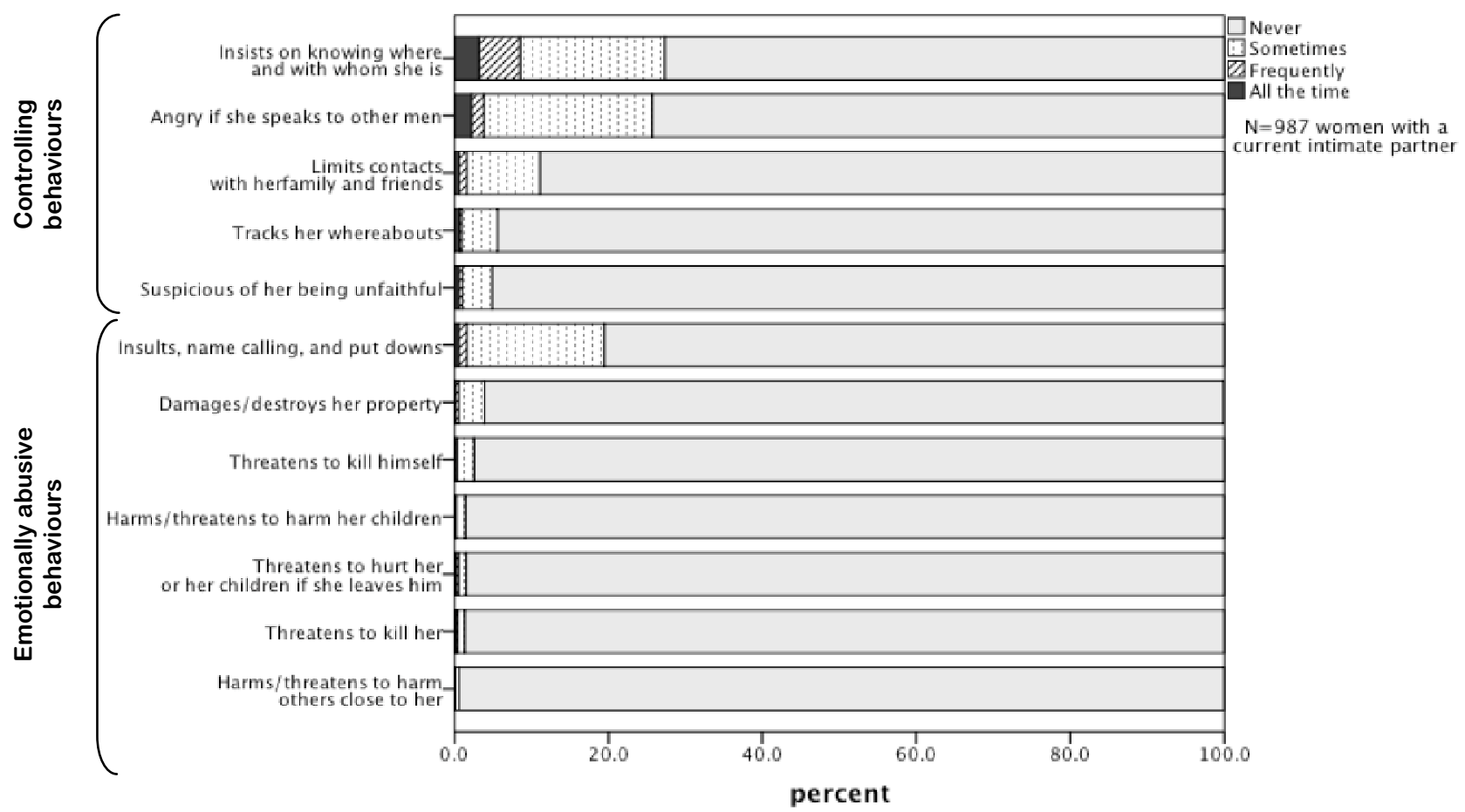

There were large and statistically significant differences in the type of behaviours of men who had been violent toward their current partner in the course of the relationship and those who hadn't been (Figure 4.5). Violent men were nearly twice as likely to use one or more controlling behaviours $(71.1 \%)$ than non-violent men (42.3\%). They were also over three times more likely to use one or more emotionally abusive behaviours $(64.7 \%)$ than non-violent men (19.3\%). This finding is consistent with the literature on violence against women, which argues that control of women is an inherent part of abuse, and respondents whose intimate partners exhibited controlling or/and emotionally abusive behaviours experienced a significantly higher prevalence of violence over the past five years (Figure 4.6). Women who had been subject to controlling behaviours by their partner experienced about four times the level of violence by that partner than women who had not (5.3\% and $1.3 \%$ respectively); women who had been emotionally abused by their partner were eight times more likely to experience violence than women who had not $(9.8 \%$ and $1.2 \%$ respectively).

The diversity of negative behaviours by the current partner also had a significant impact on the likelihood of that partner using violence: of the men who did not use controlling nor emotionally abusing behaviours, 1.4 per cent had been violent toward their female partner at some point during the relationship; of those who used only controlling behaviours or only emotionally abusive behaviours, 5.7 per cent had also been violent; however, of those who used both types of behaviours, 17.7 per cent had also used violence $(p<.001)$. While the number of negative behaviours by the male partner was associated with the likelihood of violent victimisation by that partner, the type of behaviours did not predict the kind of violence, i.e. physical or sexual.

Another question related to control by the male partner asked respondents, do you bave a say in how all or part of your personal income is spent? Eleven per cent of 602 women with a personal income said that they did not have a say in how their income was spent. This item did not correlate with women's experiences of violence; however, there was a positive correlation approaching statistical significance 


\section{Hong Kong IVAWS}

$(p=.053)$ between the use of controlling behaviours by the male partner and the woman's lack of control over her income.

Figure 4.5. Controlling and emotionally abusive behaviours by violent former partner and violent and non-violent current partner

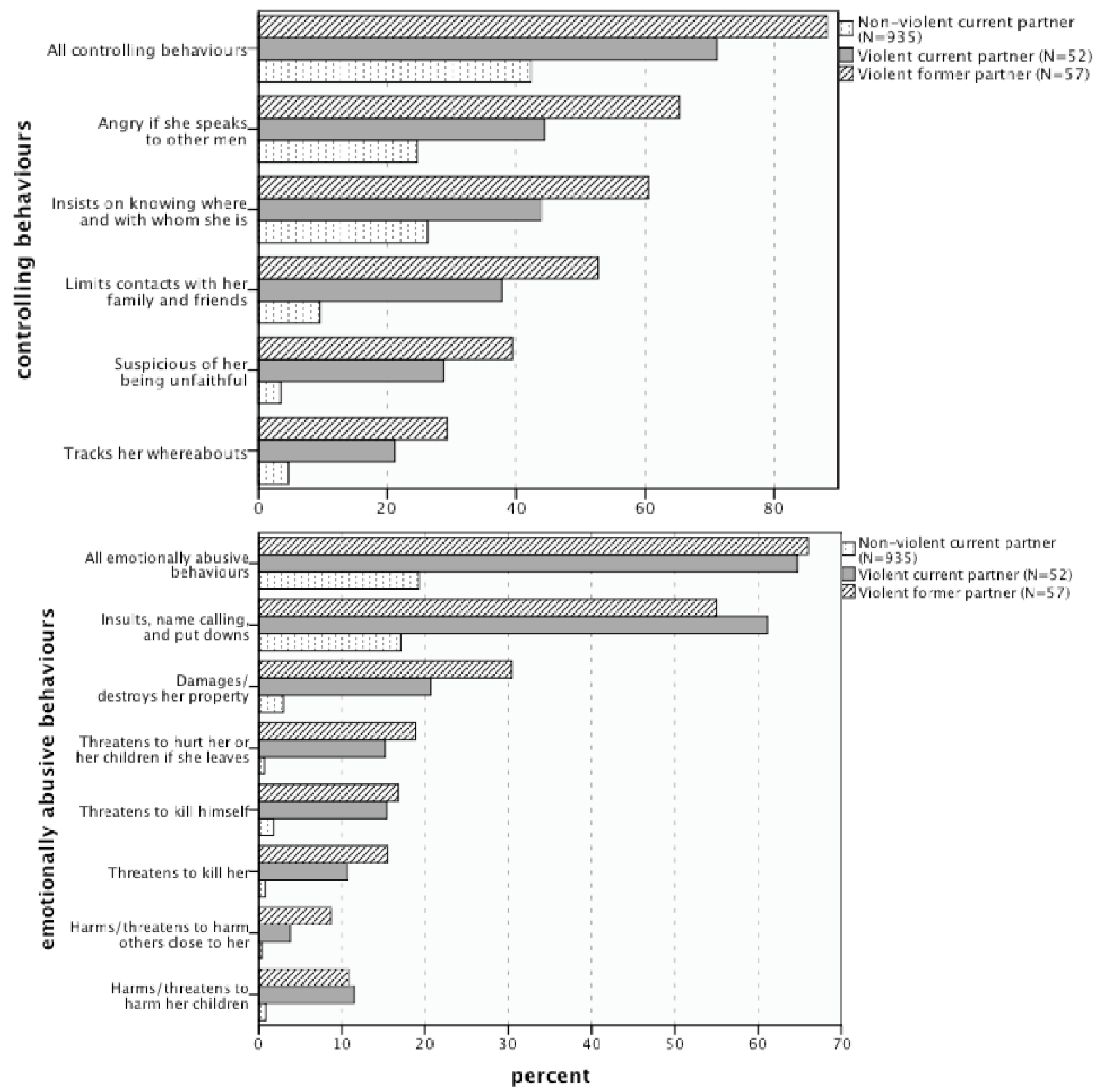

Notes Use of behaviours combines 'frequently', 'sometimes' and 'all the time'. Intimate partner violence based on lifetime rate. All differences between violent and non-violent current partners are significant at $p<.001$ or below.

Finally, one positive item was included in the survey: is your partner supportive of your work or studies or other activities taking place outside of the home? Over two-thirds of respondents (67.4\%) said that their partner was supportive 'all the time' or 'frequently', and this constituted a protective factor against the use of violence. Men who always or frequently showed support for their partner's activities were significantly less likely to resort to violence than men who did not show such support: 2 per cent of supportive male partners had been violent in the past five years compared to 5.3 per cent of less supportive partners $(p<.05)$. 
Figure 4.6. Violence by current intimate partner by controlling and emotionally abusive behaviours, past five years

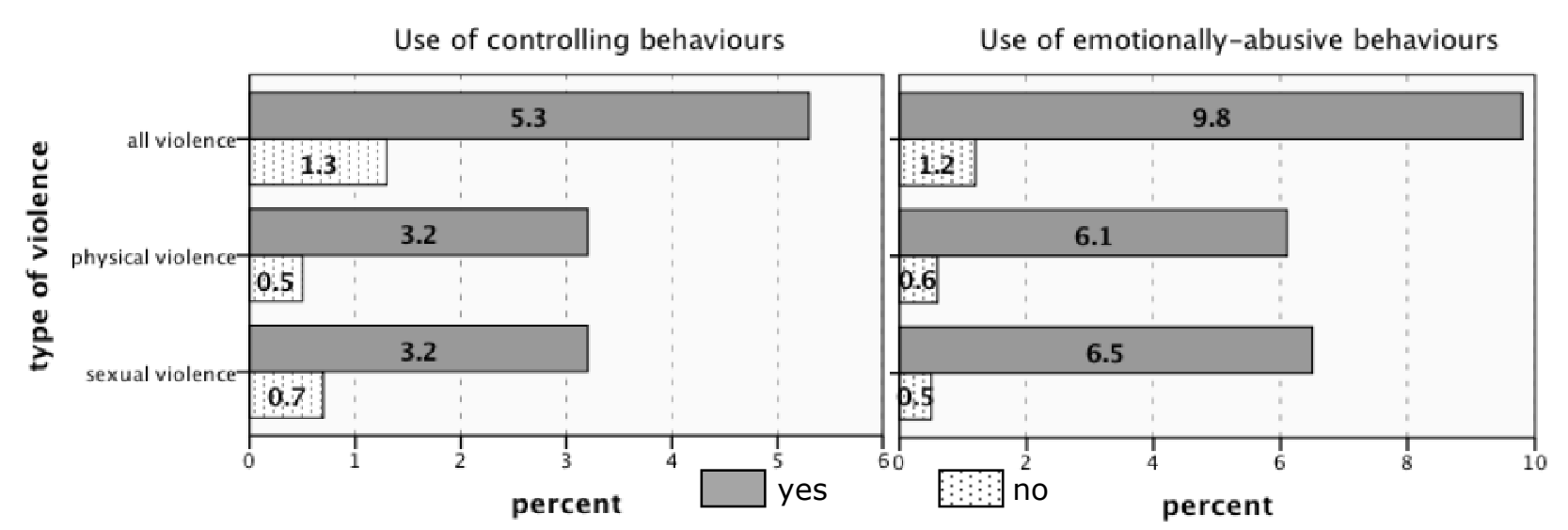

Note Based on $\mathrm{N}=987$ women with a current partner; all differences are significant at $p<.001$.

\subsection{Violence by Former Intimate Partner}

A total of $\mathrm{N}=648$ respondents indicated that they had been in an intimate relationship in the past. Unlike those in current relationships, who were mostly married, only 20.7 per cent of former partners were husbands; 8.8 per cent were de facto partners, and most were boyfriends (70.5\%). About nine per cent of women with former partners had experienced violence from that partner in their adult lifetime: 6.5 per cent, physical violence, and 4.8 per cent, sexual violence reducing to 2.8 per cent in the past five years, and 0.6 per cent in the previous year (Figure 4.7). It is to be expected that rates of violence by former partners would be low in the past year, since most women would probably have little contact with their ex-partners, although abuse can continue after separation. Respondents with a former intimate partner experienced similar levels of violence from ex-husbands $(18 \%)$ and de facto husbands $(22.8 \%)$ and were least likely to experience violence from boyfriends $(5 \%, p<.001)$.

Figure 4.7. Types of violence by former intimate partner: adult lifetime, past five years and one year

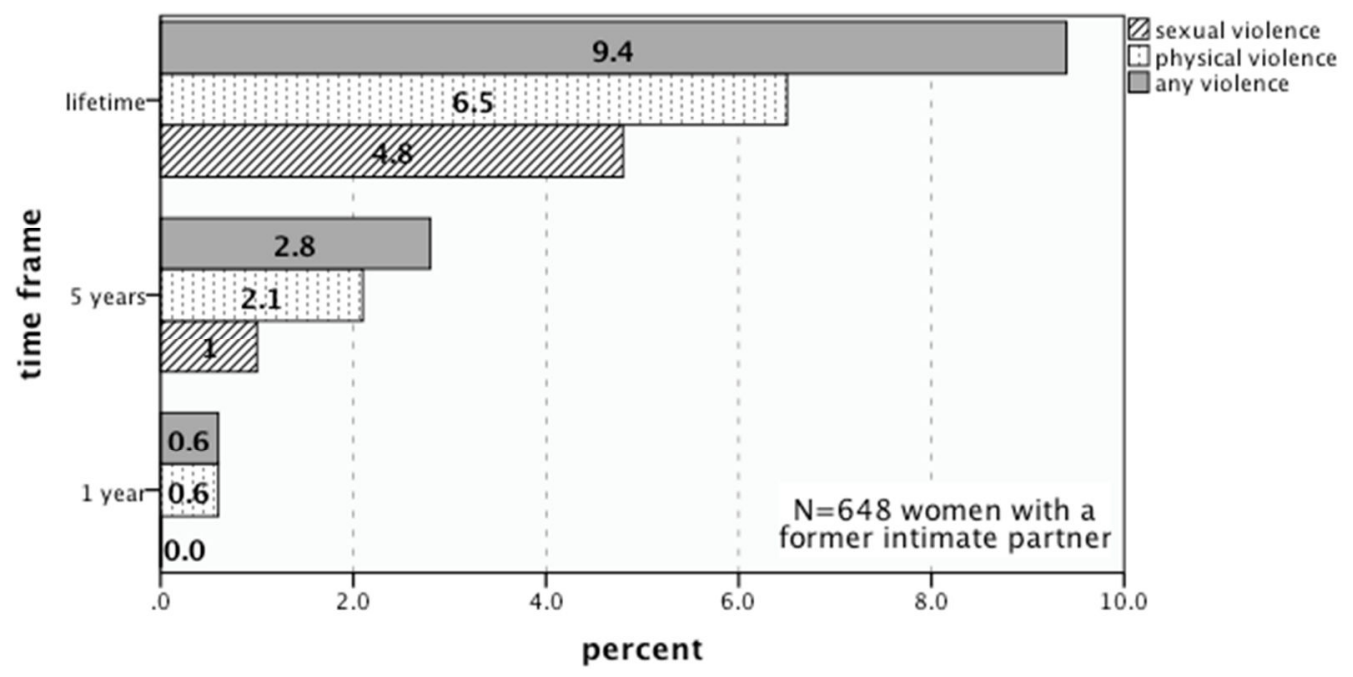

As Table 4.3 shows, former partners were also more likely to use actual violence, such as pushing, slapping, and hitting with fists or some object, than threats of violence, although they often accompanied each other. The most frequent form of sexual violence was unwanted sexual touching, experienced by four per cent of women, followed by forced and attempted forced intercourse $(1.8 \%$ and $1.5 \%$ respectively). Of the women who were abused by former partners, 20 per cent experienced 
both physical and sexual violence. Forty-four per cent of victims of physical violence experienced multiple forms, suggesting a pattern of repeated victimisation.

Table 4.3. Forms of physical and sexual violence by former intimate partner: adult lifetime, past five years and one year (\%)

\begin{tabular}{|c|c|c|c|}
\hline$N=648$ & Lifetime & Past 5 years ${ }^{b}$ & Past 1 year $^{b}$ \\
\hline At least one form of physical violence ${ }^{a}$ & 6.5 & 2.1 & 0.6 \\
\hline Pushing, grabbing, twisting arm, pulling hair & 3.7 & 0.8 & 0.2 \\
\hline Slapping, kicking, biting or hitting with a fist & 3.5 & 0.6 & 0.1 \\
\hline Throwing/hitting with something & 2.6 & 0.3 & 0.0 \\
\hline Threats to hurt physically & 2.1 & 0.3 & 0.3 \\
\hline Using/threatening to use a knife or other weapon & 0.8 & 0.1 & 0.0 \\
\hline Strangling, trying to suffocate, burning or scalding & 0.5 & 0.0 & 0.0 \\
\hline Other physical violence & 0.2 & 0.1 & 0.0 \\
\hline At least one form of sexual violence ${ }^{a}$ & 4.8 & 1.0 & 0.0 \\
\hline Unwanted sexual touching & 4.0 & 0.6 & 0.0 \\
\hline Forced sexual intercourse & 1.8 & 0.3 & 0.0 \\
\hline Attempted forced sexual intercourse & 1.5 & 0.5 & 0.0 \\
\hline Forced sex with someone else & 0.0 & 0.0 & 0.0 \\
\hline Other sexual violence & 0.0 & 0.0 & 0.0 \\
\hline
\end{tabular}

Notes a Total may add up to more than $100 \%$ because of multiple responses. ${ }^{\mathrm{b}}$ Five-year and one-year rates may be underestimated because a few respondents said they had been sexually abused, but did not specify when the incident occurred.

Only women with a violent former partner were asked about this partner's characteristics and behaviours. Although we cannot compare the behaviours of violent with non-violent former partners, we see on Figure 4.8 that relatively large proportions of these men behaved in controlling and/or emotionally abusive ways with their female partners. Looking back at Figure 4.5, that describes the behaviours of violent and non-violent current partners and that of violent former partners we see that respondents reported the highest level of controlling and emotionally abusive behaviours by their violent former partner, even when compared with violent current partners. Again it could be that the abusive behaviour of former partners contributed to the ending of that relationship, or that respondents were more forgiving of the behaviour of their current partner than their former partner and hence minimised their abusive behaviour toward them. 
Figure 4.8. Emotionally abusive and controlling behaviours by violent former intimate partner

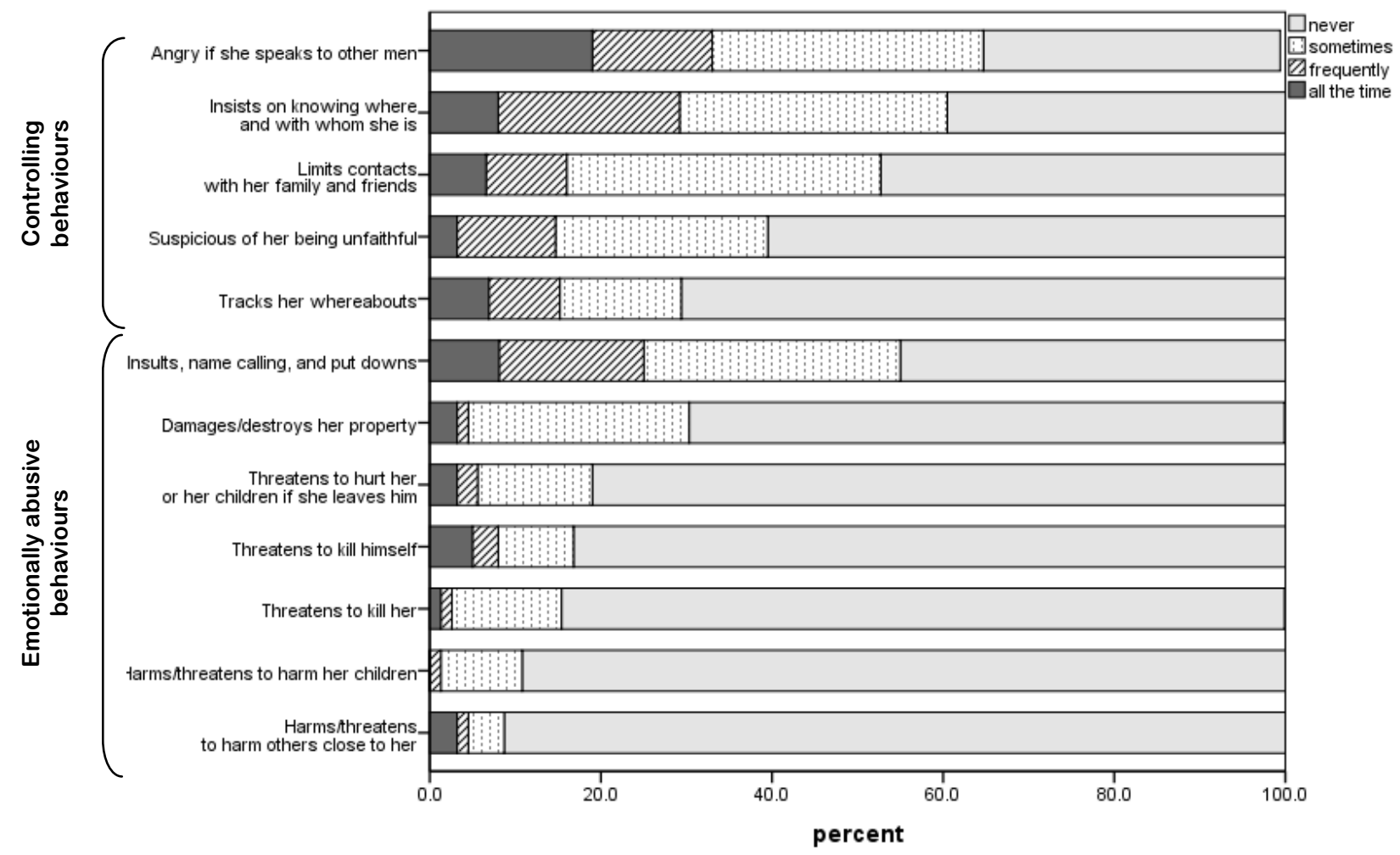

\subsection{Correlates of Violence by Current Intimate Partners}

We now turn to the 'risk factors' associated with violence by a current partner in the past 12 months, looking at the characteristics of both female victim and male perpetrator. Analyses are based on $\mathrm{N}=987$ married, de facto and dating couples. We found that correlates were similar for physical and sexual violence, but because numbers are small we report on the combined rate.

\subsubsection{Risk factors in intimate partner violence}

Age

From Table 4.4, we see that women from the youngest age group (18-24 years) were more prone to violence by their current partner than older women, and men from the same age group were more likely to be the perpetrators of violence than older men. Of women aged between 18 and 24 years, 8.5 per cent had experienced physical or sexual abuse by their partner, compared to 1.2 per cent for other age groups combined. Of men aged 18 to 24 years, 11.5 per cent had been violent compared to 1 per cent for the other age groups combined. Both results are statistically significant at $p<.001$. There was also a significant difference in the average age of victims and perpetrators. Female victims of violence by their current partners were 32.6 years on average but non-victims were 10 years older. The mean age of the male perpetrators was 36.1 years, with non-perpetrators also 10 years older. This is a common finding in victimisation research and possible explanations are that young males are more likely to resort to violence and that young people in general may lack the maturity and problem solving skills to settle conflicts and avoid violent situations. 
Table 4.4. Violence by current partner by age of female and male partner, past year (\%)

\begin{tabular}{ccc}
\hline $\mathbf{N = 9 8 7}$ & Female partner & Male partner \\
\hline 18-24 years & $8.5^{* * *}$ & $11.5^{* * *}$ \\
25-34 years & 2.4 & 0.6 \\
35-44 years & 0.7 & 1.6 \\
$45-54$ years & 1.7 & 0.8 \\
$55+$ years & 0.0 & 0.8 \\
\hline
\end{tabular}

*** $p<.001$.

\section{Relationship status and length}

The rate of violence in married couples (1.4\%) was about half that of de facto couples (3.4\%) and dating couples (3.1\%), but these differences were not statistically significant. Rates of intimate violence were highest in relationships shorter than five years (3.1\%) and decreased in longer relationships (5-14 years, $2.6 \% ; 15-24$ years, $1.1 \%$ ). Shorter relationships mostly involved younger women and men, which may contribute to the higher rate of violence. In addition, violent relationships are more likely to end quickly than peaceful ones.

\section{Level of education}

We found no correlation between the female or male partner's level of education, or the difference in educational attainment between partners and rates of intimate partner violence.

\section{Work status and income}

There were no differences in the risk of intimate violence depending on whether each partner worked for pay, had his/her own source of income, had a say in how each other's income was spent, or by household monthly income.

\section{Violence by former partners}

The literature on VAW suggests that women who had been physically or sexually abused in previous relationships are more prone to intimate violence in their current relationship. We found that 7.3 per cent of respondents who had experienced any type of violence by a former partner reported being abused by their current partner, compared to 1.4 per cent of women with no past experience of intimate violence $(p<.01)$.

\section{Behaviour of the male partner}

There was a strong correlation between the male partner's drinking habits and the risk that he engaged in violence: 8 per cent of men who got drunk two or more times per month had assaulted their partner compared to 1.5 per cent of those who drunk moderately (Table 4.5). In the majority of incidents $(82.6 \%)$, however, the male partner had used neither alcohol nor drugs prior to the violence.

Men who were violent outside the family were nearly 13 times more likely to have abused their partner in the past 12 months than men who were not violent outside of the family $(15.4 \%$ and $1.2 \%$ respectively). 
Table 4.5. Violence by current partner by behaviour of the male partner, past year (\%)

\begin{tabular}{lc}
\hline $\begin{array}{l}\text { N=987 } \\
\text { Drinking level }\end{array}$ & Male partner \\
$\quad \begin{array}{l}\text { Gets drunk two or more times a month } \\
\text { Does not drink, never gets drunk, or gets drunk } \\
\text { less than twice a month }\end{array}$ & 1.5 \\
Violence towards others outside of family \\
$\quad \begin{array}{l}\text { Violent toward others } \\
\text { Not violent toward others }\end{array}$ \\
\hline${ }^{*}<.05 ;{ }^{* * *} p<.001$.
\end{tabular}

\subsubsection{Predictors of intimate partner violence}

Based on the bi-variate analyses above and the literature on VAW, we conducted logistic regressions to assess the relative influence of each predictor, controlling for other factors, on the risk of becoming victim of partner violence. Because of the relatively small number of women who had experienced intimate violence in the last 12 months, we conducted the analyses on the rate of combined physical and sexual violence by a current partner over the adult lifetime. Three sets of variables were included in the regression:

\section{Characteristics of the female partner}

- Age: $1=18$ to 24 years, $0=25$ years and over

- Previous intimate partner violence in the lifetime: $1=$ experienced violence from a former partner, and $0=$ no prior intimate partner violence

\section{Characteristics of the male partner}

- Male partner's controlling behaviours toward female partner: 1=displayed one or more controlling behaviours 'all the time', 'frequently' or 'sometimes'; and $0=$ never displayed any of these behaviours

- Male partner's emotionally abusive behaviours toward female partner: $1=$ displayed one or more emotionally abusive behaviours 'all the times', 'frequently' or 'sometimes'; and $0=$ never displayed any of these behaviours

- Male partner's drinking habits: $1=$ gets drunk twice a month or more; and $0=$ never drinks, never gets drunk, or gets drunk twice a year or less

- Male partner's violent behaviour outside of family: $1=$ male partner is violent outside of the family, and $0=$ male partner is not violent outside the family

\section{Characteristics of the relationship}

- Marital status: $1=$ married and $0=$ not married but living together or dating

Although we saw above that men aged 18 to 24 years were more likely to be violent toward their partner, we did not include age of male partner as a variable in the logistic regression because it correlates highly with the age of the female partner $(r=.94)$. We also did not include the length of the relationship because it correlates with the age of the partners $(r=.74)$. Table 4.6 displays the results of the logistic regression.

Two predictors were highly significant and both were associated with characteristics of the male partners: use of emotionally abusive behaviours and violence outside of the family. The regression indicates that when a woman's intimate partner engaged in emotionally abusive behaviours, her risk of 


\section{Hong Kong IVAWS}

experiencing violence by this partner increased by a factor of 5.6; if a woman's intimate partner was violent outside the family, she was nearly five times more at risk of experiencing violence from him. Two other variables, also related to the behaviour of the male partner, approached statistical significance $(p=.06)$ : the male partner's drinking habits and his use of controlling behaviours towards his female partner. These suggest that women were over three times more likely to experience violence from partners who got drunk twice a month or more often than from men with more moderate drinking habits; and that women living with men who attempted to control them were nearly twice as likely to experience violence by these men than women living with partners who did not exercise such control. The woman's history of abuse by former partners and the type and length of the relationship were not found to be significantly related to the risk of intimate violence.

Table 4.6. Predictors of violence by current intimate partner, adult lifetime

\begin{tabular}{lcccc}
\hline $\mathbf{N = 9 8 7}$ & $\boldsymbol{\beta}$ & $\begin{array}{c}\text { Standard } \\
\text { Error }\end{array}$ & $\begin{array}{c}\text { Exp( } \boldsymbol{\beta}) \\
\text { (odds ratio) }\end{array}$ & $\boldsymbol{p}$ \\
\cline { 1 - 2 } Characteristics of female partner & & & & \\
Aged 18-24 years & 0.27 & 0.70 & 1.31 & .70 \\
Violence by former intimate partners & 0.69 & 0.57 & 1.99 & .23 \\
Characteristics of male partner & & & & \\
Uses controlling behaviours & 0.65 & 0.34 & 1.91 & .06 \\
Uses emotionally abusive behaviours & 1.72 & 0.32 & 5.58 & $\mathbf{. 0 0 0}$ \\
Gets drunk twice a month or more often & 1.17 & 0.64 & 3.23 & .06 \\
Violent outside of the family & 1.60 & 0.51 & 4.97 & $\mathbf{. 0 0 2}$ \\
Characteristics of the relationship & & & & .29 \\
Married & 0.10 & 0.54 & 1.11 & .000 \\
Model Chi square & 61.10 & & & \\
\hline
\end{tabular}

Notes Nagelkerke pseudo $R^{2}=.19 ; 95.0 \%$ of cases classified correctly; Hosmer and Lemeshow test of the model was not statistically significant indicating the model fits the data well.

Analyses of the Australian IVAWS data also found that the strongest risk factors for intimate partner violence were associated with the men's behaviour: use of controlling behaviour, drinking habits and violence outside of the family (Mouzos and Makkai 2004, pp. 61-62). The Australian IVAWS combined five items measuring the male's controlling and emotionally abusive behaviour: three were related to control (tracking the woman's whereabouts, limiting her contacts, and jealousy) and two, to emotional abuse (name calling and insults and destroying/damaging her property). Because the Hong Kong IVAWS contained a larger number of items, we were able to differentiate the influence of controlling and emotionally abusive behaviours, and found that, when controlling for other variables, the use of emotionally abusive behaviours had a greater influence on the risk of intimate partner violence than the use of controlling behaviours.

\subsection{Severity of Violence by Intimate Partners}

Violence by intimate partners tends to be more severe than violence by non-partners, and about half the women who experience violence in an intimate relationship are injured. They are also more likely to sustain injuries by a former partner than a current partner and it could be that the strong violence leads women to separate from their violent partner (Johnson et al. 2008). In this section we analyse 
how women described the most recent episode of violence by a current or former partner. We include $\mathrm{N}=108$ respondents who experienced such violence: 51 by a current partner and 57 by a former partner.

Around one-third of women victimised by an intimate partner sustained injuries and there was no difference between current or former partners: 36 per cent injured by current partners and 31.6 per cent by former partners (Table 4.7). Injuries were significantly more frequent during incidents of physical violence than sexual violence, from both current and former partners. Over half the women who experienced physical violence by a current partner were injured (51.7\%), compared to 13.6 per cent who experienced sexual violence. Violence by former partners resulted in comparable levels of injuries: 44.7 per cent due to physical violence and 5.3 per cent due to sexual violence. The most common type of injuries were bruises and swelling, sustained by 78.7 per cent of injured women; 17.1 received some cuts or burns. ${ }^{29}$ Of the 36 injured women one-third required medical care.

Table 4.7. Severity of violence in the most recent partner incident (\%)

\begin{tabular}{|c|c|c|c|}
\hline & $\begin{array}{l}\text { Current partner } \\
\qquad \mathbf{N}=51\end{array}$ & $\begin{array}{l}\text { Former partner } \\
\mathbf{N}=\mathbf{5 7}\end{array}$ & $\begin{array}{l}\text { Any partner } \\
\qquad \mathbf{N}=108\end{array}$ \\
\hline Physical injuries & 36.0 & 31.6 & 33.6 \\
\hline $\begin{array}{l}\% \text { of women with injuries needing } \\
\text { medical care }{ }^{a}\end{array}$ & 27.7 & 38.8 & 33.3 \\
\hline Felt her life was in danger & 21.6 & 31.6 & 26.9 \\
\hline Pregnant at time of incident & 3.9 & 1.8 & 2.8 \\
\hline
\end{tabular}

${ }^{*} p<.05$. Note ${ }^{\text {a }}$ Overall $\mathrm{N}=36$ women were injured: 18 by their current partners and 18 by their former partner.

A slightly higher proportion of women felt that their life was in danger when abused by a former partner $(31.6 \%)$ than by their current partner $(21.6 \%)$, but this difference was not statistically significant. Just under three per cent of women $(2.8 \%)$ were pregnant at the time of the most recent incident of partner violence.

\footnotetext{
${ }^{29}$ Thirty-six women reported injuries by partners and this number is too small to conduct meaningful analyses of the types of injuries by current/former partners.
} 



\section{CHAPTER 5}

\section{Non-Partner Violence}

We now turn to Hong Kong women's experiences of physical and sexual violence by any male other than a current or former intimate partner. These include:

- family members, such as fathers or brothers, and relatives, such as uncles or cousins;

- men who are known, such as friends, work colleagues, neighbours, teachers; and

- strangers.

The media, for example, often report that violence by stranger is widespread; however, research has shown that women are more at risk of violence by people they know: intimate partners, dating partners and family members. This chapter examines the prevalence, severity and correlates of violence by any male non-partner. We report the prevalence of non-partner violence across the respondents' adult lifetime, and in the past five years and one year. The severity of the violence is analysed using the women's description of the most recent incident of non-partner violence. Then, we explore whether some factors are associated with higher risks of violent victimisation by non-partners.

\subsection{Violence by any Non-Partner}

Fourteen per cent of all the women who participated in the Hong Kong IVAWS had experienced violence by a non-partner male since the age of 16: 5.6 per cent reported one or several incidents of physical violence and 10 per cent mentioned at least one incident of sexual violence (Figure 5.1). Rates for any type of violence reduce to 5.2 per cent in the past five years, and 2.6 per cent in the past year. Figure 5.1 shows that women were nearly twice as likely to experience sexual rather than physical violence by a non-partner male. Over their adult lifetime, 1.7 per cent of women had experienced both physical and sexual violence, in the same or in separate incidents.

Figure 5.1. Types of non-partner violence: adult lifetime, past five years and one year

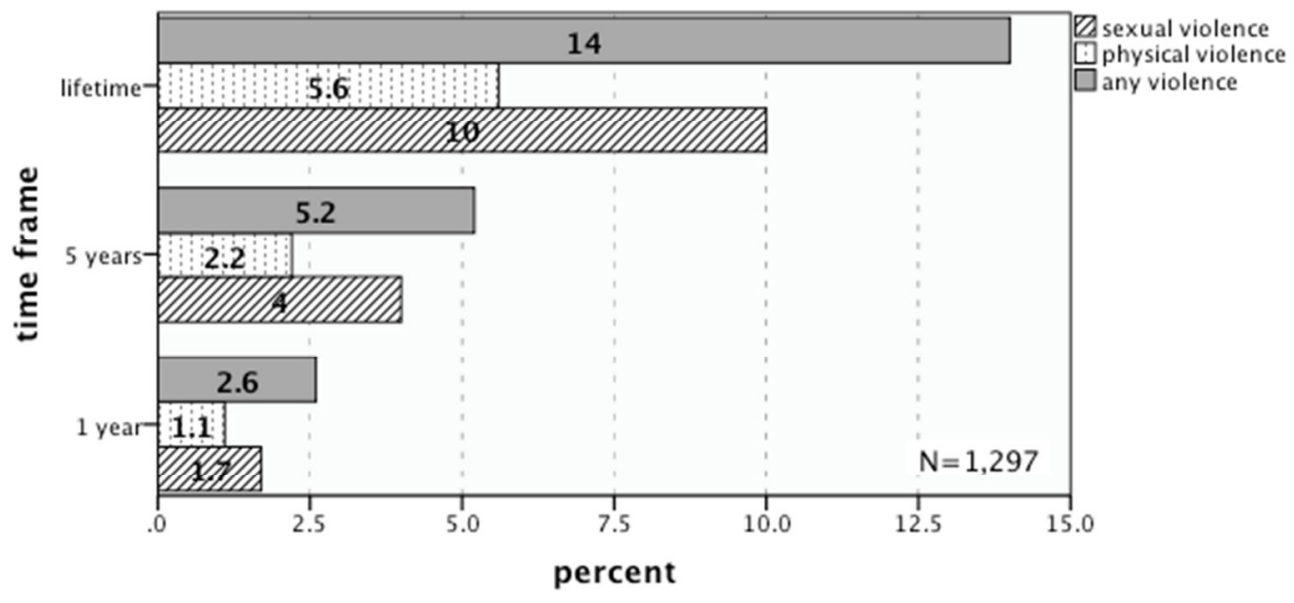


The most frequent form of physical violence by non-partners over the adult lifetime was slapping, kicking, or hitting with a fist (2.6\%), followed by throwing or hitting with something (1.8\%) (Table 5.1). Actual physical violence was reported more frequently than threats. Unwanted sexual touching was the most common form of sexual violence by non-partners: 10.4 per cent, 3.8 per cent and 1.5 per cent of women experienced such violence in their adult lifetime, previous five years and previous year respectively. Other forms of sexual violence were much less frequent.

Table 5.1. Forms of physical and sexual violence by non-partners: adult lifetime, past five years and one year (\%)

\begin{tabular}{|c|c|c|c|}
\hline$N=1,297$ & Lifetime & Past 5 years $^{\text {b }}$ & Past 1 year $^{b}$ \\
\hline At least one form of physical violence ${ }^{a}$ & 5.6 & 2.2 & 1.1 \\
\hline Slapping, kicking, biting or hitting with a fist & 2.6 & 0.5 & 0.4 \\
\hline Throwing/hitting with something & 1.8 & 0.9 & 0.4 \\
\hline Pushing, grabbing, twisting arm, pulling hair & 1.5 & 0.9 & 0.5 \\
\hline Threats to hurt physically & 1.2 & 0.8 & 0.6 \\
\hline $\begin{array}{l}\text { Using/threatening to use a knife or other } \\
\text { weapon }\end{array}$ & 1.2 & 0.0 & 0.0 \\
\hline $\begin{array}{l}\text { Strangling, trying to suffocate or strangle, } \\
\text { burning or scalding on purpose }\end{array}$ & 0.3 & 0.1 & 0.1 \\
\hline Other physical violence & 0.2 & 0.0 & 0.0 \\
\hline At least one form of sexual violence ${ }^{a}$ & 10.0 & 4.0 & 1.7 \\
\hline Unwanted sexual touching & 10.4 & 3.8 & 1.5 \\
\hline Attempted forced sexual intercourse & 1.4 & 0.2 & 0.2 \\
\hline Forced sexual intercourse & 1.2 & 0.3 & 0.2 \\
\hline Forced sex with someone else & 0.1 & 0.0 & 0.0 \\
\hline Other sexual violence & 0.0 & 0.0 & 0.0 \\
\hline
\end{tabular}

Notes ${ }^{a}$ Total may not add up to $100 \%$ because of multiple responses. ${ }^{b}$ Five-year and one-year rates may be underestimated because a few respondents said they had been sexually abused, but did not specify when the incident occurred.

Perpetrators of non-partner violence were more likely to be strangers than men known by the victim: since age 16, 8 per cent of women experienced physical or sexual violence by a stranger, 4.9 per cent by friends and acquaintances, and 2.5 per cent by family members and relatives (Figure 5.2).

Comparisons with lifetime rates of violence in the other countries that participated in the IVAWS show that Hong Kong generally recorded low rates of violence by non-partners. In most countries rates for any violence by non-partners ranged between 25 to 33 per cent. The lowest rate was found in the Philippines (10\%, lower than Hong Kong with 14\%) and the highest in Costa Rica (42\%). The rate of physical violence by non-partners was low in Hong Kong (5.6\%) followed by the Philippines (4\%), which was the lowest. For most countries the rate of physical violence was around 20 per cent. Sexual violence by non-partners was lower in the Philippines (7\%) than in Hong Kong (10\%) and was highest in Costa Rica with 31 per cent of women reporting at least one incident of victimisation.

In all the IVAWS countries except Costa Rica, family members and relatives were least likely to perpetrate violence against women. Rates of violence by relatives were generally under ten per cent, but in Costa Rica it reached 14 per cent. In the Philippines, five per cent of respondents reported they 
had been abused by a family member or relative, that is, twice the rate of Hong Kong (2.5\%). In most of the countries between 12 and 18 per cent of women mentioned at least one incident of victimisation by a friend or relative, but rates were lower in Mozambique (9\%), Hong Kong (4.9\%) and the Philippines (3\%). Finally, violence by strangers was least likely in the Philippines (3\%) but Denmark and Costa Rica recorded the highest rates (23\% and 24\% respectively). Hong Kong's rate of eight per cent was second lowest on par with the rate found in Mozambique.

Figure 5.2. Types of non-partner violence in adult lifetime

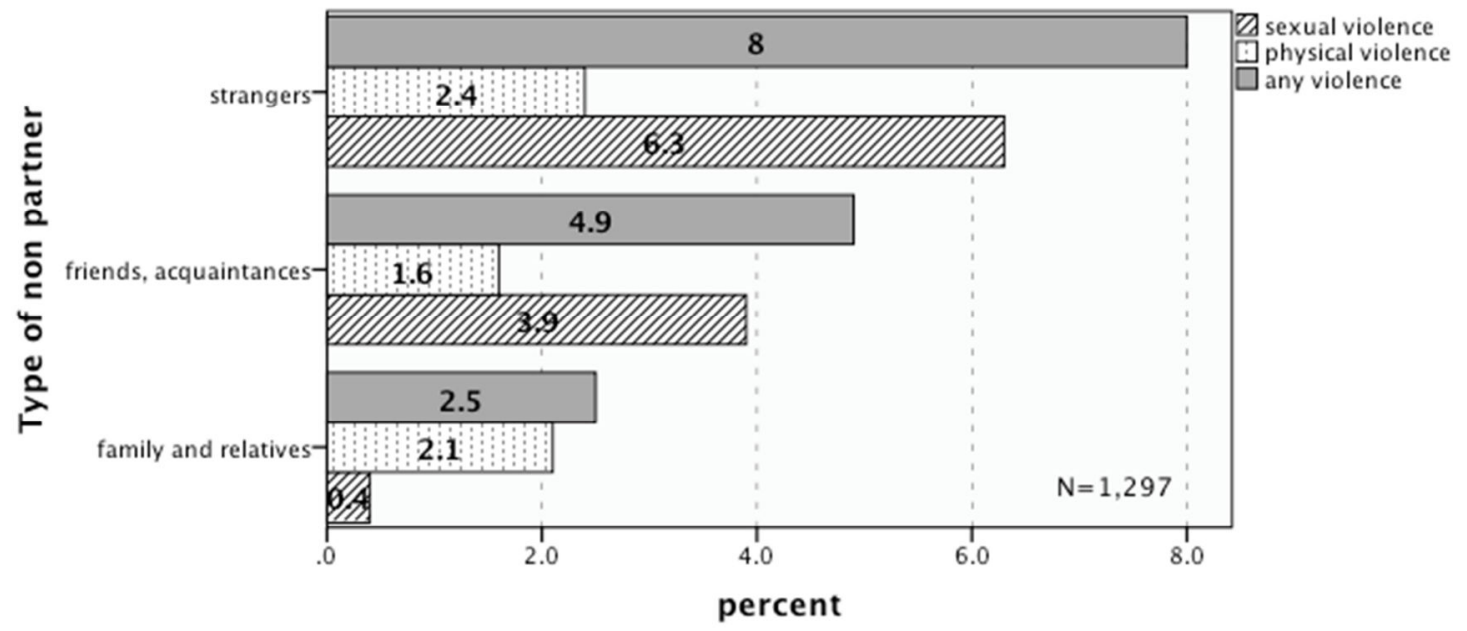

In the next section, we focus on each group of perpetrators and examine whether the type and severity of violence vary depending on the closeness of the victim/offender relationship. The numbers of women who reported experiencing violence by different types of non-partners are small; therefore, we limit our analyses to violence that occurred across the adult lifetime.

\subsection{Violence by Family Members and Relatives}

Overall 2.5 per cent of women in the sample experienced some kind of violence by a family member or a relative since age 16. Rates reduce to 0.8 per cent in the previous five years and 0.6 per cent in the past year. Violence by family members and relatives was far more likely to involve physical violence $(2.1 \%)$ than sexual violence $(0.4 \%)$. Slapping/kicking/hitting with a fist was the most frequent form of violence by family member and relatives $(1.6 \%)$ followed by throwing or hitting with something $(1 \%)$ (Table 5.2). Sexual violence by relatives was infrequent and consisted mainly of unwanted sexual touching. Counts are too small to be able to provide more details of perpetrators.

\subsection{Violence by Other Known Males}

Besides family members and relatives, women reported experiencing violence by friends and acquaintances, such as work or school-mates and neighbours. Just under five per cent (4.9\%) of women reported such violence in their adult lifetime, with rates reducing to 2.3 per cent in the past five years and 1.2 per cent in the past year. Violence by friends and acquaintances was more likely to involve sexual than physical violence $(3.9 \%$ and $1.6 \%$ respectively). Under one per cent of women reported experiencing each form of physical violence ranging from 0.7 per cent for slapping/kicking/hitting with a fist to $0.1 \%$ for strangling or burning (Table 5.2). Unwanted sexual touching was the most frequent form of sexual violence by friends and acquaintances $(3.6 \%)$; one per cent of women experienced forced intercourse, and 0.8 per cent, attempted forced intercourse. Again counts are too small to be able to provide more details of perpetrators. 
Table 5.2. Forms of physical and sexual violence by type of non-partner in adult lifetime (\%)

\begin{tabular}{|c|c|c|c|}
\hline$N=1,297$ & $\begin{array}{c}\text { Family } \\
\text { member \& } \\
\text { relative }\end{array}$ & $\begin{array}{c}\text { Friend \& } \\
\text { acquaintance }\end{array}$ & Stranger \\
\hline At least one form of physical violence ${ }^{a}$ & 2.1 & 1.6 & 2.4 \\
\hline Slapping, kicking, biting or hitting with a fist & 1.6 & 0.7 & 0.6 \\
\hline Pushing, grabbing, twisting arm, pulling hair & 0.8 & 0.5 & 0.4 \\
\hline Threats to hurt physically & 0.4 & 0.4 & 0.7 \\
\hline Throwing/hitting with something & 1.0 & 0.5 & 0.4 \\
\hline Strangling, trying to suffocate, burning or scalding & 0.2 & 0.1 & 0.1 \\
\hline Using/threatening to use a knife or other weapon & 0.2 & 0.1 & 1.0 \\
\hline Other physical violence & 0.0 & 0.2 & 0.1 \\
\hline At least one form of sexual violence ${ }^{a}$ & 0.4 & 3.9 & 6.3 \\
\hline Unwanted sexual touching & 0.5 & 3.6 & 7.0 \\
\hline Forced sexual intercourse & 0.1 & 1.0 & 0.5 \\
\hline Attempted forced sexual intercourse & 0.0 & 0.8 & 0.4 \\
\hline Forced sex with someone else & 0.0 & 0.0 & 0.1 \\
\hline Other sexual violence & 0.0 & 0.0 & 0.0 \\
\hline
\end{tabular}

Notes ${ }^{a}$ Total may not add up to $100 \%$ because of multiple responses.

\subsection{Violence by Strangers}

Eight per cent of respondents had experienced violence by a stranger in their adult lifetime; 2.7 per cent, in the previous 5 years; and just one per cent, in the previous year. In contrast to the Australian IVAWS, women in Hong Kong were more likely to experience sexual than physical violence by strangers (6.3\% vs. $2.4 \%$ ) (Table 5.2). The form of violence by strangers most frequently mentioned was being threatened with a knife or a gun $(1 \%)$, and this is most likely linked to a robbery or mugging. The most frequent form of sexual violence was, by far, unwanted sexual touching reported by seven per cent of respondents. Few women were raped by a stranger $(0.5$ per cent experienced forced intercourse and 0.4 per cent, attempted forced intercourse).

\subsection{Severity of Violence by Non-Partners}

Analyses in this section are based on a total of 181 women who experienced violence by non-partners and provided information on the most recent incident. Injuries were sustained by just over thirteen per cent of assaulted women (Table 5.3). They were significantly more frequent during incidents of physical violence than sexual violence: 28.4 per cent who experienced physical violence by non-partners were injured compared to 4.4 per cent who experienced sexual violence.

Violence by family members and relatives was more likely to lead to injuries (36\% of incidents resulted in injuries) than violence by friends and acquaintances (11.8\% resulted in injuries) or strangers $(8.6 \%$ resulted in injuries). This result is not entirely surprising since women mainly experienced physical assault from relatives and unwanted sexual touching, which is less likely to result in injuries, from strangers. Around 16 per cent of women who were assaulted by friends/acquaintances and strangers respectively felt that their life was in danger during the incident, but over twice that number $(38.5 \%)$ feared for their life when assaulted by a family member or relative. This result is consistent with the 
relatively high rate of injuries sustained during these assaults and suggests that violence by family members and relatives was particularly severe. The most common type of injuries sustained during assault by non-partners was bruises and swelling ( $83.3 \%$ of injured women). ${ }^{30}$

Table 5.3. Severity of the most recent incident of violence by non-partners (\%)

\begin{tabular}{|c|c|c|c|c|}
\hline & $\begin{array}{c}\text { Family } \\
\text { member \& } \\
\text { relative } \\
N=25\end{array}$ & $\begin{array}{c}\text { Friend \& } \\
\text { acquaintance } \\
\mathbf{N = 5 1} \\
\end{array}$ & $\begin{array}{l}\text { Stranger } \\
\mathbf{N}=105\end{array}$ & $\begin{array}{c}\text { Any non- } \\
\text { partner } \\
\mathbf{N}=\mathbf{1 8 1} \\
\end{array}$ \\
\hline Physical injuries & $36.0^{* *}$ & 11.8 & 8.6 & 13.3 \\
\hline Needed medical care & 12.0 & 3.9 & 4.8 & 5.6 \\
\hline $\begin{array}{l}\% \text { of women with injuries needing } \\
\text { medical care }\end{array}$ & 33.3 & 33.3 & 55.6 & 41.7 \\
\hline Felt her life was in danger & $38.5^{* *}$ & 15.7 & 16.2 & 19.2 \\
\hline
\end{tabular}

${ }^{* *} p<.01$. Note a Overall $\mathrm{N}=24$ women were injured: 8 by family members or relatives, 6 by friends or acquaintances and 9 by strangers.

\subsection{Correlates of Violence by Non-Partners}

We now turn to the factors that are associated with the likelihood of or 'risk factors' associated with violence by a non-partner male in the past 12 months, looking at the characteristics of the incident and the victim.

\subsubsection{Characteristics of the most recent incident by a non-partner}

\section{Location}

By contrast to assaults by intimate partners, which occurred mainly in private residences, under 30 per cent of violence by non-partners occurred in a private residence. There were differences in the location of the assault depending on the type of perpetrator (Figure 5.3). Violence by family members and relatives was most often happened in a private residence $(92.3 \%)$, but nearly 60 per cent of incidents of violence by strangers occurred in public places. The location of violence by friends and acquaintances more varied: one-third at work or school (34\%), one third in private residences $(32 \%)$, and the rest in public or other locations. The majority of physical assaults $(54.4 \%)$ occurred in private residences, but most sexual assaults $(48.2 \%)$ occurred in public spaces.

\section{Number of perpetrators}

The majority of incidents by non-partners involved just one perpetrator, regardless of the type of violence: 96 per cent of assaults by family members and relatives, 88 per cent of assaults by friends and acquaintances, and 84 per cent of assaults by strangers involved only one perpetrator.

\section{Use of alcohol or drug at time of incident:}

Numbers are too small to estimate the proportion of assaults that involved the use of drug or alcohol with a large proportion of respondents who did not know, particularly in cases of assault by strangers.

\footnotetext{
30 The number of women who reported injuries by non-partners is too small to conduct an analysis by type of perpetrators.
} 


\section{Hong Kong IVAWS}

Figure 5.3. Location of the most recent incident of violence by non-partner

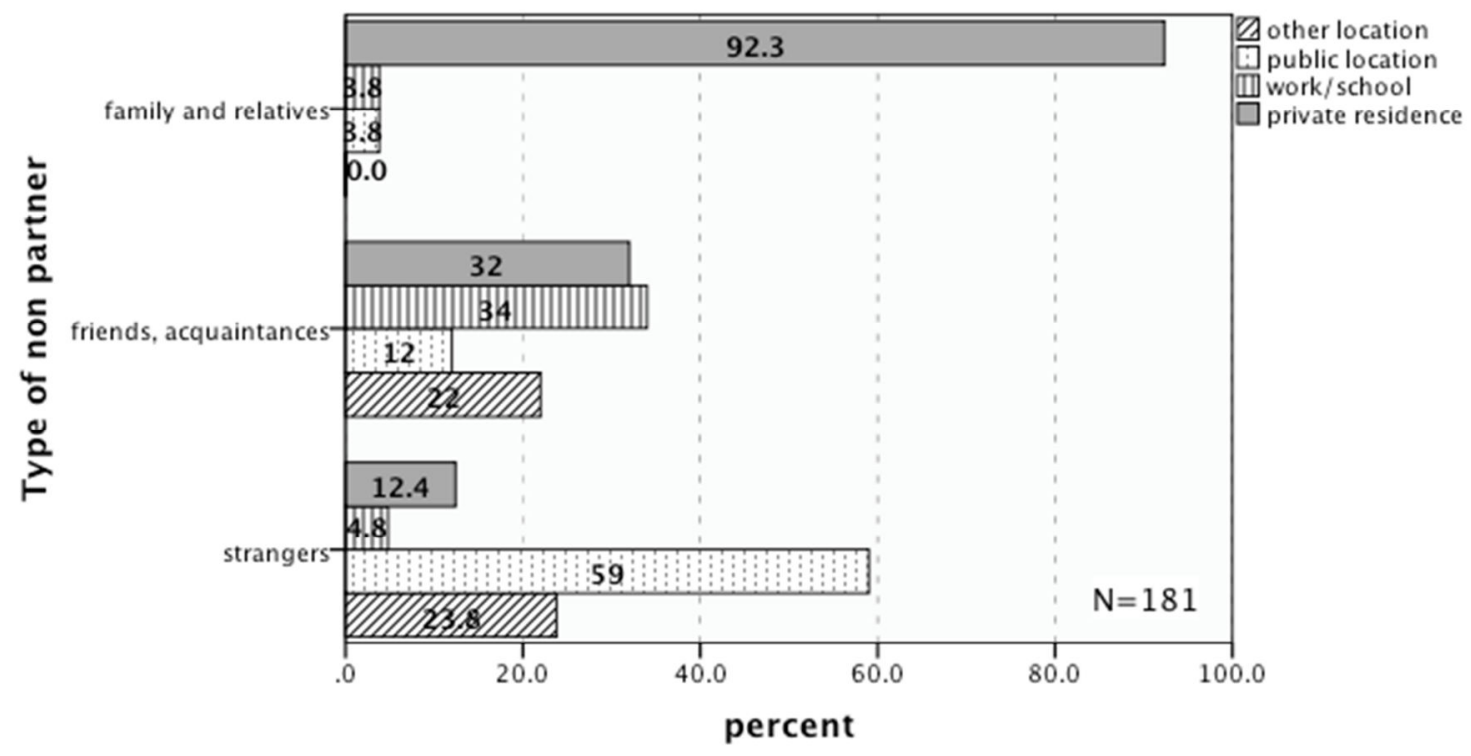

\subsubsection{Characteristics of victims of non-partner violence}

Age

Women from the two youngest age groups (18-24 years and 25-34 years) were more prone to violence by non-partners than those aged 35 years and over (Table 5.4). About five per cent of women aged 18 to 34 years had experienced at least one incident of violence in the previous year compared to 1.1 per cent of women 35 years and older. On average, victims of violence were 30.9 years; non-victims were significantly older (41.7 years, $p<.001)$.

Table 5.4. Violence by non-partner by age of female respondent, past year (\%)

\begin{tabular}{cc}
\hline $\boldsymbol{N}=\mathbf{1 , 2 9 7}$ & $\begin{array}{c}\text { Experienced violence in } \\
\text { the past year }\end{array}$ \\
\hline 18-24 years & $5.8^{* * *}$ \\
25-34 years & $4.4^{* * *}$ \\
$35-44$ years & 2.5 \\
$45-54$ years & 0.7 \\
55 years and over & 0.4 \\
\hline$* * *$ &
\end{tabular}

\section{Relationship status}

Table 5.5 shows a significant increase in the risk of victimisation by non-partners for women in a dating relationship ${ }^{31}(12.3 \%)$ compared to single women $(2.6 \%)$ and women who were married or cohabiting with a partner. Although women who were in dating relationships tended to be younger than those who were married or single (mean age: dating, 27.9 years; married, 43.7 years; single, 37.4 years) we found that after controlling for age, dating remained a significant factor associated with violent victimisation. As Table 5.5 shows, within each age group, women in a dating relationship had significantly higher risks of victimisation than married/de facto or single women.

\footnotetext{
${ }^{31}$ Note that the violence against this group of women was not perpetrated by their boyfriend, but by a non-partner male.
} 
Table 5.5. Violence by non-partner by relationship status of female respondent, past year (\%)

\begin{tabular}{|c|c|c|c|c|c|}
\hline \multirow[b]{2}{*}{$N=1,297$} & \multirow[b]{2}{*}{ All women } & \multirow[b]{2}{*}{ 18-24 } & \multicolumn{2}{|c|}{ Age group (years) } & \multirow[b]{2}{*}{$45+$} \\
\hline & & & $25-34$ & $35-44$ & \\
\hline \multicolumn{6}{|c|}{ Relationship status } \\
\hline Married/ de facto & 1.1 & $8.3_{*}$ & $2.4_{* *}$ & $0.7_{* * *}$ & 0.7 \\
\hline Dating & $12.3^{* * *}$ & $11.9^{*}$ & $13.0^{* *}$ & $14.3^{* * *}$ & 0.0 \\
\hline Single & 2.6 & 2.0 & 3.4 & 9.1 & 0.0 \\
\hline
\end{tabular}

${ }^{*} p<.05 ;{ }^{* *} p<.01 ;{ }^{* * *} p<.001$.

\section{Level of education}

The respondent's level of education had no impact on her risk of victimisation by non-partners.

\section{Work status and income}

Women who worked for pay were at significantly higher risks of victimisation than those who did not $(4.3 \%$ vs. $0.8 \%$ ) (Table 5.6). Working women were on average 10 years older than non-working women (36.3 years compared to 46.7 years, $p<.001)$.

Table 5.6. Violence by non-partner violence by work and income status of female respondents, past year (\%)

\begin{tabular}{lc}
\hline $\mathbf{N = 1 , 2 9 7}$ & $\begin{array}{c}\text { Experienced violence in } \\
\text { the past year }\end{array}$ \\
\cline { 1 - 2 } Employment status & $4.3^{* * *}$ \\
Works for pay & 0.8 \\
Does not work for pay & \\
Respondent has a say in how her income is used & $2.9^{* * *}$ \\
Yes & $9.3^{*}$ \\
No &
\end{tabular}

${ }^{* * *} p<.001$. Note ${ }^{\mathrm{a}}$ Based on $\mathrm{N}=833$ respondents with a personal income.

Respondents' monthly household income had no impact on their risk of victimisation by non-partners, but whether the respondent had a say in how her income was used did (Table 5.6). Women who did not decide how their income was used had significantly higher risks of victimisation than those who did $(9.3 \%$ vs. $2.9 \%)$. There was no significance age difference between the two groups. The number of women who were victimised by non-partners is too small to permit us to determine for which type of non-partner violence this relationship is significant. It is likely that this is linked to the control that family and relatives exerted over some of the women.

\subsubsection{Predictors of non-partner violence}

Based on the bi-variate analyses presented above and the literature on VAW, we conducted logistic regressions to assess the relative influence of each factor on the risk of becoming a victim of nonpartner violence. Although the number of women who have experienced violence by a non-partner male in the past year was small, we conducted our analyses on the 12-month rate because the predictors may be inaccurate on a longer time frame (e.g. women who were dating at the time of the survey may not have been dating five years before). All the variables included in the logistic regression relate to the female respondents because we had little information on the perpetrators. The following factors were included:

- Age: $1=$ aged $18-34$ years; $0=$ aged 35 years and over

- Relationship: $1=$ dating relationship; $0=$ married, de facto, single 
- Work status: $1=$ works for pay: $0=$ does not work for pay

- Monthly household income: $1=$ less than $\mathrm{HK} \$ 20,000 ; 0=\mathrm{HK} \$ 20,000$ and over

- Control over income: 1 has no control over income; $0=$ has control over income or has no income

Table 5.7 presents the results of the logistic regression. Three factors were significant predictors of victimisation by non-partners: relationship, work status and control over income. Women who were dating a boyfriend were over three times more likely to be the victims of violence by men (other than their boyfriend). Women who worked for pay were three and an half times more prone to violence by non-partners than women who did not work and lack of control over income increased women's risk of victimisation by a factor of 2.5. However, younger age (under 35 years) did not significantly increase the risk of victimisation by non-partners.

Table 5.7. Predictors of violence by non-partners, past year

\begin{tabular}{lcccc}
\hline Predictors & $\boldsymbol{\beta}$ & $\begin{array}{c}\text { Standard } \\
\text { Error }\end{array}$ & $\begin{array}{c}\text { Exp( } \boldsymbol{\beta}) \\
\text { (odds ratio) }\end{array}$ & $\boldsymbol{p}$ \\
\cline { 1 - 1 } Aged 18-34 years & & & & .41 \\
Dating a boyfriend & 0.37 & 0.45 & 1.44 & .41 \\
Works for pay & 1.20 & 0.47 & 3.30 & $\mathbf{. 0 1}$ \\
$\begin{array}{l}\text { Monthly household income less than } \\
\text { HK\$20,000 (yes) }\end{array}$ & 1.27 & 0.54 & 3.57 & $\mathbf{. 0 2}$ \\
No control over personal income & 0.14 & 0.38 & 1.15 & .72 \\
Model Chi square & 0.90 & 0.48 & 2.46 & $\mathbf{. 0 4}$ \\
\hline
\end{tabular}

Notes Nagelkerke pseudo $R^{2}=.17 ; 97.5 \%$ of cases classified correctly; Hosmer and Lemeshow test of the model was not statistically significant indicating the model fits the data well.

These results are consistent with the IVAWS findings in other countries. The Australian IVAWS found that younger women who were single or dating were at a greatest risk of violence by a nonpartner male. In Hong Kong, the rate of victimisation of single women was higher than that of married women $(2.7 \%$ and $1 \%$ respectively) but the difference was not statistically significant, perhaps due to the small number of women who were assaulted in the past year. The higher rates of victimisation for dating women and working women can be explained by routine activity theory. Women who work and/or socialise outside of their home are in more contact with both known men and strangers. For example, they use public transport where indecent assault by strangers is more likely to happen. It is somewhat surprising that lack of control over personal income is not related to risks of victimisation by intimate partners but is related to victimisation by non-partners - perhaps as noted reflecting control by parents and relatives. Small numbers make it difficult to examine this finding further, but we note that it confirms findings from other research that control over women is usually a predictor of violence. 


\section{CHAPTER 6}

\section{Women's Perceptions \& Responses}

So far we have examined the prevalence of VAW in Hong Kong and the characteristics of violent incidents by partners and non-partners. We now turn to the reactions of the women who had been the victims of violence by men. First, we consider the victims' perception of the violence in terms of seriousness and whether they believed the incident constituted a crime. Then, we examine if the incident was reported to the police and, if not, the reasons why not. We also look at what happened after the reported cases entered the criminal justice system, and whether victims sought help from other sources than the police. Analyses in this chapter draw from what women said about the most recent incident of violence by male partners and non-partners $(\mathrm{N}=289)$.

\subsection{Victims' Perception of Seriousness}

Women who had been the victims of violence by intimate partners and non-partners were asked to rate the seriousness of the most recent incident as 'very serious', 'somewhat serious' and 'not very serious'. Since the number of women who experienced violence is relatively small, we combine very and somewhat serious into a single 'serious' rating. Just over half $(52.3 \%)$ of the 289 victims ranked the most recent incident 'not very serious' and 47.7 per cent said it was 'serious'. Similar proportions of victims rated violence by intimate partners and by non-partners as 'serious' ( $50.5 \%$ and $46.1 \%$ respectively, Figure 6.1).

Figure 6.1. Victims' perception of the seriousness of the most recent incident by perpetrator

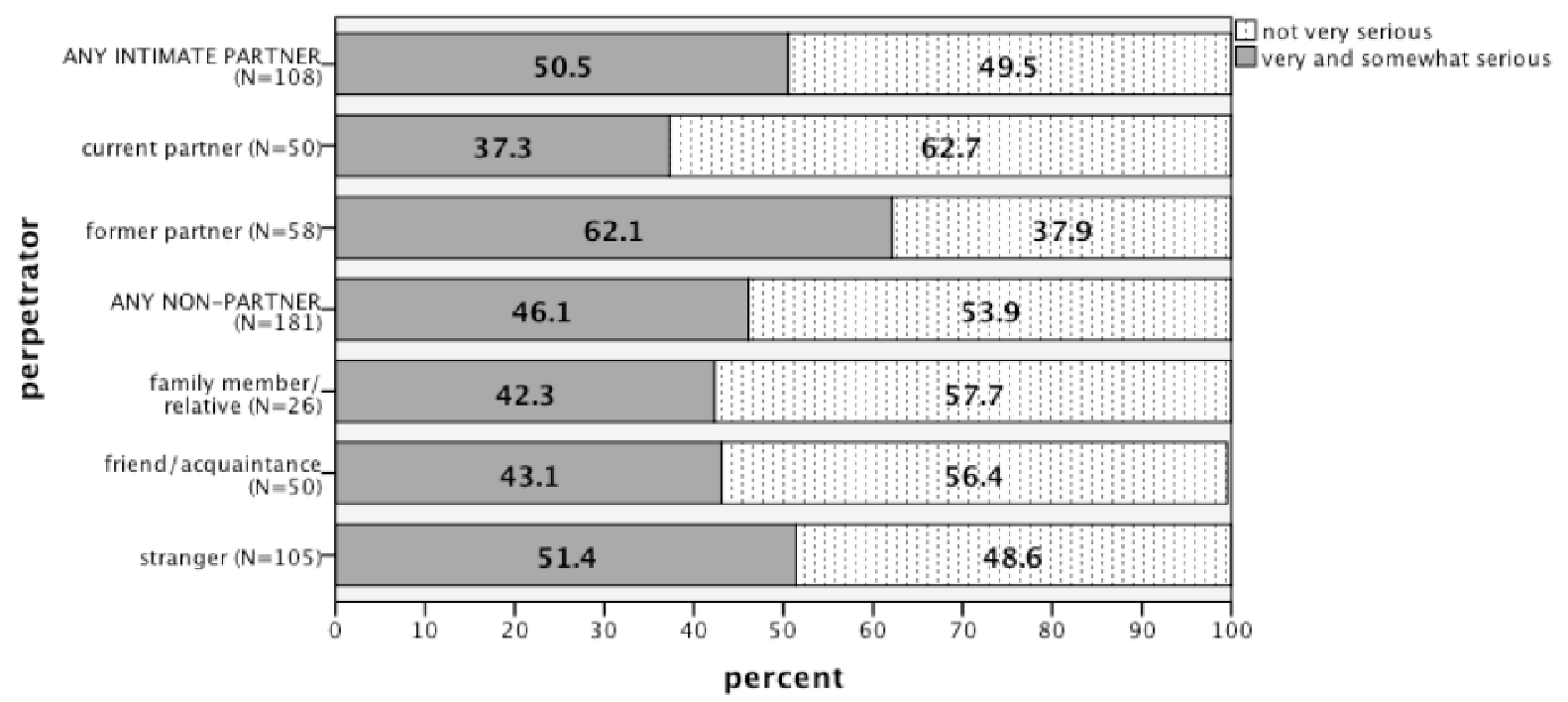




\section{Hong Kong IVAWS}

Victims of intimate partner violence perceived that violence committed by a former partner was much more serious than violence by a current partner: 62.1 per cent of victims rated the most recent incident as 'serious' when the perpetrator was a former partner compared to 37.3 per cent of victims who rated the most recent incident by their current partner as 'serious' $(p<.01)$. By contrast, among the victims of non-partner violence there was only a small difference in the rating of the most recent incident regardless of who the perpetrator was: just over half the women victimised by a stranger $(51.4 \%)$ regarded the incident as very or somewhat serious compared to 43.1 per cent of victims of violence by friends or acquaintances and 42.3 per cent of victims of violence by family members and relatives (Figure 6.1). Although these differences were not statistically significant, they are consistent with the notion that violence between people who know each other is perceived as less serious than violence by stranger (Lievore 2003), except for violence committed by ex-partners, which was regarded as the most serious.

Respondents had different perceptions depending on the type of violence they had experienced, with a majority of women $(57.8 \%)$ ranking physical violence as serious compared to 39 per cent for sexual violence $(p<.01)$. Surprisingly, there was little difference in the way that victims perceived the seriousness of incidents of rape and attempted rape, which 42.3 per cent ranked as 'serious', compared to unwanted sexual touching, which 37.8 per cent ranked as 'serious'. Victims who were injured through physical or sexual violence were more likely to regard the incident as 'very' or 'somewhat' serious than those without injuries ( $60 \%$ vs. $44.3 \%, p<.05)$.

There were some differences in the way that victims of physical and sexual violence assessed the seriousness of the most recent incident depending on the perpetrator. Among the 108 victims of intimate partner violence and as shown on Figure 6.2, two-thirds $(64.7 \%)$ said that incidents involving physical violence were serious compared to 38.9 per cent of rape and 17.4 per cent of incidents of unwanted sexual touching $(\phi<.001)$. We found previously that physical violence by intimate partners was the kind of violence most likely to lead to injuries. In cases of intimate partner violence, the presence of injuries significantly increased the likelihood that women rate the incident as serious: 66.7 per cent of injured victims regarded the violence as very or somewhat serious, compared to 42.5 per cent of non-injured women $(p<.05)$. The presence of children witnessing the violence also tended to increase the seriousness of the abuse by intimate partners. Of the 52 victimised women with children, 63.6 per cent said the incident was 'serious' when it was witnessed by children, compared to 36.7 per cent of those whose children did not witness the violence (the difference is not statistically significant, but the analysis is based on a small number of women with children). However, being pregnant did not affect women's perception of the seriousness of the incident.

Figure 6.2. Victims' perception of the seriousness of the most recent incident by type of violence

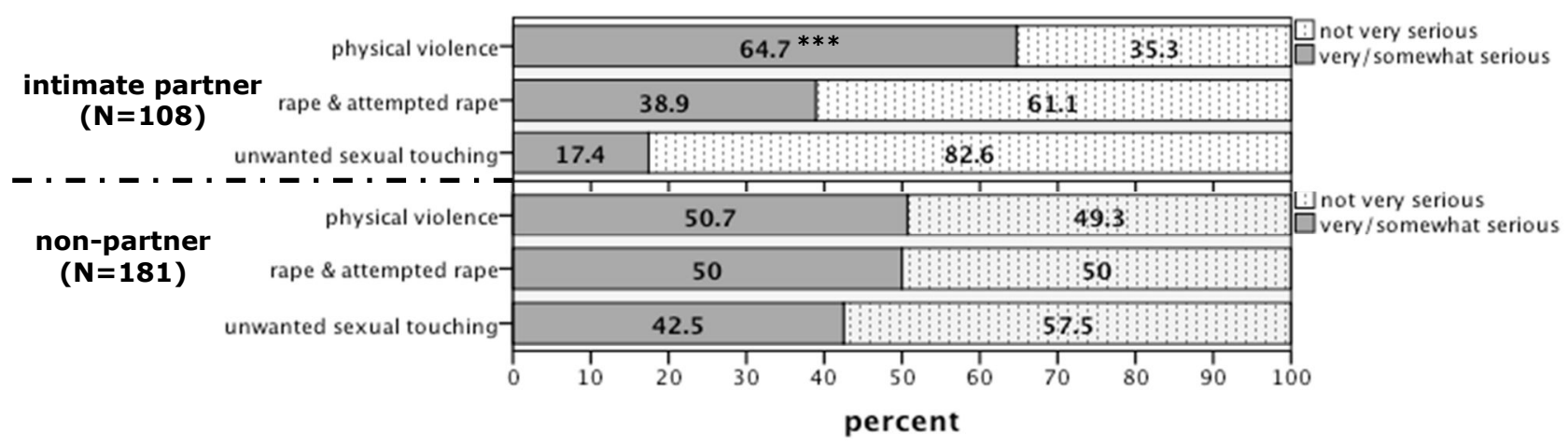

For the 181 victims of violent incidents by non-partners, there was no significant difference in their perception of the seriousness of physical and sexual violence, although slightly larger proportions rated physical violence $(50.7 \%)$ and rape $(50 \%)$ as serious compared to unwanted sexual touching $(42.5 \%)$. 
The presence of injuries did not affect the women's perception of the seriousness of the incident, regardless of the type of violence or the non-partner perpetrator.

In the other countries surveyed by the IVAWS generally larger proportions of women rated both partner and non-partner violence as very or somewhat serious, ranging from 60 per cent in Denmark to 90 per cent in Poland for partner violence, and 47 per cent in Denmark to 85 per cent in Poland for non-partner violence. Larger proportions of women in Australia, the Czech Republic and Denmark rated intimate partner violence as serious compared to non-partner violence. In the other countries, comparable proportions of women rated violence by partners and non-partners as serious (usually differences of less than 10 percentage points were reported) (see Mouzos and Makkai 2008, p. 216).

\subsection{Victims' Perception of Violence as Crime}

Respondents who had been victimised were also asked whether they believed the incident was 'a crime', 'wrong but not a crime' or 'something that just happened'. One-third (33.3\%) of all victims considered the violent attack was a crime, one-quarter that it was wrong but did not constitute a crime and 38.6 per cent said it was just something that happened (3\% did not know or preferred not to answer). Victims of violence by intimate partners and by non-partners had very different perceptions: only around 14 per cent of victims of intimate partner violence considered the incident was a crime compared to nearly half the victims of non-partner males $(44.8 \%, p<.001)$ (Figure 6.3).

Figure 6.3. Victims' perception of the most recent incident as a crime by perpetrator

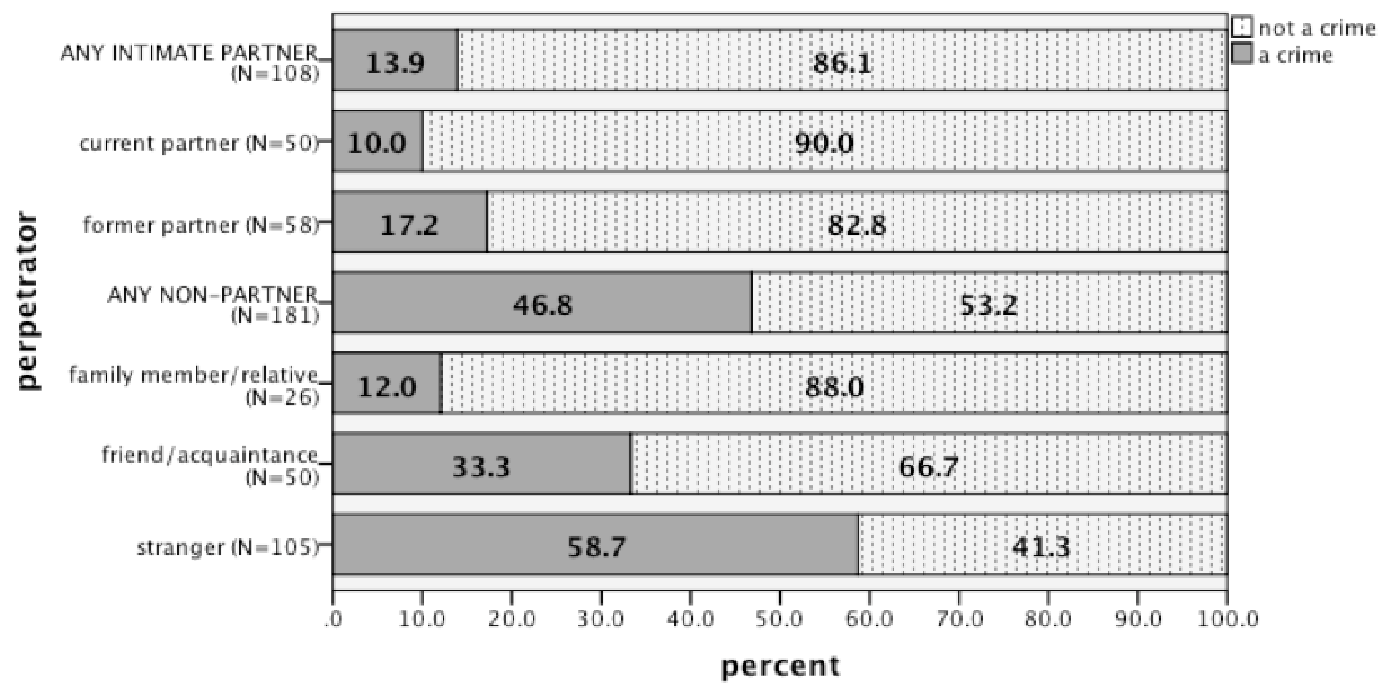

For victims of intimate partner violence it made some difference (albeit not statistically significant), whether the perpetrator was a current or former partner: ten per cent of victims believed the incident by their current partner constituted a crime compared to 17.2 per cent of women victimised by their former partner. By contrast, among women victimised by non-partners, the identity of the perpetrator influenced their perception of the incident as a crime: nearly sixty per cent of victims of assault by strangers believed the incident was a crime; a smaller proportion $(33.3 \%)$ said that an assault by a friend or acquaintance was a crime; and only 12 per cent of women victimised by family members or relatives considered the incident a crime. The latter figure is comparable to the proportion of victims who regarded violence by an intimate partner as a crime $(13.9 \%)$, indicating that as the relational proximity increased, women were less inclined to identify the violence as a crime.

Victims' perceptions also varied depending on the specific acts of violence (Figure 6.4). Victims of sexual violence (rape, attempted rape and unwanted sexual touching) were significantly more likely than victims of physical violence to say that the incident was a crime $(23.7 \%$ compared to $44.6 \%, p<.01)$. 
Surprisingly, less than one-third of all rape victims (30.8\%) considered the assault was a crime compared to nearly half the victims of unwanted sexual touching $(47.2 \%, p<.01)$. This pattern reflects that rape was most often perpetrated by partners and friends or acquaintances (relationally close) while unwanted sexual touching was most often perpetrated by strangers (relationally distant). Among victims of intimate partner violence, the largest share (22.2\%) considered rape was a crime and 14.7 per cent that the incident of physical violence was a crime, but only 4.5 per cent believed that unwanted sexual touching by their intimate partner constituted a crime (differences were not statistically significant). Turning to non-partner violence, nearly one-third $(29.9 \%)$ of the victims of physical violence considered the assault a crime, a slightly larger share of the rape victims $(37.5 \%)$ said the incident was a crime, but the majority of the victims of unwanted sexual touching $(54.3 \%, p<.01)$ regarded the incident as a crime (Figure 6.4). Again, the different perpetrators involved in the incident account for this pattern: friends and acquaintances were the most likely perpetrators of rapes and attempted rapes while strangers were the most likely perpetrators of incidents of unwanted sexual touching.

Figure 6.4. Victims' perception of the most recent incident as a crime by type of violent act

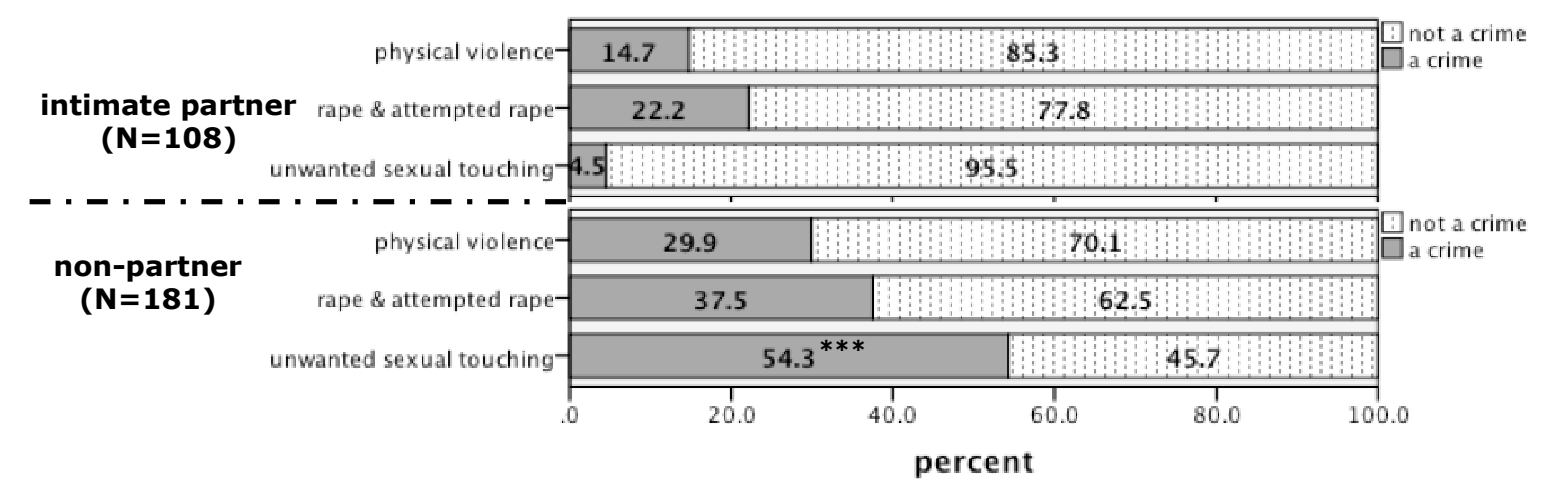

The presence of injuries altered victims' perception of the incident for intimate partner but not for non-partner violence, although differences do not reach statistical significance. For intimate partner violence, 22.2 per cent of women who were injured perceived the violence was a crime, compared to 9.7 per cent of non-injured women. For non-partner violence, 40 per cent of women who were injured perceived the incident was a crime, compared to 46.2 per cent of non-injured women. In addition women whose children witnessed violence by an intimate partner were nearly twice as likely to regard the incident as a crime than women whose children did not witness the incident $(22.7 \%$ vs. $13.8 \%$, n.s.) but the difference do not reach statistical significance due to the small numbers involved. For all types of violence, victims who rated the incident as 'serious' were significantly more likely to also regard it as a crime compared to victims who thought the incident was 'not very serious': half those who said the incident was 'serious' also said it was a crime compared to only 18.5 per cent of those who thought it was not very serious $(p<.001)$.

Among the IVAWS countries, Hong Kong and Mozambique stand out as the only two countries with large differences in the perception of intimate and non-partner violence. In both countries, victims of violence were unlikely to rate violence by intimate partners as a crime $(13.9 \%$ in Hong Kong and $21 \%$ in Mozambique) but nearly half (46.8\% in Hong Kong and 45\% in Mozambique) rated violence by non-partners as a crime. The other countries recorded comparable ratings for both types of violence. In most of the countries, between 21 and 28 per cent of victims of intimate violence said the incident was a crime, with higher rates in Poland (39\%) and Costa Rica (41\%), and there were less than a 10 percentage point difference with their rating of non-partner violence. Traditional Chinese values are strongly family-oriented; members of a family tend to assume collective responsibility and negative actions committed by one individual are considered to bring shame to the family as a whole. A Chinese saying 'family disgrace should not be made public' exemplifies this notion. The women in our survey may have been reluctant to identify actions by partners and close relatives as crime because this would 
reflect shamefully on the family as well as on themselves. In the next section we examine levels of official reporting to the police including whether the victim's perception of an event as a crime translated into reporting that event to the police.

\subsection{Reporting to Police and Satisfaction with Police Response}

Research on violence against women has shown that only a small proportion of violent victimisation is reported to the police. Generally, the closer the relationship between the victim and the offender, the less likely the violence will be reported to the police: violence by a husband is least likely to be reported and violence by a stranger, most likely (Gartner and Macmillan 1995; Mahoney 1999). Reviewing the results of victimisation surveys conducted since 1992 in five English-speaking countries, Daly and Bouhours (2010) estimated that on average only 14 per cent of sexual assault victimisation is reported to the police.

In Hong Kong, the UNICVS found that reporting rate for all the crimes surveyed combined tended to be lower than the international average, except for assault, for which rates of reporting were comparable (35.4\% in Hong Kong vs. 31\% for international average). The victim's sex had no impact on the likelihood of reporting the assault. Reporting of sexual victimisation was much lower $(12 \%)$ and about half the rate found internationally $(22 \%)$. The main reason for not reporting assaults was that it was not serious enough $(30 \%)$ and that the family solved the problem $(22 \%)$; for sexual assault, reasons given were that the police could do nothing $(26 \%)$ and the incident was not serious enough $(21 \%){ }^{32}$ For both assault and sexual violence, victims were more likely to report to the police when they perceived the incident was very or fairly serious. The Hong Kong government's own survey, the HKCVS, found similar reporting rates as the UNICVS for serious assault, but it did not provide results for indecent assault (Broadhurst et al. 2010).

In the IVAWS, victims of violence by partners and non-partners were asked whether they, or someone else, reported the most recent incident to the police, and what happened once they had reported. If the incident was not reported, women were asked the reasons why it was not. We examine rates of reporting for physical and sexual violence by partners and non-partners, and whether the reported cases ended up in conviction. Then, we analyse the reason(s) that women gave for not reporting the incident, as this was the usual outcome. At each stage of our analyses, we compare results in Hong Kong with other IVAWS countries.

\subsubsection{Reporting violent victimisation to police}

Overall, a small proportion of victims $(12.2 \%)$ reported the incident to the police. Incidents involving physical violence were reported by 23 per cent of victims, which was significantly more than incidents involving sexual violence, which was reported by only 2.6 per cent of victims (Table 6.1). No incidents of rape or attempted rape were reported to the police; 3.1 per cent of all incidents of unwanted sexual touching were reported and these were only those committed by strangers. There was no difference in the reporting of intimate partner violence compared to non-partner violence $(12 \%$ and $12.2 \%$ of incidents were reported respectively). Nearly one in five (19.4\%) victims of physical violence by an intimate partner reported the assault, a slightly lower proportion than physical violence by non-partners $(26.5 \%)$. Acts of violence by strangers were the most likely to be reported, although only 15.2 per cent of incidents were actually reported.

\footnotetext{
32 Over half the victims of sexual assault who did not report to the police (53\%) also cited 'other reasons' but did not elaborate.
} 
Table 6.1. Most recent incident reported to police by perpetrator and type of violence (\%)

\begin{tabular}{lccc}
\hline & All violence & Physical violence & Sexual violence \\
\cline { 3 - 4 } All incidents $(\mathbf{N}=\mathbf{2 8 9})$ & 12.2 & $23.0^{* *}$ & 2.6 \\
Partner violence $(\mathbf{N = 1 0 8 )}$ & $\mathbf{1 2 . 0}$ & $\mathbf{1 9 . 4}^{* *}$ & $\mathbf{0 . 0}$ \\
Current partner & 11.8 & $20.7^{*}$ & 0.0 \\
Former partner & 13.8 & $20.5^{*}$ & 0.0 \\
Non-partner violence $(\mathbf{N}=\mathbf{1 8 1})$ & $\mathbf{1 2 . 2}$ & $\mathbf{2 6 . 5}^{* * *}$ & $\mathbf{3 . 5}$ \\
Family member and relative & 8 & 9.1 & 0.0 \\
Friend and acquaintance & 8.0 & $26.7^{* *}$ & 0.0 \\
Stranger & 15.2 & $36.7^{* * *}$ & 5.4 \\
\hline
\end{tabular}

The severity, actual and perceived, of the violent incident correlated with the likelihood that it was reported to the police. As shown in Table 6.2, nearly one-third of all incidents in which women were injured or feared for their life were reported to the police compared to 7 per cent of those with no injury or the victim did not fear for their life. The perception by victims that the incident was 'very' or 'somewhat' serious or that it was a crime was also linked to significantly higher reporting rates. Yet, the perception that the violent incident was a crime did not automatically translate into reporting it to the police as only 22.7 per cent of all victims who regarded their victimisation as a crime actually reported it. Of women who said that the incident or abuse was a crime, a higher proportion of victims of intimate partners reported the abuse (40\%) compared to victims of non-partners $(19.8 \%)$, but this difference only approached statistical significance $(p=.08)$. As seen previously, women were more likely to be injured during incidents of physical rather than sexual violence, and this goes some way toward explaining why a larger proportion of cases of physical violence were reported to the police. Finally, in cases of intimate violence, the presence of children witnessing the violence also resulted in higher levels of reporting to police: 36.4 per cent of women whose children witnessed the incident reported to police compared to 10 per cent when there was no child witness $(p<.01)$.

Table 6.2. Severity of the most recent incident reported to police by perpetrator and severity of violence $(\%)$

\begin{tabular}{|c|c|c|c|}
\hline & $\begin{array}{l}\text { All incidents } \\
\quad \mathbf{N}=\mathbf{2 8 9}\end{array}$ & $\begin{array}{c}\begin{array}{c}\text { Partner violence } \\
\mathbf{N}=\mathbf{1 0 8}\end{array} \\
\end{array}$ & $\begin{array}{c}\text { Non-partner } \\
\text { violence } \\
\mathbf{N}=\mathbf{1 8 1}\end{array}$ \\
\hline \multicolumn{4}{|c|}{ Victim was injured } \\
\hline Yes & $31.1^{* * *}$ & $22.9^{*}$ & $44.0^{* * *}$ \\
\hline No & 7.0 & 6.8 & 7.1 \\
\hline \multicolumn{4}{|c|}{ Victim felt her life was in danger } \\
\hline Yes & $30.6^{* * *}$ & 20.0 & $40.6^{* * *}$ \\
\hline No & 7.3 & 9.0 & 6.4 \\
\hline \multicolumn{4}{|c|}{ Victim's perception of seriousness } \\
\hline Serious & $18.8^{* *}$ & $20.0^{*}$ & $18.1^{*}$ \\
\hline Not very serious & 6.0 & 3.8 & 7.1 \\
\hline \multicolumn{4}{|c|}{$\begin{array}{l}\text { Victim's perception that the } \\
\text { incident was a crime }\end{array}$} \\
\hline A crime & $22.7^{* * *}$ & $40.0^{* *}$ & $19.8^{*}$ \\
\hline Not a crime & 7.3 & 8.6 & 6.0 \\
\hline
\end{tabular}

${ }^{*} p<.05 ;{ }^{* *} p<.01 ;{ }^{* * *} p<.001$. 
In the other countries surveyed by the IVAWS, levels of reporting for partner and non-partner violence were below 20 per cent, apart from Poland, where 31 per cent of victims of intimate partner violence reported to the police. Reporting of partner violence was lowest in Mozambique and the Czech Republic (7\% and 8\% respectively), with the other countries comparable to Hong Kong. Reporting rates for non-partner violence ranged from 10 per cent in Costa Rica to 16 per cent in Australia and Poland. Except in Costa Rica, the Philippines and Poland, violence by stranger was more likely to be reported than violence by known men, with the highest rate of report for stranger violence found in Australia (26\%).

\subsubsection{Reasons for not reporting to police}

Although the level of reporting of violence against women in Hong Kong was close to the average in the countries surveyed by the IVAWS, most victims in Hong Kong and elsewhere did not alert the police of their victimisation. The main reason put forward by nearly half the victims $(45.7 \%)$ who did not report was that the incident was not serious enough; the second reason $(15.7 \%)$ was that the victim or her family dealt with it themselves (Table 6.3). Victims of partner and non-partner violence invoked similar reasons for not reporting. One difference, however, was that more victims of partner violence than non-partner violence said that they did not report the incident because they did not want their partner to be arrested ( $4.4 \%$ vs. $0.5 \%)$. Women mentioned the same reasons and in similar proportion for not reporting physical and sexual violence. A relatively large proportion of women (about onethird), however, invoked 'other reasons' for not reporting to the police but did not elaborate.

Table 6.3. Reasons for not reporting the most recent incident to the police by perpetrator (\%)

\begin{tabular}{|c|c|c|c|}
\hline Reasons for not reporting ${ }^{a}$ & $\begin{array}{l}\text { All violence } \\
\qquad N=254\end{array}$ & $\begin{array}{c}\text { Intimate partner } \\
\text { violence } \\
\mathrm{N}=95\end{array}$ & $\begin{array}{c}\text { Non-partner } \\
\text { violence } \\
\mathbf{N}=159\end{array}$ \\
\hline Not serious enough, too minor & 45.7 & 55.2 & 40.2 \\
\hline I/my family dealt with it & 15.7 & 24.6 & 10.4 \\
\hline Shame, embarrassment & 5.9 & 2.6 & 7.8 \\
\hline Did not think police would do anything & 3.5 & 0 & 5.4 \\
\hline Did not think police could do anything & 2.4 & 0 & 3.6 \\
\hline Wanted to keep it private & 2.4 & 3.6 & 2.2 \\
\hline Did not want offender arrested & 2.0 & 4.4 & 0.5 \\
\hline Would not be believed & 2.0 & 0 & 3.4 \\
\hline Fear of offender & 1.6 & 1.0 & 2.0 \\
\hline Reported to someone else & 1.2 & 0 & 1.9 \\
\hline Other reasons & 32.3 & 22.3 & 38.4 \\
\hline
\end{tabular}

Note ${ }^{\text {a }}$ Multiple responses allowed; totals may not add up to $100 \%$.

\subsubsection{Attrition through the criminal justice system}

A total of 35 cases (13 by intimate partners and 22 by non-partners) were reported to the police and we now look at what happened to these cases as they entered the criminal justice system (Figure 6.5). ${ }^{33}$ In 62.9 per cent of cases, the police filed a report of the complaint, and there was no difference between

\footnotetext{
33 This section is based on what victims said happened to the case they reported to the police. It is possible that some victims were not aware of the actions taken by the police or the court.
} 


\section{Hong Kong IVAWS}

cases involving intimate partners or non-partners. Police identified a suspect and laid charges in only four cases: one case of physical violence by an intimate (former) partner and three cases of physical violence by strangers; that is, charges were laid in 11.4 per cent of reported cases and 18.1 per cent of cases in which police wrote a report. The four suspects who were charged were also convicted in court, resulting in a conviction rate of 8 per cent for intimate partner violence and 13.6 per cent for violence by stranger. No incident of violence by a current partner, a family member/relative, or a friend was prosecuted.

The severity of the case had little impact on the police decision to take a report or charge a suspect: police took a report in 66.7 per cent of cases where the victim was injured compared to 56.3 per cent with no injury; a suspect was charged in 15.8 per cent of reported cases that involved injuries and 5.9 per cent of cases with no injury.

Figure 6.5 The journey of the most recent cases through the criminal justice system

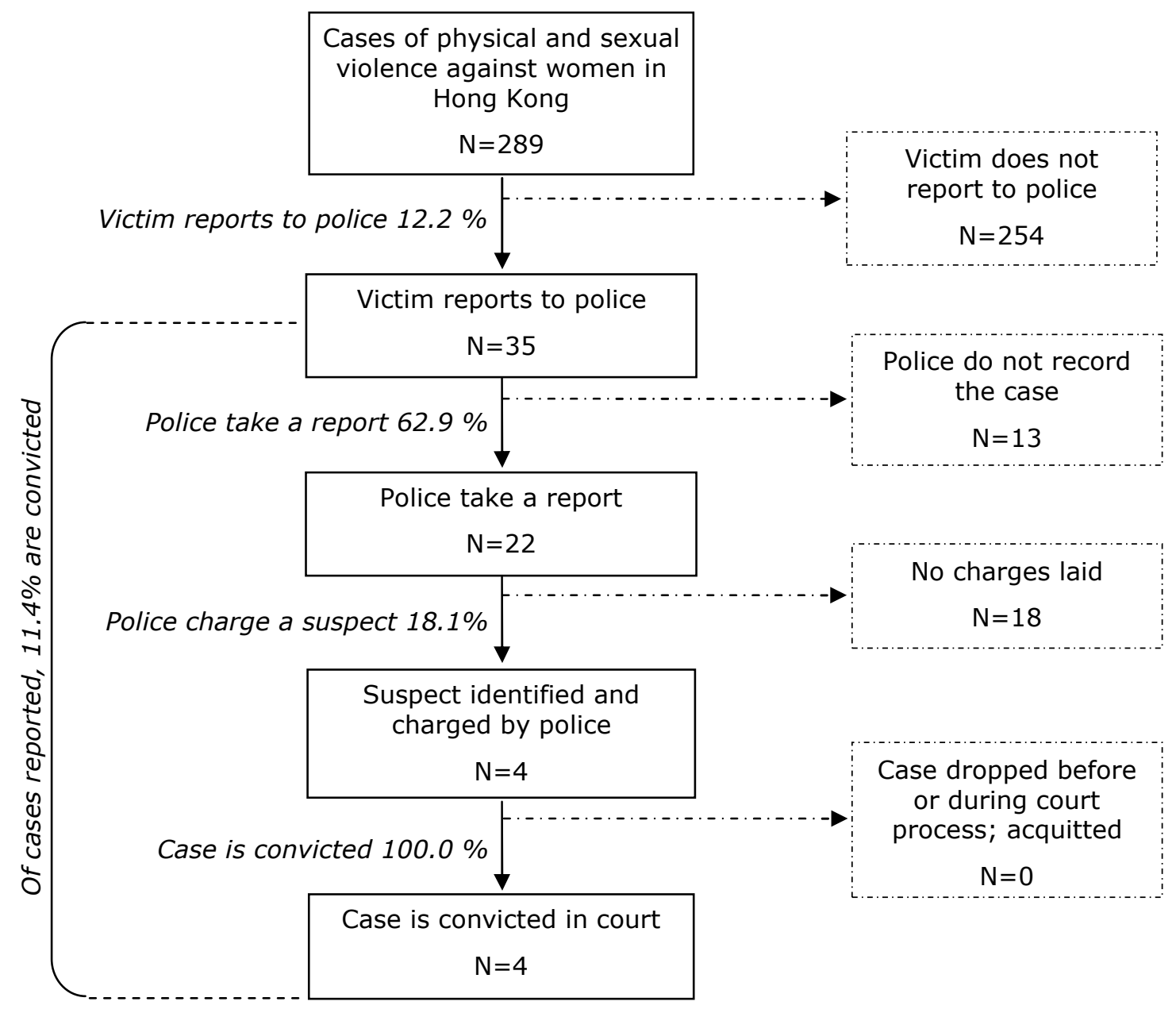

If we consider the figures above as a percentage of all victimised women, we find that only 1 per cent of cases of partner violence $(\mathrm{N}=1)$ and 1.7 per cent of cases of non-partner violence $(\mathrm{N}=3)$ were successfully prosecuted and all were cases of physical violence. While these rates are very low, there are only slightly lower than in the other IVAWS countries. For partner violence and excluding Poland, charges were laid in between 2 and 4 per cent of cases of victimisation, and conviction occurred in 1 to 3 per cent of cases. Poland was the exception with 10 per cent of cases of intimate violence were charged and convicted. Rates of prosecution were marginally higher for cases involving non-partners, ranging between 3 (Denmark and Poland) and 7 per cent (Australia) of cases that were charged and none (Mozambique and the Philippines) to 5 per cent (Australia) of cases that resulted in conviction. 


\subsubsection{Satisfaction with police response}

The few victims who did report the violence to the police were generally satisfied with the response of the police, ranging from 62 per cent of victims of intimate partner violence to 75 per cent of victims of non-partner violence, and 68 per cent to 75 per cent of physical and sexual assault victims respectively. Counts were too small to analyse satisfaction by type of perpetrator or type of violence. Women who reported to the police were asked if they would have liked the police to do something else to assist them, but few suggested any additional or different police responses.

\subsection{Seeking Help Outside of the Criminal Justice System}

Only 11 women contacted a specialised agency following their victimisation: 5.6 per cent of victims of intimate partner violence and 2.8 per cent of victims of non-partner violence. The majority of victims $(70.6 \%)$, however, talked to and sought help from others, mostly their immediate family and friends (Table 6.4). Yet, for nearly 30 per cent of victims, talking to the IVAWS interviewer was the first time that they disclosed their victimisation. Victims of non-partner violence were significantly more likely than victims of intimate partner violence to talk to others about what happened $(76.2 \%$ compared to $61.1 \%$ respectively), and particularly when the perpetrator was their current partner: $70.2 \%$ discussed the violence by a former partner with others compared to just over half $(51 \%)$ the women victimised by their current partner $(p<.01)$. Comparable proportions of victims of non-partner violence talked about the incident regardless of who the perpetrator was: 76.9 per cent of victims disclosed the incident when the perpetrator was a family member or relative; 64 per cent when the perpetrator was friend or acquaintance; and 81 per cent when the perpetrator was a stranger.

Table 6.4. Victims of partner and non-partner violence who talked to someone about the incident $(\%)$

\begin{tabular}{|c|c|c|c|}
\hline & $\begin{array}{l}\text { All violence } \\
\quad \mathrm{N}=\mathbf{2 8 9}\end{array}$ & $\begin{array}{c}\text { Intimate partner } \\
\text { violence } \\
\mathbf{N}=108\end{array}$ & $\begin{array}{c}\text { Non-partner } \\
\text { violence } \\
\mathbf{N}=\mathbf{1 8 1}\end{array}$ \\
\hline $\begin{array}{l}\text { Victim talked to someone about the } \\
\text { incident }\end{array}$ & 70.6 & 61.1 & $76.2^{* *}$ \\
\hline \multicolumn{4}{|l|}{ Talked to: ${ }^{a}$} \\
\hline Immediate family members & 40.5 & 35.8 & 43.8 \\
\hline Friend/neighbour & 40.5 & 36.3 & 43.3 \\
\hline Co-worker/co-student & 12.1 & 5.4 & 15.9 \\
\hline Other relative & 6.2 & 7.3 & 5.6 \\
\hline Doctor/psychologist/counsellor & 4.2 & 5.3 & 2.9 \\
\hline Religious leader/worker & 1.0 & 0 & 1.6 \\
\hline Victim support agency & 3.8 & 5.6 & 2.8 \\
\hline Other persons & 5.2 & 3.4 & 6.3 \\
\hline
\end{tabular}

${ }^{* *} p<.01$. Note ${ }^{a}$ Multiple responses allowed; totals may not add up to $100 \%$. We do not include victims who reported to the police because all those who did also talked to someone else about the incident.

Victims of violence found it easier to share their experience of physical violence than sexual violence $(80 \%$ talked about the incident of physical violence compared to $62.3 \%$ about the incident of sexual violence, $p<.01)$. Victims of rape or attempted rape were the least likely to seek support from others: less than half (48.1\%) talked about the rape while 64.8 per cent talked about being touched sexually against their will.

As shown in Table 6.5 there are strong correlations between the actual and perceived severity of the violence and the likelihood that victims talked to anyone, but only in relation to violence by intimate partners. Only about half the victims of intimate partner violence who were not injured in the most 


\section{Hong Kong IVAWS}

recent incident talked about it, but nearly four in five who were injured by their partner disclosed the incident to someone, with a similar pattern in relation to fear for life $(p<.001)$. The perception that the incident was serious or that it was a crime also encouraged victims of partner violence to disclose the incident; for example, 93.3 per cent of victims of intimate partner violence talked to someone about the incident compared to just 55.9 per cent of those who did not think the incident was a crime. This pattern suggests that women who were the victims of intimate partner violence remained silent about the violence until it became severe, e.g. they were injured, when they disclosed it to their family and friends, or more rarely to the police and/or other professionals such as doctors or counsellors.

Table 6.5. Victims of partner and non-partner violence who talked to someone and severity of the most recent incident (\%)

\begin{tabular}{|c|c|c|c|}
\hline & $\begin{array}{l}\text { All violence } \\
\quad \mathbf{N}=\mathbf{2 8 9}\end{array}$ & $\begin{array}{c}\text { Intimate partner } \\
\text { violence } \\
\mathbf{N}=108\end{array}$ & $\begin{array}{c}\text { Non-partner } \\
\text { violence } \\
\mathrm{N}=\mathbf{1 8 1}\end{array}$ \\
\hline \multicolumn{4}{|c|}{ Victim was injured } \\
\hline Yes & $82.0^{*}$ & $77.8^{* * *}$ & 88.0 \\
\hline No & 67.2 & 52.1 & 74.4 \\
\hline \multicolumn{4}{|c|}{ Victim felt her life was in danger } \\
\hline Yes & 80.6 & $76.7^{*}$ & 84.4 \\
\hline No & 67.9 & 55.1 & 75.0 \\
\hline \multicolumn{4}{|c|}{ Victim's perception of seriousness } \\
\hline Serious & $83.3^{* * *}$ & $83.3^{* * *}$ & $83.3^{*}$ \\
\hline Not very serious & 58.9 & 38.9 & 69.4 \\
\hline \multicolumn{4}{|c|}{$\begin{array}{l}\text { Victim's perception that the } \\
\text { incident was a crime }\end{array}$} \\
\hline Yes, a crime & $82.3^{* *}$ & $93.3^{* *}$ & 80.2 \\
\hline Not a crime & 64.6 & 55.9 & 72.7 \\
\hline
\end{tabular}

${ }^{*} p<.05 ;{ }^{* *} p<.01 ;{ }^{* * *} p<.001$.

Victims of non-partner violence who had been injured, feared for their life or thought that the incident was a crime were only slightly more likely to talk about the incident with others and the differences were not statistically significant; only the perception that the incident was serious had a significant impact, with 83.3 per cent of victims of non-partner violence who perceived the incident was a crime disclosing it to someone else compared to 69.4 per cent of those who did not perceive it was a crime.

\subsection{Summary}

This chapter examined women's perceptions of and responses to their violent victimisation. Since the age of 16 years, 108 Hong Kong women in our sample experienced one or several instances of physical or sexual violence by a current or former intimate partner. Half of them perceived that the most recent incident was very or somewhat serious, 13.9 per cent regarded that incident as a crime and 12 per cent reported it to the police. Over one-third of these victims (38.9\%) kept it a secret and did not talk to anyone about the violence, particularly if the perpetrator was their current partner; the majority of the others disclosed the abuse to their family and/or their friends, but few $(5.6 \%)$ contacted a victim support agency.

In the Hong Kong IVAWS sample, 181 respondents experienced violence by a non-partner male since the age of 16. Nearly half of them (46.1\%) regarded the most recent incident as very or somewhat serious and a similar proportion (44.8\%) thought this incident constituted a crime; yet, only 12.2 per 
cent reported it to the police. Three-quarters of the victims talked to others about the incident but only 2.8 per cent contacted a specialised agency.

More victims of physical violence rather than sexual violence rated the latest incident as very or somewhat serious. There are two reasons for this finding: 1) physical violence was more likely to result in injuries or in women fearing for their life than sexual violence, and 2) a large proportion of sexual violence consisted of unwanted sexual touching, which rarely led to injuries. Victims of partner and non-partner violence were significantly more likely to discuss incidents of physical violence with others and to alert the police than victims of sexual violence.

Victims of both intimate partner and non-partner violence were more likely to perceive incidents of physical and sexual violence as serious if they had been injured or felt their life was in danger. However, victims of intimate partner violence were unlikely to regard even such severe incidents as crimes. While a larger proportion of victims of non-partner violence said that their victimisation constituted a crime, particularly if it involved a stranger, this did not translate into a higher level of reporting to the police than when the event involved violence by partners.

On average, three-quarters of the victims of non-partner violence, particularly physical violence, talked to someone about the incident regardless of its severity. However, it seems that many victims of intimate partner violence tended to keep the abuse to themselve until it became severe; for example, they were injured or their children witnessed the violence. The reluctance to speak about these incidents may be because they hope that the violence will stop, they are afraid of the perpetrator if they say anything, they believe they are partly responsible for what happened, or they feel ashamed. When the violence became more severe, victims disclosed it to their family or friends but rarely to the police. One of the main reasons evoked by victims for not contacting the police was that they or their family dealt with the incident, which is consistent with Hong Kong family-oriented culture.

A limitation of the IVAWS is that although respondents are asked general questions about the timing of violent incidents, they are not asked when the most recent incident occurred. For some women, it happened only a short time before the survey but some older women reported victimisation that occurred 20 years before. During this time, social attitudes and responses to violence, particularly violence between intimates, have changed. It would be important to examine whether trends in reporting to police and disclosing to others have changed over time. 



\section{CHAPTER 7}

\section{Summary and Conclusion}

This final chapter reviews the main results of the IVAWS in Hong Kong and summarises how these results compare with those of the other countries surveyed. Then we briefly discuss the findings of the survey, its limitations and areas for further research.

\subsection{Summary of Results}

\subsubsection{Violence by any man}

- Nearly 20 per cent of women reported experiencing at least one incident of physical or sexual violence by a man since age 16, and 3.7 per cent in the year preceding the survey.

- Over the adult lifetime and in the past 12 months, they were more likely to report sexual violence than physical violence.

- The most common form of sexual violence over the lifetime and the past year was unwanted sexual touching $(11.8 \%$ and $2.2 \%$ respectively).

- The risk of victimisation decreased with age. Women under 35 years were significantly more likely to have experienced violence in the past year than women aged 35 years and older.

- Women who were dating reported higher level of victimisation than married/cohabiting women or single women. Although there was a significant age effect, dating relationships constituted an additional risk factor for violent victimisation.

- Women who worked were significantly more likely to experience both physical and sexual violence that those who did not work.

- Women who did not have a say in how their income was used were more at risk of experiencing violence than those who had control over their income.

\subsubsection{Violence by intimate partners}

- Less than ten per cent of women with a current or former partner reported experiencing at least one form of violence by this partner in their adult lifetime. Physical violence (6.2\%) was more frequent than sexual violence $(4.8 \%)$ over the lifetime but levels were similar in the previous year (around 1\%).

- Over the lifetime, women were more likely to have been victimised by a former partner $(9.4 \%)$ than by a current partner $(5.3 \%)$.

- The most common form of intimate sexual violence over the lifetime and the past year was unwanted sexual touching.

- Of women abused by their current partner, 36 per cent were injured and 21.6 per cent feared for their life in the most recent incident. A slightly lower proportion of women abused by a 
former partner were injured (31.6\%), but the same proportion $(31.6 \%)$ feared for their life during the incident.

- Women whose current partner used controlling or emotionally abusive behaviours were at significantly higher risks of experiencing violence than women whose partner did not use such behaviours.

- The three main risk factors for violence by current partners were: emotionally abusive behaviour, generally aggressive behaviour (violence outside of the family), heavy drinking (getting drunk at least twice a month) and controlling behaviour.

\subsubsection{Violence by non-partners}

- Fourteen per cent of respondents had experienced violence by a man other than an intimate partner since the age of 16 , with rates reducing to 2.6 per cent in the past year.

- Perpetrators of non-partner violence were most likely to be strangers: 8 per cent of women experienced violence by strangers over their adult lifetime, 4.9 per cent by friends and acquaintances and 2.5 per cent by family members and relatives.

- Sexual violence was the most common form of violence by strangers and friends and acquaintances, but it was rarely perpetrated by relatives, who were more likely to inflict physical violence.

- One in five victims of violence by relatives, and friends and acquaintances were injured, but only 8.6 per cent of victims of stranger violence. However, over half the women attacked by a stranger felt that their life was in danger during the most recent incident, compared to one third of victims of violence by friends and relatives.

- Three risk factors were significant predictors of violence by non-partners: being in a dating relationship; working; and not having a say in how personal income was used.

\subsubsection{Perceptions and responses to violence}

- Just under half the victims of non-partner violence (46.1\%) perceived the assault was serious with little difference by type of non-partner. For intimate partner violence, however, women who had been abused by their current partner were less likely to say that the violence was serious $(37.3 \%)$ compared to women who had been abused by a former partner $(62.1 \%)$.

- Physical violence by an intimate partner was considered more serious than sexual violence, but there were no such differences in perception of seriousness of the incident (physical or sexual) for non-partner violence.

- Victims of violence were much more likely to regard violence by non-partner as a crime than violence by intimate partner ( $46.8 \%$ and $13.9 \%$ respectively). As the relational proximity decreased, women were more likely to consider the violence as a crime and the highest proportion of victims who considered the violent event was a crime were those attacked by strangers $(58.7 \%)$.

- Few victims $(12.2 \%)$ reported the most recent incident to the police with a similar proportion applicable to either partner or non-partner violence. Only 2.6 per cent of incidents of sexual violence were reported compared to 23 per cent of physical violence. Women were more likely to contact the police if they had been injured, if they perceived the incident was serious, or if they regarded it as a crime. The main reasons for not contacting the police were that the incident was too minor and that the victim or her family dealt with it.

- Of the 13 cases of intimate partner violence that were reported to the police, only one by former partner resulted in conviction. Of 22 cases of non-partner violence reported to the police, 14 per cent $(\mathrm{N}=3)$ were charged and convicted, and all involved strangers. No cases of sexual violence ended up in a conviction. 
- Victims were unlikely to contact victim support agencies: only 5.6 per cent of victims of partner violence and 2.8 per cent of victims of non-partner violence did so. The majority of victims talked to and sought help and support from others, particularly their family and friends, although victims of intimate partner violence tended to remain silent about the abuse until it became severe, for example if they were injured.

\subsection{Comparisons with other IVAWS Countries}

The results of the IVAWS are available for eight countries surveyed between 2003 and 2005 beside Hong Kong: Australia, Costa Rica, the Czech Republic, Denmark, Mozambique, the Philippines, Poland and Switzerland. This gives us the opportunity to compare the extent of violence in Hong Kong with these other countries.

\subsubsection{Prevalence of violence against women}

Table 7.1 presents the range of rates for various types of violence in the eight countries and Hong Kong. For all types of violence against women, Hong Kong recorded much lower lifetime rates of violence against women than most countries apart from the Philippines. Physical violence by any man was lowest in Hong Kong (11.5\%) followed by the Philippines (15\%); sexual violence by any man was lowest in the Philippines (6\%), followed by Hong Kong (13.3\%). The rate of violence by current intimate partners in Hong Kong (5.3\%) was not as low as in Denmark (3\%) and Switzerland (2\%). Physical violence by non-partners was least frequent in Hong Kong (6.9\%) on par with the Philippines $(7 \%)$; the rate of sexual violence by non-partners $(10.7 \%)$ was on par with Mozambique $(11 \%)$ and the second lowest after the Philippines (4\%).

There were some differences in the type of violence experienced by Hong Kong women. In most other countries, overall physical violence, ranging from 27 to 51 per cent, was more frequent than sexual violence, ranging from 17 to 41 per cent. By contrast, in Hong Kong, sexual violence occurred more frequently than physical violence $(13.3 \%$ compared to $11.5 \%$ over the adult lifetime). In all countries, rates of physical violence by current intimate partners, ranging between 15-36 per cent, were higher than rates of sexual violence, ranging between 5-15 per cent; in Hong Kong the difference was only small $(6.4 \%$ and $4.8 \%$ respectively). In contrast to most of the other IVAWS countries, where rape was the most frequently reported type of sexual violence by intimate partners (between 6-9\%), in Hong Kong it was unwanted sexual touching. ${ }^{34}$ This pattern suggests that men stopped their sexual advances when their partners indicated that they did not wish to have sex. Without further qualitative data it is difficult to explain why Hong Kong differs from other countries. We can speculate that with prostitution easily available and broadly tolerated, men may opt to pay for sex rather than force their partner to have intercourse.

Rates of sexual violence by relatives, and friends and acquaintances were lower in Hong Kong than in the other countries, but sexual violence by strangers was about average $(6.9 \%$ in Hong Kong, with a range of $4-19 \%$ in the other countries except for a low of $2 \%$ in the Philippines). In all countries including Hong Kong, unwanted sexual touching was the most frequently reported form of sexual violence by non-partners.

\footnotetext{
34 A similar pattern occurred in the Philippines and Switzerland where $2 \%$ of women said they had been raped by their partner but 3\% experienced unwanted sexual touching, albeit not as high as in Hong Kong.
} 
Table 7.1. Rates of violence in Hong Kong and IVAWS countries, adult lifetime

\begin{tabular}{|c|c|c|c|}
\hline \multirow{2}{*}{ Type of violence } & \multirow{2}{*}{ Eight IVAWS countries ${ }^{a}$} & \multicolumn{2}{|c|}{ Hong Kong } \\
\hline & & $\%$ & rank \\
\hline \multicolumn{4}{|l|}{ Violence by any man } \\
\hline All violence & $\begin{array}{l}\text { Most countries: } 35-60 \% \\
\text { Philippines: } 17 \%\end{array}$ & 19.9 & $2^{\text {nd }}$ lowest \\
\hline Physical violence & $\begin{array}{l}\text { Most countries: } 27-51 \% \\
\text { Philippines: } 15 \%\end{array}$ & 11.5 & lowest \\
\hline Sexual violence & $\begin{array}{l}\text { Most countries: } 17-41 \% \\
\text { Philippines: } 6 \%\end{array}$ & 13.3 & $2^{\text {nd }}$ lowest \\
\hline \multicolumn{4}{|c|}{ Current partner violence } \\
\hline All violence & $\begin{array}{l}\text { Most countries: } 5-20 \% \\
\text { Switzerland: } 2 \% \text {; Denmark: } 3 \%\end{array}$ & 9.4 & $3^{\text {rd }}$ lowest \\
\hline Physical violence & $\begin{array}{l}\text { Most countries: } 6-20 \% \\
\text { Switzerland: } 2 \% \text {; Denmark: } 3 \%\end{array}$ & 6.4 & $3^{\text {rd }}$ lowest \\
\hline Sexual violence & $\begin{array}{l}\text { Most countries: } 3-6 \% \\
\text { Switzerland \& Denmark: } 0 \% \\
\text { Australia, Philippines, Poland: } 1 \%\end{array}$ & 4.8 & average \\
\hline \multicolumn{4}{|l|}{ Non-partner violence } \\
\hline All violence & $\begin{array}{l}\text { Most countries: } 25-42 \% \\
\text { Philippines: } 10 \% \text {; Mozambique: } 19 \%\end{array}$ & 14.9 & $2^{\text {nd }}$ lowest \\
\hline Physical violence & $\begin{array}{l}\text { Most countries: } 17-23 \% \\
\text { Philippines: } 7 \% \text {; Mozambique: } 12 \%\end{array}$ & 6.9 & lowest \\
\hline Sexual violence & $\begin{array}{l}\text { Most countries: } 18-31 \% \\
\text { Philippines: } 4 \% \text {; Mozambique: } 11 \% \text {; } \\
\text { Poland: } 12 \%\end{array}$ & 10.7 & $2^{\text {nd }}$ lowest \\
\hline \multicolumn{4}{|c|}{ Non-partner violence by perpetrator } \\
\hline $\begin{array}{l}\text { Family members and } \\
\text { relatives }\end{array}$ & Most countries: $3-8 \%$ & 2.7 & lowest \\
\hline $\begin{array}{l}\text { Friends and } \\
\text { acquaintances }\end{array}$ & $\begin{array}{l}\text { Most countries: } 9-18 \% \\
\text { Philippines: } 3 \%\end{array}$ & 5.2 & $2^{\text {nd }}$ lowest \\
\hline Strangers & $\begin{array}{l}\text { Most countries: } 13-24 \% \\
\text { Philippines: } 3 \% \text {; Mozambique: } 8 \%\end{array}$ & 9.2 & $3^{\text {rd }}$ lowest \\
\hline
\end{tabular}

Note ${ }^{a}$ Australia, Costa Rica, the Czech Republic, Denmark, Mozambique, the Philippines, Poland and Switzerland. For each type of violence, we indicate the range observed across most countries and countries with rates lower than the range. Data are from Johnson et al. (2008).

\subsubsection{Seriousness of and responses to the violence}

In all countries, women were most likely to sustain injuries during intimate partner violence, and this was also the case in Hong Kong (Table 7.2). The proportion of women who were injured during incident of intimate partner violence and violence by friends or relatives in Hong Kong was about average relative to the other countries surveyed, but fewer victims of stranger violence sustained injuries in Hong Kong (8.6\% compared to $13-27 \%$ in most of the countries). Comparable proportions of victims in Hong Kong and internationally reported that they felt their life was in danger during the most recent incident of violence by a partner or non-partner. These comparisons suggest that incidents of violence against women in Hong Kong were of similar seriousness as those reported in other countries.

Yet, Hong Kong women were less inclined to rate these incidents as serious as did women in other countries. For example, only 38 per cent of victims of current partner violence thought the most recent incident was serious, compared to a range of 56-87 per cent in most other countries (with the 
exception of Denmark with 43\%). The pattern was similar for violence by non-partners. As we have seen previously, even women who were injured during the assault or feared that their life was in danger, were less likely than women in other countries (except the Philippines) to judge that the assault was serious.

Table 7.2. Injuries and perception of seriousness, Hong Kong and IVAWS countries

\begin{tabular}{|c|c|c|c|}
\hline \multirow{2}{*}{ Type of violence } & \multirow{2}{*}{ Eight IVAWS countries ${ }^{a}$} & \multicolumn{2}{|c|}{ Hong Kong } \\
\hline & & $\%$ & rank \\
\hline \multicolumn{4}{|c|}{ Victim injured in most recent incident by } \\
\hline Current intimate partner & $\begin{array}{l}\text { All countries: } 20-45 \% \\
\text { Philippines: } 17 \%\end{array}$ & 36.0 & average \\
\hline Friend/relative & $\begin{array}{l}\text { Most countries: } 17-31 \% \\
\text { Denmark: } 11 \%\end{array}$ & 19.8 & average \\
\hline Stranger & $\begin{array}{l}\text { Most countries: } 13-27 \% \\
\text { Denmark: } 10 \% \text {; Philippines: } 11 \%\end{array}$ & 8.6 & lowest \\
\hline \multicolumn{4}{|c|}{ Victim feared for her life in most recent incident by } \\
\hline Current intimate partner & $\begin{array}{l}\text { Most countries: } 33-52 \% \\
\text { Denmark: } 10 \% \text {; Australia: } 15 \%\end{array}$ & 21.6 & $3^{\text {rd }}$ lowest \\
\hline Friend/relative & $\begin{array}{l}\text { Most countries: } 23-55 \% \\
\text { Denmark: } 8 \% \text {; Australia: } 15 \%\end{array}$ & 33.3 & average \\
\hline Stranger & $\begin{array}{l}\text { Most countries: } 29-61 \% \\
\text { Denmark: } 15 \% \text {; Mozambique: } 79 \%\end{array}$ & 55.5 & average \\
\hline \multicolumn{4}{|c|}{ Victim considered most recent incident was serious } \\
\hline Current intimate partner & $\begin{array}{l}\text { Most countries: } 56-87 \% \\
\text { Denmark: } 43 \%\end{array}$ & 38.0 & lowest \\
\hline Friend/relative & $\begin{array}{l}\text { Most countries: } 49-78 \% \\
\text { Czech Rep.: } 44 \%\end{array}$ & 42.0 & lowest \\
\hline Stranger & $\begin{array}{l}\text { Most countries: } 56-90 \% \\
\text { Denmark: } 44 \%\end{array}$ & 50.0 & $2^{\text {nd }}$ lowest \\
\hline \multicolumn{4}{|c|}{ Victim considered most recent incident was a crime } \\
\hline Current intimate partner & $\begin{array}{l}\text { Most countries: } 10-15 \% \\
\text { Poland: } 31 \% \text {; Costa Rica: } 32 \%\end{array}$ & 12.0 & average \\
\hline Friend/relative & $\begin{array}{l}\text { Most countries: } 21-36 \% \\
\text { Czech Rep.: } 14 \%\end{array}$ & 24.0 & average \\
\hline Stranger & $\begin{array}{l}\text { Most countries: } 31-42 \% \\
\text { Costa Rica: } 51 \% \text {; Mozambique: } 59 \%\end{array}$ & 60.0 & highest \\
\hline
\end{tabular}

Note ${ }^{a}$ Australia, Costa Rica, the Czech Republic, Denmark, Mozambique, the Philippines, Poland and Switzerland. For each category, we indicate the range observed across most countries and countries outside of the range. Data are from Johnson et al. (2008).

Turning to the perception that the assault was a crime, we see in Table 7.2 that a comparable proportion of victims in Hong Kong believed that the most recent incident was a crime. This was particularly true for stranger violence with 60 per cent of victims (the highest proportion of all countries) believing that the assault constituted a crime.

In Hong Kong, one in five woman reported physical violence by a partner to the police and one in four, physical violence by a non-partner. Although these rates are not high, as Table 7.3 shows, victims of violence in Hong Kong were more likely than in most other countries to report incidents of physical violence to the police; however, they were least likely to report sexual violence by either partners or 
non-partners. Reporting of violence by current partners was comparable to most other countries (range $8-15 \%$ ), but that of violence by non-partners tended to be lower.

Table 7.3. Reporting to police, Hong Kong and IVAWS countries

\begin{tabular}{|c|c|c|c|}
\hline \multirow{2}{*}{ Type of violence } & \multirow{2}{*}{ Eight IVAWS countries ${ }^{a}$} & \multicolumn{2}{|c|}{ Hong Kong } \\
\hline & & $\%$ & rank \\
\hline \multicolumn{4}{|c|}{ Reporting to police by type of violence ${ }^{b}$} \\
\hline Partner/physical & $\begin{array}{l}\text { All countries: } 7-18 \% \\
\text { Poland: } 29 \%\end{array}$ & 19.4 & $2^{\text {nd }}$ highest \\
\hline Partner/sexual & $\begin{array}{l}\text { All countries: } 6-16 \% \\
\text { Poland: } 39 \%\end{array}$ & 0.0 & lowest \\
\hline Non-partner/physical & All countries: $15-27 \%$ & 26.5 & $2^{\text {nd }}$ highest \\
\hline Non-partner/sexual & All countries: $4-8 \%$ & 3.5 & lowest \\
\hline \multicolumn{4}{|c|}{ Reporting to police by perpetrator } \\
\hline Current intimate partner & $\begin{array}{l}\text { Most countries: } 8-15 \% \\
\text { Mozambique: } 4 \%\end{array}$ & 12.0 & average \\
\hline Friend/relative & $\begin{array}{l}\text { Most countries: 10-16\% } \\
\text { Czech Rep.: } 7 \% \text {; Philippines: } 11 \%\end{array}$ & 8.0 & $2^{\text {nd }}$ lowest \\
\hline Stranger & $\begin{array}{l}\text { Most countries: } 18-26 \% \\
\text { Costa Rica: } 10 \% \text {; Philippines: } 11 \%\end{array}$ & 15.0 & $3^{\text {rd }}$ lowest \\
\hline
\end{tabular}

Notes ${ }^{a}$ Australia, Costa Rica, the Czech Republic, Denmark, Mozambique, the Philippines, Poland and Switzerland. For each category, we indicate the range within which most countries fell and countries outside of the range. Data are from Johnson et al. (2008). b Excludes the Philippines because Ns were too small.

In summary, Hong Kong women tended to consider incidents of violence against them less seriously than women in the other countries surveyed, despite similar proportions being injured or fearing their life was in danger during the attack. Despite this perception, a similar proportion as in other countries considered that the violence was a crime; but like elsewhere, women were less likely to consider violence by a current partner as a crime compared to violence by non-partners. Nevertheless, victims of VAW in Hong Kong were among the most likely to report incidents of physical violence to the police, but the least likely to report sexual violence. One explanation may be that the majority of incidents of sexual victimisation were indecent assault (unwanted sexual touching), which victims said were too minor to report.

\subsection{Conclusion}

This report has explored the prevalence and characteristics of physical and sexual violence against women in Hong Kong. Nearly 1,300 women participated in the survey and reported varying levels of violent victimisation. One in five women said that they had experienced violence since they were 16 years of age and nearly one in ten were assaulted by an intimate partner. Of the countries surveyed by the IVAWS, Hong Kong, along with the Philippines, recorded the lowest levels of VAW. Preliminary results of the Singapore IVAWS also show a low rate of VAW in Singapore $(9.2 \%$ for all violence across the lifetime, see SAFV-NUS [2010]), and from the UNICVS, we know that rates of violence are also low in Japan (van Dijk et al. 2007). The low rate of VAW in Hong Kong is consistent with low prevalence rates across all types of crime. This suggests the presence of cultural influences that maintain criminality at low levels. It is puzzling, however, that VAW is low in states that were traditionally patriarchal, but have followed a relatively similar path to western countries in terms of improvement to the status of women. 
Based on the IVAWS, we can only put forward some suggestions and hypotheses to explain the low rate of VAW in Hong Kong and we suspect that a combination of factors is at play. As with any survey of population, there is always the possibility that participants are not fully or completely truthful in their answers and do not disclose all of their victimisation experiences. As noted before, the Chinese culture is strongly family-oriented and people tend to assume collective responsibility for the actions of family members; therefore, women may tend to under-report violence by their partner or other family members as it may reflect badly on them or their kin, even if their answers are kept strictly confidential. However, the IVAWS has been carefully designed to encourage women to talk about their experiences, and it is conducted by highly skilled interviewers who are able to build rapport with respondents. It is doubtful that the method used in Hong Kong - i.e. telephone survey - resulted in under-reporting because the survey was conducted face-to-face in the Philippines, and rates of violence were also low. ${ }^{35}$

In Hong Kong, situational factors certainly play a role in maintaining low levels of crime. As an extremely urbanised city state with a high ratio of police per population, Hong Kong is relatively easy to police and has high levels of formal social control. There are also high levels of informal social control. High density living means that 'capable guardians' are often present to prevent violent incidents and to stop conflicts from escalading into violence.

Modernisation and economic growth have influenced the expression of the Chinese culture in Hong Kong. It is essential for Hong Kong economy that women are educated and empowered, and enter the workforce as fully productive contributors. Although male authority was traditionally supreme, with the advent of modernity and western influences, traditional extended kinship households are less common and male authority is declining.

We must also consider the results of the IVAWS in the context of a city with generally low rates of crime. Hong Kong (and Singapore) is a modern, wealthy, cosmopolitan, dynamic city. Traditional Chinese values, although they are declining, are still strong, particularly in the familial domain. It is likely that these Chinese values, linked to Confucianism, are stronger than in the Mainland, where they have to some extent been replaced with Communist ideology. Perhaps Hong Kong is going through a transitional, hybrid stage where the benefits of modernization and economic expansion are present, along with some protective factors retained in the adherence to traditional values. For example, the family system remains strong, albeit that the typical household is becoming more limited to the nuclear family. Filial piety fosters respect for elders but also for authority and conformity more generally. The results of the IVAWS support Chan and Lee's argument that the 'belief system as currently prevalent in Hong Kong ... is a belief system, which situates upon the broad conjuncture of traditionalism and modernism, while mitigated by the specific substance of traditional Chinese culture and present Hong Kong conditions. ... One must conclude that this belief system functions remarkably well, both in terms of its own persistence, as well as in providing the ideological groundwork for economic advancement and social stability' (1995, p. 87).

To explore these influences further, it would be important to extend the IVAWS to other Asian countries, such as Japan, Thailand and Cambodia; and of course in a number of cities in Mainland China, such as Beijing and Shanghai, and in rural cities such as Xi'an or Chongqing. It would be as helpful to repeat the survey in Hong Kong at regular intervals as a means of gauging change and assessing the impact of policy changes in respect to women's rights. For example, official data from police and social services suggested a peak in the prevalence of domestic violence in 2007 followed by a decline until 2010 (Table 1.2). A second sweep of the IVAWS would permit an assessment of whether this decline is due to a reduction in the prevalence of victimisation or to other factors such as a growing reluctance to report such offences by victims or to changes in the recording practices of police.

\footnotetext{
35 A comparison of the IVAWS in Hong Kong and Singapore, where interviews were done face-to-face is to be completed
} in 2012. This will provide an opportunity to test the effect of the methodology used. 



\section{REFERENCES}

Asian Migrant Centre (2001). Baseline Research on Racial and Gender Discrimination towards Filipino, Indonesian and Thai Domestic Helpers in Hong Kong. Hong Kong SAR: Asian Migrant Centre.

Australian Bureau of Statistics (ABS) (1996). Women's Safety Survey. Canberra: Australian Bureau of Statistics.

Bacon-Shone, John and Liam Lau (2006). 'Mobile vs. fixed-line surveys in Hong Kong', paper presented at the $2^{\text {nd }}$ International Conference on Telephone Survey Methodology, Florida, 12-15 January.

Beh, Phillip (1998). 'Rape in Hong Kong: an overview of current knowledge', Journal of Clinical Forensic Medicine, 5(3), 124-128.

Broadhurst, Roderic, King Wa-lee and Ching-yee Chan (2008). 'Crime Trends'. In Chui, Winghong and Lo, Tit-wing (eds.), Understanding Criminal Justice in Hong Kong, (pp. 45-68). Cullompton: Willan.

_ John Bacon-Shone, Brigitte Bouhours, King Wa-lee and Lena Y. Zhong (2010). Hong Kong, The United Nations International Crime Victim Survey: Final Report of the 2006 Hong Kong UNICVS. Hong Kong and Canberra: The University of Hong Kong and The Australian National University.

— John Bacon-Shone, Brigitte Bouhours and Thierry Bouhours (2011). Business and the Risk of Crime in China. Canberra: ANU E Press.

Census and Statistics Department, Hong Kong (2002). Demographic trends in Hong Kong 1981-2001. Hong Kong SAR, China: Census and Statistics Department.

(2006a). Crime and its Victims in Hong Kong in 2005 (Thematic Household Survey Report No. 31). Hong Kong SAR, China: Census and Statistics Department.

(2006b). Women and Men in Hong Kong: Key Statistics. Hong Kong SAR: Census and Statistics Department. Department.

(2007a). Hong Kong Annual Digest of Statistics. Hong Kong SAR: Census and Statistics

(2007b). Hong Kong in Figures, 2007 Edition. Hong Kong SAR: Census and Statistics Department.

(2007c). Women and Men in Hong Kong: Key Statistics. Hong Kong SAR: Census and Statistics Department.

Central Intelligence Agency (CIA) (2009). The World Factbook: Distribution of Family Income-GINI Index. Available at <https://www.cia.gov/library/publications/the-worldfactbook/fields/print_2172.html>, accessed 5 March 2010. 
Chan, Annie Hau-nung (2006). 'The effects of full-time domestic workers on married women's economic activity status in Hong Kong, 1981-2001', International Sociology, 21, 133-158.

Chan, Aris, Philip Beh and Roderic Broadhurst (2003). 'Homicide-suicide in Hong Kong, 19891998'. Forensic Science International, 137, 165-171.

- (2010). 'To flee or not: "escaping behavior" of intimate homicide offenders in Hong Kong'. Homicide Studies, 14(4), 400-418.

Chan, Hoiman and Rance Lee (1995). 'Hong Kong families: at the crossroads of modernism and traditionalism', Journal of Comparative Family Studies, 26(1), 83-99.

Chan, Wai-to (2003). 'Victims of crime: a critical review of essential programmes in Hong Kong'. In Tatsuya Ota (ed.), Victims and Criminal Justice: Asian Perspectives (pp. 45-61). Tokyo: Keio University.

Chang, Jui-shan (2006). 'Familism and modernity amongst young Chinese: an exploration into multiple modernity', paper presented at the $16^{\text {th }}$ Biennial Conference of the Asian Studies Association of Australia, Wollongong, 26-29 June.

Cheng, M. (2007). 'Domestic Violence Cases Rising in Hong Kong', South China Morning Post, 14 May, A3.

Cheung, Fanny (ed.) (1997). Engendering Hong Kong Society: A Gender Perspective on Women's Status. Hong Kong: The Chinese University Press.

and Eleanor Holroyd (eds.) (2009). Mainstreaming Gender in Hong Kong Society. Hong Kong: The Chinese University of Hong Kong.

Betty L.L. Lai, Au Kit-chun and Steven Ngai (1997). 'Gender role identity, stereotypes, and attitudes in Hong Kong’. In Fanny Cheung (ed.), Engendering Hong Kong Society: A Gender Perspective on Women's Status (pp. 201-235). Hong Kong: The Chinese University Press.

Chui, Wing-hong and Rebecca Ong (2008). 'Indecent assault on the public transport in Hong Kong', International Journal of Law, Crime and Justice, 36(1), 2-14.

Chow, Winnie (2009). 'An Overview of the Domestic Violence Ordinance in Hong Kong'. Paper presented at Law Asia Family Law Conference, Children and the Law Conference, Hong Kong, May.

Daly, Kathleen and Brigitte Bouhours (2010). 'Rape and attrition in the legal process: a comparative analysis of five countries', Crime and Justice: A Review of Research, 39, 565-650.

Edwards, Louise and Mina Roces (eds.) (2000). Women in Asia: Tradition, Modernity and Globalisation. St Leonards: Allen and Unwin.

Fischler, Lisa (2004). ‘Women's activism during Hong Kong’s political transition'. In Eliza Lee (ed.) Gender and Change in Hong Kong (pp. 49-77). Honolulu: University of Hawai'i Press. 
Garcia-Moreno Claudia, Henrica Jansen, Mary Ellsbert, Lori Heise and Charlotte Watts (2005). Multi-country Study on Women's Health and Domestic Violence against Women: Initial Results on Prevalence, Health Outcomes and Women's Responses. Geneva: WHO.

Gelb, Karen (2008). Measuring Public Opinion about Sentencing. Melbourne: Sentencing Advisory Council.

Harmony House (2006). Third Path Man Service, available at $<$ www.harmonyhousehk.org/chi/serviceimage/service5_chi.htm>.

Hong Kong Police Force (2007). Police Review 2007. Hong Kong SAR: Hong Kong Police Force. International Monetary Fund (2009). World Economic and Financial Surveys: World Economic Outlook Database, 2009. Available at

<imf.org/external/pubs/ft/weo/2009/02/weodata/index.aspx>, accessed 5 March 2010.

Johnson, Holly (2001). 'Enhancing knowledge on violence against women'. In Natalia Ollus and Sami Nevala (eds.), Women in the Criminal Justice System: International Examples and National Responses (pp. 198-213). Helsinki: European Institute for Crime Prevention and Control.

—, Natalia Ollus and Sami Nevala (2008). Violence Against Women: An International Perspective. New York: Springer.

Killias, Martin, Mathieu Simonin and Jacqueline de Puy (2005). Violence Experienced by Women in Switzerland over their Lifespan: Results of the International Violence Against Women Survey (IV AWS).

Berne: Stæmpfli Publishers.

Kuo, Shih-ya, Steven J. Cuvelier and Kuang-ming Chang (2009). 'Explaining criminal victimization in Taiwan: A lifestyle approach', Journal of Criminal Justice, 37(5), 461-71.

Lau, Liam (2006). 'Methodology of mobile phone surveys in Hong Kong', M.Phil thesis, The University of Hong Kong. Hong Kong, China.

Lauristen, Janet and Norma White (2001). 'Putting violence in its place: the influence of race, ethnicity, gender and place on the risk for violence', Criminology and Public Policy, 1(1), 37-59.

Lee, Ching-kwan (2000). 'Public discourses and collective identities: the emergence of women as collective actor in the women's movement in Hong Kong'. In Stephen Wing Kai-chiu and Tailok Lui (eds.), The Dynamics of Social Movement in Hong Kong (pp. 227-258). Hong Kong: Hong Kong University Press.

Lee, Eliza (ed.) (2004). Gender and Change in Hong Kong. Honolulu: University of Hawai'i Press.

Lievore, Denise (2003). Non-Reporting and Hidden Recording of Sexual Assault: An International Literature Review. Canberra: Commonwealth Office of the Status of Women.

Lo, Susanna (2003). 'Perceptions of work-family conflict among married female professionals in Hong Kong', Personnel Review, 32(3): 376-90.

Lynch, James P. (1995). 'Problems and promise of victimisation surveys for cross-national research', Crime and Justice, 34: 229-87. 
Mon, Wei-teh (2003). 'What does victimization survey reveal about victims and responses of police agencies Taiwanese experience', Journal of Asian Association of Police Studies, 1 (1), 1-26.

Mouzos, Jenny and Toni Makkai (2004). Women's Experiences of Male Violence: Findings from the Australian Component of the International Violence Against Women Survey (IVAWS) (Research and Public Policy Series No. 56). Canberra: Australian Institute of Criminology.

Ngo, Tak-wing (ed.) (1999). Hong Kong's History: State and Society under Colonial Rule. London, New York: Routledge.

Pearson, Veronica and Benjamin K. P. Leung (eds.) (1995). Women in Hong Kong. Hong Kong: Oxford University Press.

(1995). 'Introduction: perspectives on women's issues in Hong Kong'. In Veronica Pearson and Benjamin K. P. Leung (eds.), Women in Hong Kong (pp. 1-21). Hong Kong: Oxford University Press.

SAFV-NUS (2010). International Violence Against Women Survey: The Singapore Report (preliminary results). Singapore: SAFV and NUS. Available at

<www.ncss.org.sg/vwocorner/research_gateway/Family_abstract_12.pdf>.

Salaff, Janet (1981). Working Daughters of Hong Kong: Filial Piety or Power in the Family. Cambridge: Cambridge University Press.

Samuels, Harriet (1999). 'Hong Kong on women, Asian values, and the law', Human Rights Quarterly, 21(3), 707-734.

Schwartz, Martin (2000). 'Methodological issues in the use of survey data for measuring and characterizing violence against women', Violence Against Women, 6(8), 815-838.

Sheu, C., Y. Chen, W. Mong, T., Tsai, L., Huang, C. Huang, et al. (2005). 2005 Taiwan Areas Criminal Victimization report. Taipei, Taiwan: National Police Agency, Vol. 1 and 2 (in Chinese).

Social Institutions and Gender Index (SIGI) (2010). Gender Equality and Social Institutions in Hong Kong, China. Available at < genderindex.org/country/hong-kong-china $>$.

Social Welfare Department (SWD) Working Group on Combating Violence (2011). Procedural Guide for Handling Intimate Partner Violence Cases. Hong Kong SAR: Social Welfare Department, available at <www.swd.gov.hk/en/index/site_pubsvc/page_family/sub_fcwprocedure/ id_batteredspouse $/>$.

Statistics Canada (1994). Violence Against Women Survey (VAWS). Ottawa: Statistics Canada.

Tam, Suet-yan and Catherine So-kum Tang (2005). 'Comparing wife abuse perceptions between Chinese police officers and social workers', Journal of Family Violence, 20(1), 29-38.

Tang, Catherine So-kum (1994). 'Prevalence of spouse aggression in Hong Kong', Journal of Family Violence, 9(4), 347-356. 
(1999). 'Wife abuse in Hong Kong Chinese families: a community survey', Journal of Family Violence, 14(2), 173-189.

Wing-tung Au, Stephen Yue-ping Chung and Hang-yue Ngo (2000). 'Breaking the patriarchal paradigm: Chinese women in Hong Kong'. In Louise Edwards and Mina Roces (eds.), Women in Asia: Tradition, Modernity and Globalisation (pp. 188-207). St Leonards: Allen and Unwin.

Tang, Loretta So-fong (2006). 'Violence against women: a study of victimisation reporting in Hong Kong', M.Phil thesis, The University of Hong Kong. Hong Kong, China.

Thein, Htwe-htwe, Siobhan Austen, Janice Currie and Erica Lewin (2010). 'The impact of cultural context on the perception of work/family balance by professional women in Singapore and Hong Kong', International Journal of Cross Cultural Management, 10(3), 303-320.

Tjaden, Patricia (2005). 'Defining and measuring violence against women: Background, issues, and recommendations'. Expert paper presented at the Expert Group Meeting, UN Division for the Advancement of Women, 11 - 14 April, Geneva. Available at

$<$ www.unece.org/stats/gender/vaw/resources/Tjaden.pdf>.

and Nancy Thoennes (2000). Full Report of the Prevalence, Incidence, and Consequences of Violence Against Women: Findings from the National Violence Against Women Survey. Washington, D.C.: U.S. Department of Justice, National Institute of Justice.

Tsang, Gar-yin (1995a). 'Chronology of women's achievements'. In Veronica Pearson and Benjamin K. P. Leung (eds.), Women in Hong Kong (pp. xiv-xvii). Hong Kong: Oxford University Press.

(1995b). 'The women's movement at the crossroads'. In Veronica Pearson and Benjamin K. P. Leung (eds.), Women in Hong Kong (pp. 276-290). Hong Kong: Oxford University Press.

Tsun, Angela On-kee and Priscilla Sun-kai Lui Tsang (2005). 'Violence against wives and children in Hong Kong', Journal of Family and Economic Issues, 26(4), 465-486.

US Department of State (2007), Country Reports on Human Rights Practices: China (Includes Tibet, Hong Kong, and Macau), US Department of State, Bureau of Democracy, Human Rights and Labor, Washington, DC

van Dijk, Jan, John van Kesteren, and Paul Smit (2007). Criminal Victimisation in International Perspective: Key Findings from the 2004-2005 ICVS and EU ICS. The Hague: Ministry of Justice, VODC.

Women's Commission Hong Kong (2006). Women's Safety in Hong Kong: Eliminating Domestic Violence. Hong Kong: Women's Commission. Available at <www.women.gov.hk/download/ empowerment/women_safety_report.pdf>.

Women's Commission Hong Kong (2007). Hong Kong Women in Figures 2007. Hong Kong: Women's Commission. 


\section{Hong Kong IVAWS}

(2009). Women's Safety in Hong Kong: Eliminating Domestic Violence - An Update and the Next Step. Hong Kong SAR: Women's Commission. Available at <www.women.gov.hk/ download/library/report/Safety-Supp.pdf>.

(2010). What Do Women and Men in Hong Kong Think about the Status of Women at Home, Work and in Social Environments: Survey Findings. Hong Kong: Women's Commission. Available at $<$ www.women.gov.hk/colour/en/research_statistics/ research_status_of_women.htm>.

Wu, Anna (2008). 'The Hong Kong position on gender equality', Women Living Under Muslim Laws, Dossier 29. Available at

$<$ www.wluml.org/sites/wluml.org/files/import/English/pubs/dossier29/dossier29-en.pdf>.

Yates, Robin (2009). Women in China from Earliest Times to the Present: A Bibliography of Studies in Western Languages. Boston: Brill.

Yip, Paul, Billy Li, Kathy Xie and Eddy Lam (2006). 'An analysis of the lowest total fertility rate in Hong Kong SAR'. Paper presented at the International Conference on Declining Fertility in East and Southeast Asian Countries, Tokyo, 14-15 December. Available at $<$ ideas.repec.org/p/hit/piedp2/289.html>.

Zhu, Hongde, Lixian Wang, Jialun Lu, Jianan Guo and Lu Zhou (1995). 'The international crime (victim) survey in Beijing'. In Ugljesa Zvekic and Anna Alvazzi del Frate (eds), Criminal Victimization in the Developing World (pp. 67-87). Rome: United Nations Interregional Crime and Justice Research Institute.

Zhuo, Yue, Steven F. Messner and Lening Zhang (2008). 'Criminal victimization in contemporary China: A review of the evidence and challenges for future research', Crime, Law, and Social Change, 50, 197-209. 
APPENDICES 



\section{Appendix A}

\section{Schematic Overview of the IVAWS Hong Kong Questionnaire, 2006}

\begin{tabular}{ll}
\hline $\begin{array}{l}\text { A. Composition of household and respondent's age } \\
\text { Who is living in your }\end{array}$ & Partner \\
household & Children under 18 years \\
& Children 18 years and over \\
& Parents or parents-in-law \\
& Other relatives or in-laws \\
& Others (lodgers, maids, etc.) \\
Respondent's age & Year of birth or approximate age
\end{tabular}

\section{B. Marital status and respondent's characteristics}

\section{Relationship status \\ Past relationships \\ Respondent's current level of education}

Respondent's income
Are you married?

Are you living with your husband?

Are you separated?

Are you living together with a man without being married?

Are you involved in a relationship with a man without living with him?

In the past, have you ever been married? Living with a man without being married? Involved in a relationship with a man without living with him?

Have you ever been widowed?

Do you work for pay either at home or outside of home?

Do you have other sources of income?

Do you decide how to spend all or some of the money that comes to you?

\section{Experiences of violence}

Since you were 16 or older, has any man ever...

\section{Threatened to hurt you physically}

Thrown something at you or hit you with something

Pushed or grabbed you or twisted your arm or pulled your hair

Slapped, kicked, bit or hit you with a fist

Tried to strangle or suffocate you, burn or scald you for each perpetrator

\begin{tabular}{|c|c|c|}
\hline 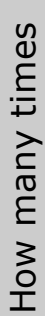 & 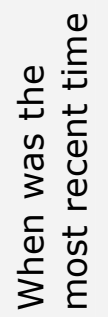 & 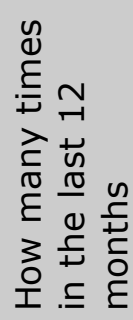 \\
\hline$\checkmark$ & $\checkmark$ & $\checkmark$ \\
\hline$\checkmark$ & $\checkmark$ & $\checkmark$ \\
\hline$\checkmark$ & $\checkmark$ & $\checkmark$ \\
\hline$\checkmark$ & $\checkmark$ & $\checkmark$ \\
\hline$\checkmark$ & $\checkmark$ & $\checkmark$ \\
\hline
\end{tabular}




\section{Hong Kong IVAWS}

Threatened to use a knife or gun on you

Been physically violent in a way not already mentioned

Forced you into sexual intercourse

Attempted to force you into sexual intercourse

Touched you sexually when you did not want him to

Forced or attempted to force you into sexual intercourse with someone else for money or goods

Been sexually violent toward you in a way not already mentioned

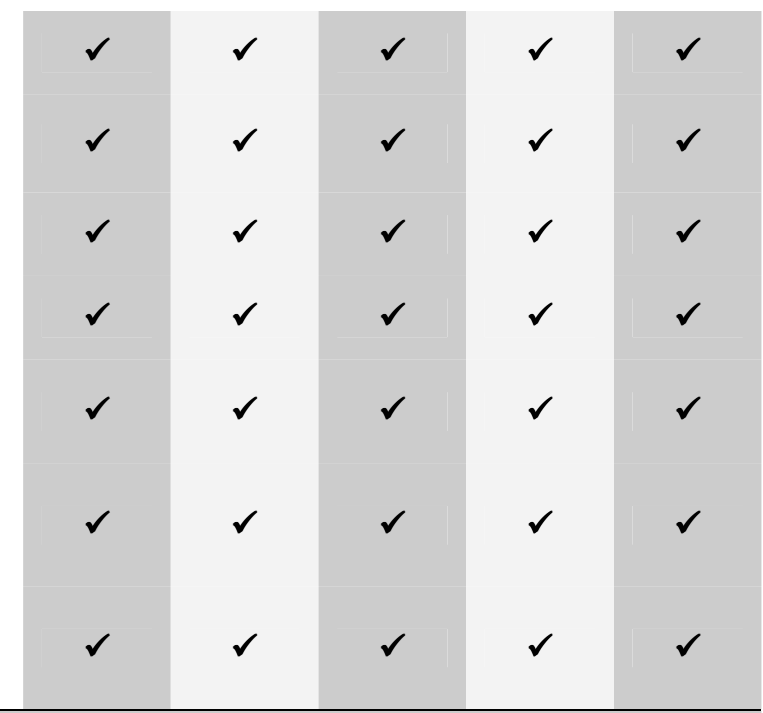

D. Most recent incident by non-partner

E. Most recent incident by intimate partner

In the most recent incident...

What happened? (specific acts of violence)

Who was involved?

How many men were involved

Where did it happen

In which country?

Had he been drinking/using drugs

Did you feel your life was in danger

Were you physically injured? Types of injuries?

Did you need medical care

Were you pregnant at the time of the violence

Have used medication/alcohol to cope

Did you contact a specialised agency

How serious do you consider the incident was

Was it a crime

Did you or someone else report to the police? If not, why not

What did police do to help you? How satisfied are you with the way police handled the case

Were charges brought against him? Did they lead to a conviction in court

Is there anything the police should have done

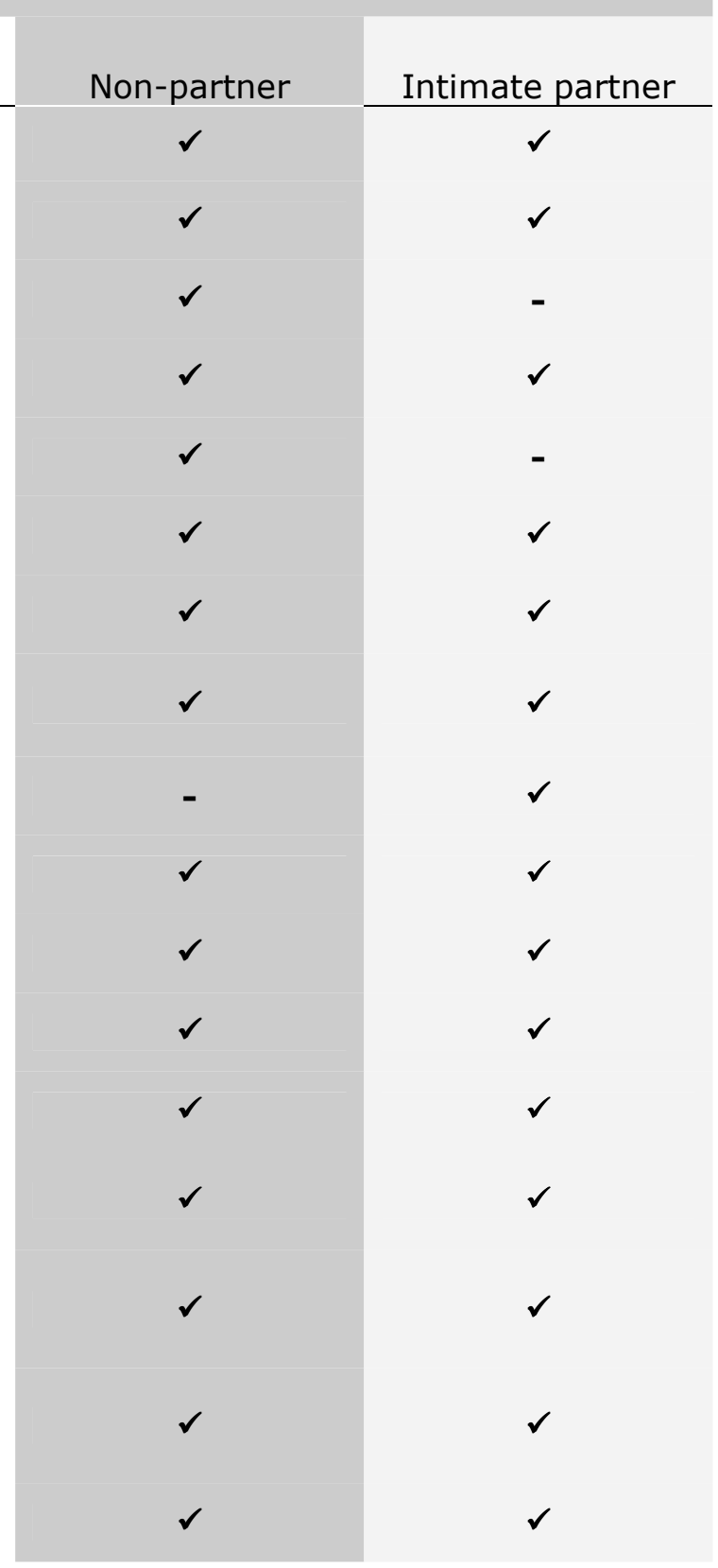


Did you ever talk to anyone about what happened, such as family members, friends, co-workers, etc

Did any violence occur after you separated from a partner

Did any children witness the violence by your partner

Has your partner ever received counselling for his violent behaviour

\section{F. Characteristics of previous violent partner \\ G. Characteristics of current partner}

\section{About previous (violent) / current partner...}

Does your partner work for pay

Has other sources of income

Do you have a say in how the money your partner get is used

How long have you been together in total

When did this relationship end? How long ago did you become a widow

Partner's year of birth / age

\section{Partner's drinking behaviour}

Is your partner violent outside of the family? If yes, has he ever been in trouble with the police

\section{Controlling behaviours}

partner gets angry if you speak to other men; tries to limit your contact with family and friends; follows you or keeps track of your whereabouts; is constantly suspicious that you have been unfaithful; insists on knowing where you are at all times

\section{Emotionally abusive behaviours}

partner calls you names, insults you or puts you down; damages or destroys your possessions; harms or threatens to harm your children; harms of threatens to harm someone else close to you; threatens to kill you; threatens to kill himself; threatens to hurt you or your children if you leave

\section{Supportive behaviour}

partner is supportive towards your work, studies or other activities taking place outside the home

\section{Household income}

Monthly income of whole household

Estimated based on population's median income

Design of this table adapted from van Dijk et al. (2007: 195-96). 



\section{Appendix B Weighting of the IVAWS Data}

The IVAWS sample demographics revealed differences in the age of participants when compared with the 2006 population data compiled by the United Nations Demographic Yearbook. Younger women were underrepresented in the Hong Kong sample, and middle-aged women, overrepresented.

Statistical weighting was applied to compensate for the over- and under-sampling of particular groups within the sample and to make the results more representative of the HK population aged 18 and above (Table 2). Weights were calculated as the ratio of the population distribution by age group, compared to that of the sample using the formula:

$$
\text { Weight }=\text { proportion in population / proportion in sample }
$$

Table B.1. Weights applied to HK IVAWS data, 2006

\begin{tabular}{|c|c|c|c|c|}
\hline Age group & $\begin{array}{l}\text { population } \\
(, 000)^{\mathrm{a}}\end{array}$ & $\begin{array}{c}\text { Age group as } \% \\
\text { of female } \\
\text { population }\end{array}$ & $\begin{array}{l}\text { Age group as \% } \\
\text { of IVAWS sample }\end{array}$ & $\begin{array}{l}\text { Weight } \\
\text { applied }\end{array}$ \\
\hline $18-24$ & 377.0 & 13.4 & 12.0 & 1.12 \\
\hline $25-29$ & 278.5 & 9.9 & 7.1 & 1.39 \\
\hline $30-34$ & 309.6 & 11.0 & 10.1 & 1.09 \\
\hline $35-39$ & 331.4 & 11.7 & 13.0 & 0.90 \\
\hline $40-44$ & 365.3 & 12.9 & 16.7 & 0.77 \\
\hline $45-49$ & 335.7 & 11.9 & 15.8 & 0.75 \\
\hline $50-54$ & 267.6 & 9.5 & 12.1 & 0.78 \\
\hline $55-59$ & 207.8 & 7.4 & 7.8 & 0.95 \\
\hline $60-64$ & 116.3 & 4.1 & 3.2 & 1.28 \\
\hline 65 and over & 232.5 & 8.2 & 2.2 & 3.73 \\
\hline $\begin{array}{l}\text { Total female population } \\
\text { aged } 18-75 \text { years }\end{array}$ & $2,821.7$ & 100.0 & 100.0 & - \\
\hline
\end{tabular}

Note a Source: United Nations (2010). United Nations Demographic Yearbook: Population by age, sex and urban/rural residence. Available at <data.un.org/Data.aspx?d=POP\&f=tableCode:22>. 